\title{
Plant Gene Expression in Early Stages of Rhizobium-Legume Symbiosis
}


Promotor: Dr. A. van Kammen, hoogleraar in de moleculaire biologie Co-promotor: Dr. A.H.J. Bisseling, universitair hoofddocent. 


\title{
WN08201, 1248
}

\section{Ton Gloudemans}

\section{Plant Gene Expression in Early Stages of Rhizobium-Legume Symbiosis}

\author{
Proefschrift \\ ter verkrijging van de graad van \\ doctor in de landboumwetenschappen, \\ op gezag van de rector magnificus, \\ dr. H. C. van der Plas, \\ in het openbaar te verdedigen \\ op dinsdag 6 december 1988 \\ des namiddags te vier uur in de aula \\ van de Landbouwuniversiteit te Wageningen.
}


The investigations described in this thesis were carried out at the department of Molecular Biology, Agricultural University, Wageningen, The Netherlands, and were sponsored by a research contract from Agrigenetics Research Associated Ltd. (presently Lubrizol Genetics Inc.), Madison, WI, USA.

The cover shows a phase contrast photomicrograph of freeze-fractured pea (Pisum sativum L.) root hairs. 


\section{NNO 8201,1248}

Knolvorming geinduceerd door Rhizobium bacteriën wordt veroorzaakt door een factor die uitgescheiden wordt door de bacteriën en die plaatselijk in wortelweefsel een verandering van de phytohormoon balans bewerkstelligt.

\section{II}

Voor het tot stand komen van een stikstofbindende wortelknol zijn minstens drie verschillende signalen van Rhizobium bacteriën nodig.

\section{III}

De bewering van Horvath et al. dat vorming van infectiedraden niet noodzakelijk is voor noduTatie en ontwikkeling van een stikstofbindende wortelknol kan niet gebaseerd zijn op de door hen gepresenteerde resultaten.

Horvath et al. (1986) Cell 46, 335-343

\section{IV}

Berichten in de media dat zeehondensterfte door hetzelfde virus veroorzaakt wordt als hondeziekte berusten op een onjuiste weergave van de feiten.

Osterhaus et al. (1988) Nature 334, 301-302 Osterhaus et al. (1988) Nature 335, 403-404 Kennedy et al. (1988) Nature 335, 404

V

Het lijkt onwaarschijnlijk dat het methionine-codon op positie -48 van het mRNA voor Insuline-achtige groeifactor-I (IGF-I) wordt gebruikt voor initiatie van translatie.

Rotwe in (1986) Proc. Nat1. Acad. Sci. USA 83, 77-81 Rotwein et al. (1987) J. Biol. Chem. 262, 11807-11812

\section{VI}

Er zijn geen argumenten om het gen coderend voor $\beta$-nerve growth factor ( $\beta-N G F$ ) bij de insuline gen familie in te delen.

Ul lrich et al. (1983) Nature 303, 821-825 


\section{VII}

Bij het verbieden van de toediening van groeistimulerende middelen aan slachtvee moet onderscheid gemaakt worden tussen middelen die wel en niet schadelijk zijn voor de volksgezondheid.

\section{VIII}

Er kunnen veel ongelukken voorkomen worden als de uitritconstructie van woonerven voldoet aan de door de wetgever gestelde eisen.

\section{$\mathbf{I X}$}

De TV actie voor de 1-2-3 boot heeft het werk van de Zonnebloem op een verkeerde manier belicht.

\section{$x$}

Pasteurse pipetten zijn over het algemeen nauwkeuriger dan automatische pipetten.

Stellingen behorend bij het proefschrift "Plant Gene Expression in Early Stages of Rhizobilur-Legune Symbiosis"

Wageningen, 6 december 1988

Ton Gloudemans 
Ter nagedachtenis aan mijn opa

hij heeft altijd gemeend dat ik voor boer studeerde Voor Adrie 


\section{Contents}

Chapter 1

Outline

Chapter II

Nodulin gene expression during soybean

(Glycine max) nodule development

Chapter III

Characterization of soybean

early nodulin CDNA clones

Chapter IV

Bacteria involved in regulation

of nodulin gene expression 51

Chapter V

Identification of plant genes involved

in Rhizobium-root hair interactions.

Chapter VI

Plant gene expression in early stages

of $R$ hizobium-legume symbiosis. 101

References. 123

Samenvatting 143

Nawoord 149

Curriculum vitae 153 
CHAPTER I

Outline 


\section{Outline}

Upon infection of the root of a leguminous plant with bacteria of the genus Rhizobium or Bradyrhizobium root nodules are formed in which symbiotic dinitrogen fixation occurs. In the host plant a set of genes is only expressed during the formation of a root nodule. These plant genes are termed nodulin genes (Van Kammen, 1984). Based upon the stage of development of the root nodule in which nodulin genes become expressed a distinction is made between early and late nodulin genes (Nap and Bisseling, 1988). The genes encoding early nodulins are expressed when the roots become infected by the rhizobia and the nodule is formed. Late nodulin genes become first expressed at the onset of dinitrogen fixation, when the nodule structure is ready. This thesis deals with the identification and characterization of plant genes specifically expressed during the early stages of the symbiosis of Rhizobium and the host plant.

The work in this thesis can be divided into two parts. One part deals with the plant genes involved in early stages of root nodule formation (chapters II, III and IV), and the second part is related to the plant genes involved in the interaction between root hairs and Rhizobium (chapter V).

Both in root hairs and young nodule, plant genes involved in the interaction of the plant with the (Brady)Rhizobium bacteria were identified after in vitro translation of nodule and root hair RNA, respectively, followed by two-dimensional gel electrophoresis (chapters II and V). From the root hairs also the in vivo proteins were studied (chapter $V$, section 5.1). For the genes regulated by Rhizobium in the root hairs we studied the involvement of the bacterial nodulation (nod) genes and the genes required for exopolysaccharide synthesis.

Early nodulin gene expression in soybean nodules was studied by using Bradyrhizobium mutants that arrest nodule development at different stages. In these studies we also analyzed the expression of some late nodulin genes (chapter IV). Finally three early nodulin cDNA clones from soybean were isolated and characterized (chapter III).

In chapter VI the present knowledge about plant genes that are involved in preinfection, infection, nodule formation, and the involvement of bacterial genes and signals responsible for host responses in these stages are discussed. This is integrated with the results in the preceding chapters. It is speculated about the mechanism by which the bacterial signal elicits nodule formation. 


\section{CHAPTER II}

\section{Nodulin Gene Expression during}

\section{Soybean Nodule Development}

Ton Gloudemans, Sacco C. de Vries, Henk-Jan Bussink, Nasir S.A. Malik, Henk J. Franssen, Jeanine Louwerse, and Ton Bisseling. Plant Molecular Biology 8, 395-403 (1987) 


\title{
Nodulin gene expression during soybean
}

\section{(Glycine max) nodule development}

\begin{abstract}
In vitro translation products of total root RNA isolated from soybean nodules at successive stages of root nodule development were analyzed by two-dimensional gel electrophoresis. In that way the occurrence of over twenty mRNAs specifically transcribed from nodulin genes was detected. The nodulin genes could be divided into two classes according to the time of expression during nodule development. Four nodulin mRNAs are already found when a globular meristem is present in the root cortex. These nodulin genes have a transient pattern of expression and will be named early nodulin genes. The remaining nodulin genes are expressed when the formation of a nodule structure has been completed and will be referred to as late nodulin genes. Bradyrhizobium japonicum nod ${ }^{+}$fix mutants, with large deletions spanning the nifH,DK region, still induced nodules showing normal expression of all nodulin genes, indicating that bacterial genes located in the nifH,DK region are not involved in the induction of nodulin genes. In nodules induced by Bradyrhizobium japonicum nod ${ }^{+}$fix mutant HS124 the bacteria are rarely released from the infection thread and the few infected cells appear to be collapsed. All early nodulin genes are expressed in HS124 nodules and, with the exception of five late nodulin genes, all late nodulin genes.
\end{abstract}

\section{Introduction}

Soybean root nodule formation is a process that is induced by infection with bacteria belonging to the genus Bradyrhizobium or Rhizobium. Detectable nodule formation starts twelve hours after inoculation of soybean roots with Bradyrhizobium japonicum when anticlinal divisions can be observed in some cells of the outer cortical cell layers (Calvert et al., 1984; Newcomb et al., 1979) indicative of a dedifferentiation process in these cells induced by the bacterium. The dividing cells then form a globular meristem and the bacteria penetrate the root by infection threads, which are formed in the root hairs and grow towards the meristem. The bacteria are released from the infection threads into the meristematic cells whereupon a nodule is formed, the central part of which consists of uninfected cells and cells fully packed with bacteria (Newcomb et al., 1979). 
Auger et al. (1979) have made an estimation of the number of plant genes involved in soybean root nodule formation, based on a comparison of polysomal polyA( ${ }^{+}$) RNA populations from roots and mature nodules using CDNA/mRNA hybridization kinetics. They concluded that some twenty abundant and moderately abundant mRNAs were newly synthesized in nodule tissue and were regulated at the transcriptional level.

Since the number of genes in nodule development seems rather limited while these genes are relatively high expressed (Van Kammen, 1984), root nodule formation presents an attractive system to study plant differentiation. In addition, the achievements of Rhizobium genetics make it possible to modulate plant gene expression during nodule development, which may be of great use in trying to understand the functions of proteins encoded by nodulin mRNAs. In vitro translation of mRNA from mature nodules and roots has demonstrated the existence of nodulin mRNAs (Legocki and Verma, 1980) and several cDNAs representing these nodulin mRNAs have been cloned in the mean time (Fuller et al., 1983; Marcker et al., 1984b; Sengupta-Gopalan et al., 1985). So far it has been found that all soybean nodulin genes studied are expressed concomitantly with the best studied nodulin genes, those coding for leghemoglobin (Fuller and Verma, 1984; Marcker et al., 1984b). To study the differentiation process that leads to root nodule formation we have examined nodulin gene expression in root segments shortly after the induction of cortical cell divisions up to the mature $\mathrm{N}_{2}$-fixing nodule employing in vitro translation of mRNA followed by two-dimensional gel electrophoresis (2-D) of the labeled products. Furthermore, the expression of nodulin genes is described in response to different Bradyrhizobium japonicum nod $^{+}$fix ${ }^{-}$strains that yield non-effective root nodules.

\section{Results}

\section{Nodulin gene expression in mature nodules}

From 21-day-old $\mathrm{N}_{2}$-fixing nodules, 5-day-old uninoculated roots and 2-day-old root tips total RNA was isolated and in vitro translated in a wheat germ extract, followed by 2-D gel electrophoresis of the labeled products. By this method only small quantities of RNA yield a 2-D pattern of about 500 spots representing the products of the most abundantly transcribed genes. Comparison of the root nodule 2-D pattern with the root and root tip 2-D pattern, obtained when $\left[{ }^{35} \mathrm{~S}\right]$-methionine was used as the labeled amino acid, by spot by spot analysis, revealed 20 nodule specific products, from which the twelve most abundant ones are indicated by arrowheads in figure 2-1B. Since only plant encoded RNAs are translated in the wheat germ system, which was shown by Govers et al. (1985) for 

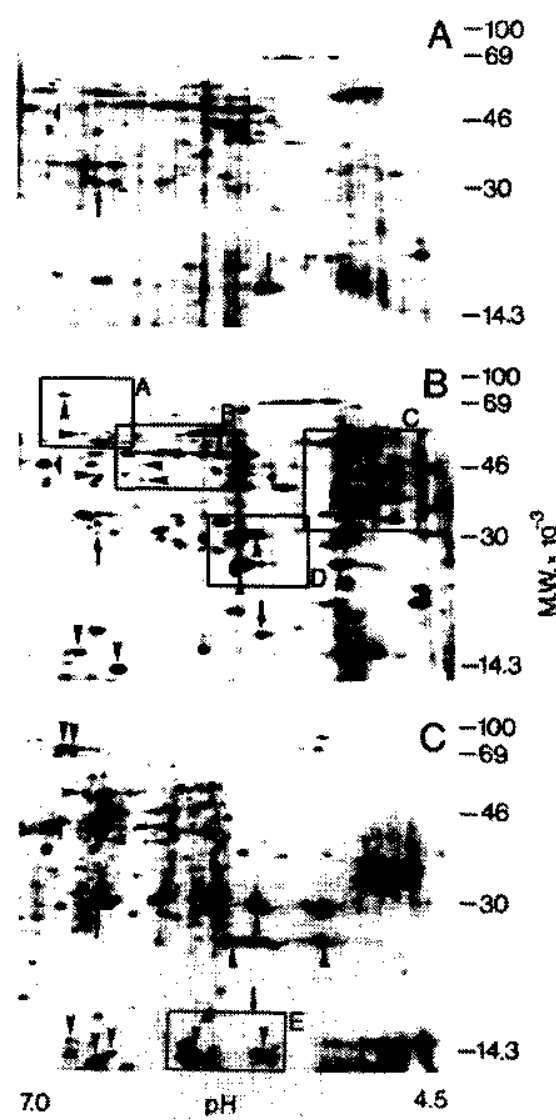

Figure 2-1: Identification of nodulin mRNAs. Fluorographs are shown of two-dimensional (2-D) gels of in vitro translation products from total RNA isolated from [A] 5-day-old uninoculated roots, $[B, C]$ 21-day-old $\mathrm{N}_{2}$-fixing root nodules induced by Bradyrhizobium japonicum USDA110. The in vitro translation products in panel $A$ and $B$ were visualized with $\left[{ }^{35} \mathrm{~S}\right]$-methionine as the labeled amino acid, while in panel $\mathrm{C}\left[{ }^{3} \mathrm{H}\right]$-leucine was used. Nodule specific spots are indicated by arrowheads, a nodule stimulated spot by a triangle, and some nodule reduced spots by arrowheads.

the pea/Rhizobium leguminosarum symbiosis and was confirmed by us for the soybean/Bradyrhizobium japonicum symbiosis (data not shown), the additional polypeptides in the root nodule 2-D pattern represent nodulin mRNAs and not bacterial RNAs. The level of expression of about 10 plant genes appeared to be enhanced in nodules (one example is shown in figure 2-1, triangle), while the expression of approximately another 10 genes is reduced below detection level in nodules (some examples are shown in figure 2-1, arrows).

By using $\left[{ }^{3} \mathrm{H}\right]$-leucine instead of $\left[{ }^{35} \mathrm{~S}\right]$-methionine as the labeled amino acid four additional nodulins were detected which apparently do not contain methionine; three of these were identified as leghemoglobins (Lbs) by immune precipitation with an anti-Lb serum (data not shown); two of the leghemoglobins are indicated in figure $2-1 \mathrm{C}$ rectangle $\mathrm{E}$, by arrowheads. The fourth additional nodulin had the same molecular weight as nodulin-75 (figure 2-1C, upper left corner) but a slightly 


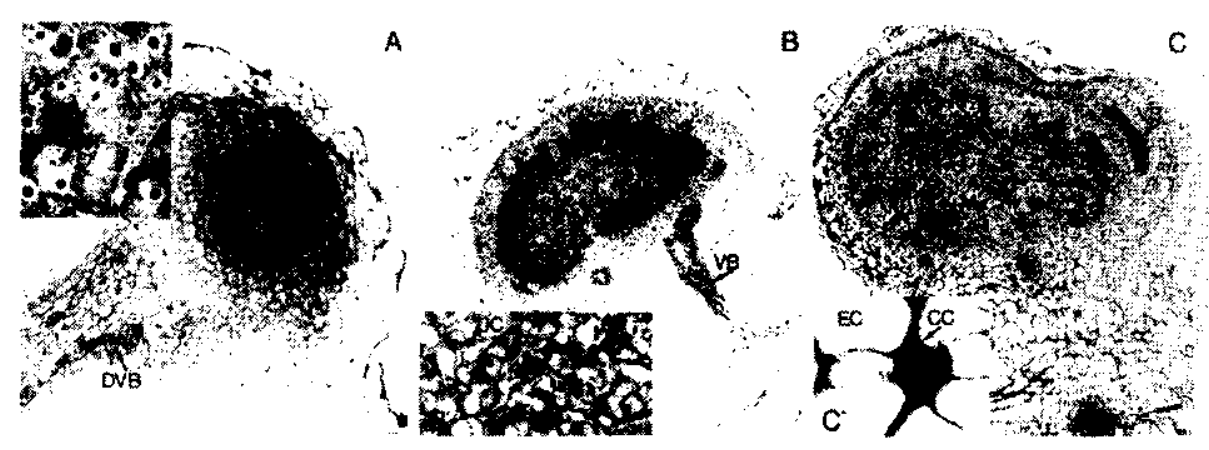

Figure 2-2: Sections through soybean nodules induced by Bradyrhizobium japonicum. [A] and [B] show longitudinal sections of nodules, 8 and 12 days after sowing and inoculation with wildtype Bradyrhizobium japonicum USDA110, respectively. [C] shows a section of a 21-day-old nodule induced by Bradyrhizobium japonicum mutant $H S^{124}$. [A'], [B'], and [C'] show magnifications from cells in the central part of the nodules. [VB] vascular bundle, [DVB] developing vascular bundle, [UC] uninfected cell, [IC] infected cell, [EC] empty cell, [IT] infection thread, and [CC] infected cell which appears to be collapsed.

more basic isoelectric point. From a soybean cDNA library against nodule mRNA a nodule specific CDNA clone, PGmENOD2, was isolated and when nodule RNA, hybrid selected by PGmENOD2 was translated in the wheat germ system with $\left[{ }^{3} \mathrm{H}\right]$-leucine as the labeled amino acid both $\mathrm{Ngm}-75$ nodulins were formed indicating that the two nodulins are related (Franssen et al., 1987; chapter III, section 3.1). We will refer to the methionine containing nodulin as Ngm-75-2, while the non-methionine containing one will be named Ngm-75-1.

\section{Nodule development and nodulin gene expression}

Longitudinal sections through 8-day-old infected roots show that by then a globular meristem has been formed in the root cortex (figure 2-2A). Furthermore cell divisions take place in the inner cortical cell layers from which a vascular bundle will develop. At day 12 a root nodule has clearly been formed consisting of peripherically located vascular bundles round a center of bacteria-containing infected and, much more vacuolated, uninfected cells (figure 2-2B). Then at day 13 under our conditions of growing plants the first $\mathrm{N}_{2}$-fixation is detectable.

In parallel with the cytological studies on the development of a soybean root nodule we examined the expression of the different nodulin genes. We focussed our analysis on eight nodulin spots: Ngm-75-2, Ngm-59, Ngm-44, Ngm-41, Ngm-38, Ngm-23, Lb-1, and Lb-2. Figure 2-3 is a composite of fragments of 2-D 

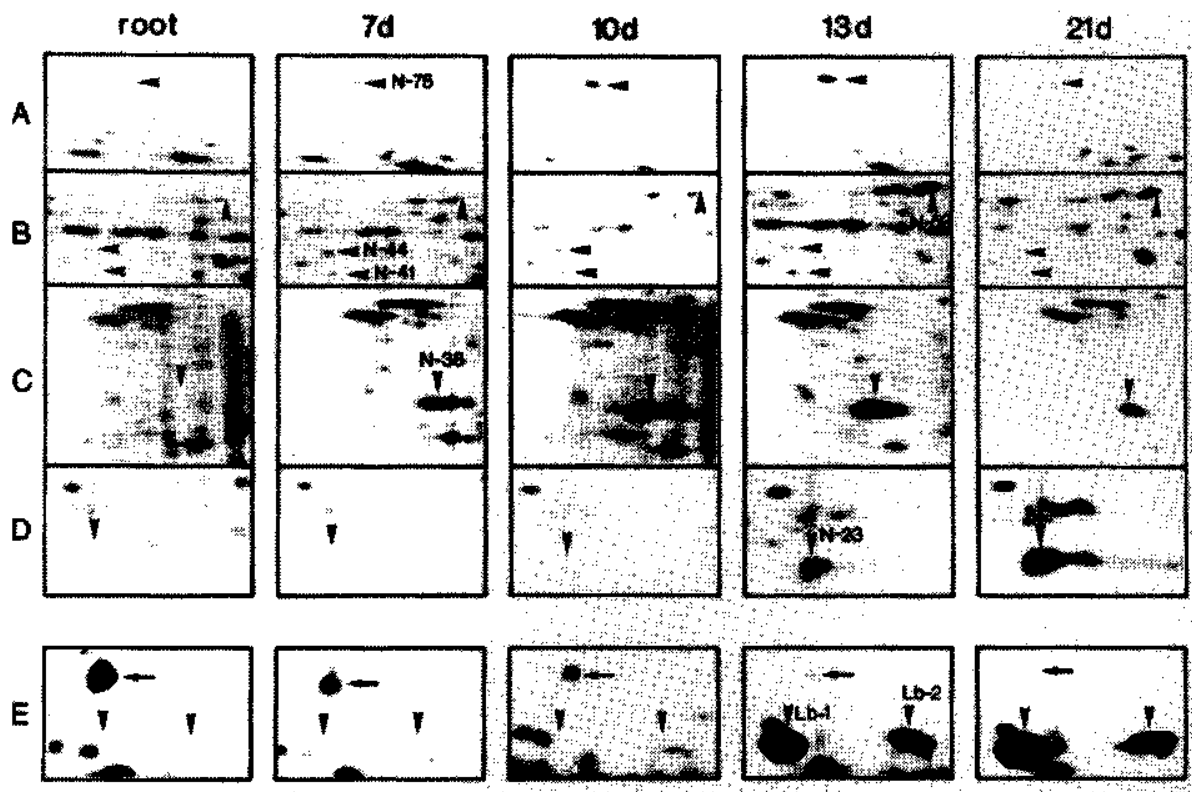

Figure 2-3: Expression of nodulin genes during nodule development. Fragments of fluorographs of 2-D gels (indicated in figure 2-1B and 2-1C by rectangles) from in vitro translation products of total RNA isolated from 5-day-old uninfected roots and root nodules 7, 10, 13, and 21 days after sowing are shown. Nodule specific spots are indicated by an arrowhead, a nodule reduced spot is indicated by an arrow. The appearance in time is shown for Ngm-75-2 in [A], Ngm-59, Ngm-44, and Ngm-41 in [B], Ngm-38 in [C], Ngm-23 in [D], and Lb-1 and Lb-2 in [E]. When a nodule specific spot first appears during nodule development its code is printed next to the arrowhead.

gels, indicated in figure $2-1$ by rectangles, containing these spots. The 2-D gel patterns of the in vitro translation products of RNA from nodules harvested at day $7,10,13$, and 21 show that nodulins can be divided into two distinct categories based on their time course of appearance. Four nodulins (Ngm-75-2, Ngm-44, $\mathrm{Ngm}-41$, and $\mathrm{Ngm}-38$ ) are first detectable at day 7 , when only a globular meristem is present (see figure 2-2A); these nodulins will be named early nodulins. The early nodulins have a transient appearance: Ngm-44 (figure 2-3B) reached its maximum concentration at day 7 , and after day 10 its concentration decreased, while the concentration of Ngm-75-2, Ngm-41, and Ngm-38 (figure 2-3 row A, B, and C respectively) still increases from day 7 to day 13 whereupon their concentration decreases. The other nodulins, including Ngm-59, Ngm-23, Lb-1, and Lb-2, shown in the rows B, D, and E of figure 2-3, respectively, are first detectable at day 13 , when a nodule structure has been formed (see figure 2-2B), and accumulate when nodules become older. These nodulins will henceforth be named late nodulins. 
Before day 7 the nodules had not yet emerged through the epidermis so nodulin gene expression before this stage was investigated in infected root segments. If 2-D gels of in vitro translated RNA from root segments of pouch-grown plants harvested $16,24,48$, and 96 hours after inoculation were compared to the 2-D pattern of root segments of uninoculated pouch-grown plants of the same ages, no nodulins could be detected. However, for the 96 -hour root segments this will be due to dilution of RNA from centers of cortical cell division with RNA commonly present in root tissue, since in the 2-D pattern of 7-day-old infected root segments, bearing just emerged nodules, also no nodulins could be detected, while in 7-day-old excised nodules early nodulins were detectable.

\section{Nodulin gene expression in non-effective root nodules formed by Bradyrhizobium japonicum mutants}

The region containing the bacterial symbiotic genes nifH and nifDK, encoding the structural nitrogenase proteins in Bradyrhizobium japonicum USDA110 is located on the chromosome. The nifD and nifK genes form one transcriptional unit located $15 \mathrm{~kb}$ upstream from the nifH gene, which has its own promoter (Hahn et al., 1984). The Bradyrhizobium japonicum mutants $F 4-6$, in which a large region including the nifDK region is deleted, and $45 \mathrm{~K}-13$, having a large deletion spanning the whole nifH,DK region, form Fix nodules on soybean (Hahn et al., 1984). In addition we used a nod ${ }^{+}$fix $^{-}$Bradyrhizobium japonicum mutant designated HS124 (Noel et al., 1982) obtained by UV irradiation, in which the defect is not well defined. Histological examination of nodules formed by the two deletion mutants showed that they have a structure similar to the wildtype nodule $(\mathrm{H}$. Hennecke, personal communication). At the other hand, light microscopical observations on sections of 21-day-old HS124 nodules (figure 2-2C) showed that with that mutant nodule development is blocked at a relatively early stage. Still a nodule is formed with peripherically located vascular bundles but the center of the nodule consists of large empty cells and dark staining material which probably consists of collapsed infected cells. Hence these results support the EM observations of Noel et al. (1982) that HS124 bacteria are rarely released from the infection thread and that the few cells which have become infected appear to be collapsed.

Analysis of the 2-D pattern of nodules induced by the nod ${ }^{+}$fix- mutants F4-6 and $45 \mathrm{~K}-13$ indicated that all nodulins observed in nodules induced by wildtype bacteria are present in the mutant induced nodules. The results obtained with F4-6 are shown in figure 2-4, which is a composite of the same fragments of 2-D gels as in figure 2-3 with the exception of region E. In nodules formed by HS124 the early nodulin genes are expressed, but only half of the late nodulin mRNAs are detectable. This is illustrated in the 2-D pattern from in vitro translated HS124 

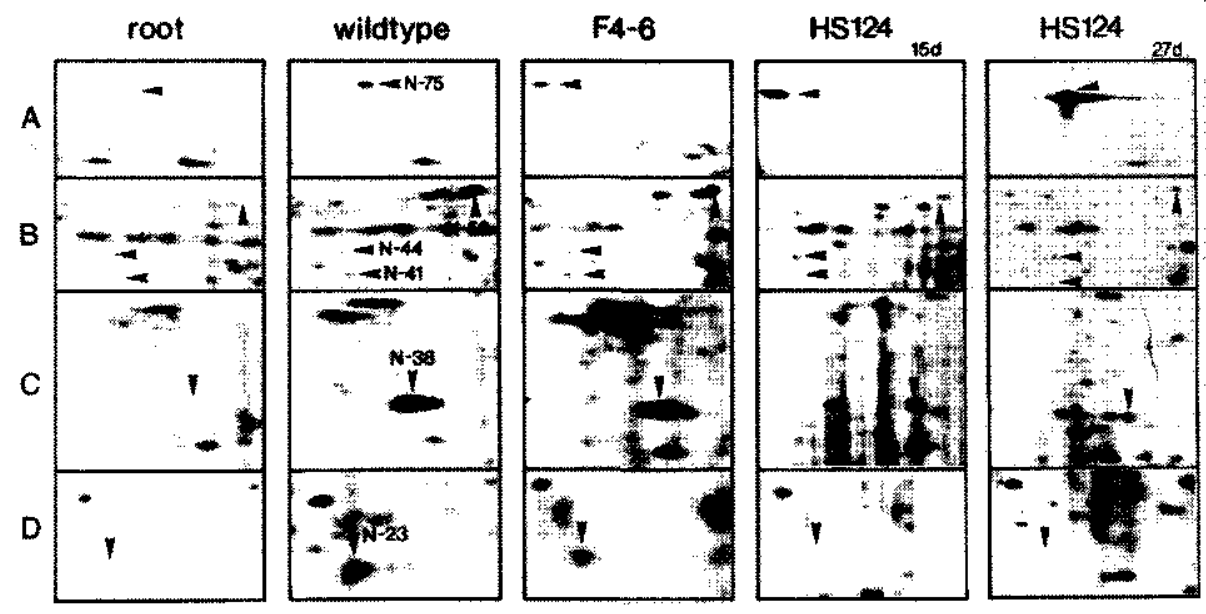

Figure 2-4: Expression of nodulin genes in non-effective root nodules. A comparison of in vitro translation products from total RNA isolated from 5-day-old uninfected roots, nodules induced by Bradyrhizobium japonicum USDA110, 15 days after sowing, Bradyrhizobium japonicum deletion mutant F4-6, 15 days after sowing, and Bradyrhizobium japonicum mutant HS124, 15 and 27 days after sowing respectively. Only the fragments of the 2-D gels within the rectangles indicated in figure 2-1B are shown. The expression is shown for Ngm-75-2 [A], Ngm-59, Ngm-44, and Ngm-41 [B], Ngm-38 [C], and Ngm-23 [D]. It should be noted that the 2-D gels of the mutant strains were run separately so that the exact position of the nodulins varies slightly.

nodule RNA, shown in the last two columns of figure 2-4. Moreover, the appearance of the early nodulins Ngm-75-2, Ngm-44, and Ngm-41 is no longer transient in HS124 nodules since they are still present at high levels even at day 27 after infection (figure 2-4 row A and B respectively). The amount of early nodulin Ngm-38 was low at day 15 compared to wildtype nodules and remained low during development (figure 2-4 row C). Four late nodulins, Ngm-23, Ngm-23', Ngm-16, and Ngm-14, were not detectable, as is illustrated in figure 2-4 row D for Ngm-23, while Lbs were hardly present (data not shown). The other late nodulins, such as Ngm-59 (figure 2-4 row B), are found at almost the same levels as in wildtype nodules. The difference in nodulin gene expression in HS124 nodules and the nodules formed by the deletion mutants is further exemplified by the RNA transfer blots in figure 2-5. Blots of total RNA from wild-type nodules or from nodules formed by deletion mutant $45 \mathrm{~K}-13$ or mutant HS124 were hybridized with either cDNA clone pGmENOD2, representing the two early nodulins Ngm-75-1 and Ngm-75-2, or with CDNA clone pGmENOD3, a late nodulin cDNA clone for which the corresponding nodulin has not been identified yet. In both types of non-effective nodules GmENOD2 mRNA was detectable while GmNOD3 mRNA was only observed in nodules formed by the deletion mutant $45 \mathrm{~K}-13$ but not in 


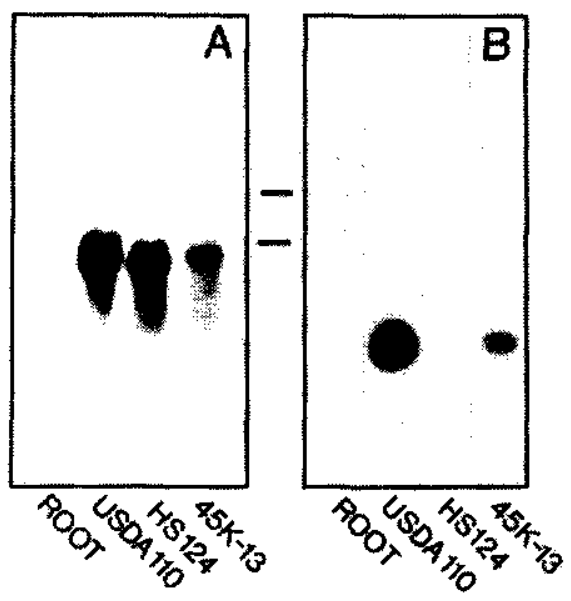

Figure 2-5: RNA transfer blot analysis of total RNA from nodules formed by wildtype Bradyrhizobium japonicum and mutant strains. Two identical RNA transfer blots are shown containing from left to right 1 microgram polyA $\left(^{+}\right.$) RNA isolated from 5-day-old uninfected roots and 10 microgram total RNA isolated from nodules induced by Bradyrhizobium japonicum USDA110, 21 days after sowing. Bradyrhizobium japonicum mutant strain HS124, 21 days after sowing, and Bradyrhizobium japonicum mutant strain 45K-13, 22 days after sowing. [A] RNA transfer blot hybridized with [ ${ }^{32} \mathrm{P}$ ]-labeled early nodulin cDNA clone pGmENOD2, representing the Ngm-75 nodulins, [B] RNA transfer blot hybridized with $\left[{ }^{32} \mathrm{P}\right]$-labeled late nodulin cDNA clone pGmNOD3. The position of the ribosomal RNAs is indicated by lines between panels [A] and $[B]$. Each lane in RNA transfer blot $[A]$ and [B] was exposed for the same time to the film.

HS124 induced nodules, confirming that in the latter case all late nodulin genes are expressed.

\section{Discussion}

In this chapter we have described the occurrence of over 20 nodulins in soybean root nodules and we have classified these nodulins with respect to the time of appearance of the mRNAs encoding the nodulins during nodule development, which in turn stands for the expression of the corresponding nodulin genes. The expression of four nodulin genes was detected already at day 7 when only a globular meristem is present (early nodulins) while the majority of the nodulin mRNAs, including the Lb mRNAs, appeared when a nodule structure has been formed (late nodulins).

The early nodulins were first detected during nodule development in excised nodules from plants 7 days after sowing and inoculation. At this stage of development the nodules are first macroscopically visible since they just emerge through the epidermis. Before this stage of development the mRNA analyses were restricted to mRNA from root segments. However, when the mRNA from root segments of inoculated 7-day-old plants was analyzed the early nodulins were not detectable, although they were shown to be present in excised nodules of the same age. Hence we might have missed the expression of early nodulin genes at 
stages preceding day 7 . The early nodulin mRNAs, with the exception of Ngm-44 mRNA, markedly increase in concentration between day 7 and 13, which is the stage of development when the globular meristem differentiates into a nodule structure. Hence we assume that these early nodulins are related to this differentiation process. If these early nodulin genes are expressed before day 7 , we assume the level of expression to be similar or lower than on day 7. Hence these nodulin genes show at least a markedly enhanced expression level when the meristem differentiates into a nodule.

One early nodulin mRNA, Ngm-44 mRNA, occurs at a similar level on day 7 and 10, whereupon its concentration decreases. Therefore this nodulin appears to be correlated with meristematic activity since mitotic activity in soybean nodules disappears between day 10 and 20 (Bieberdorf, 1938; Dart, 1977). Since the Ngm-44 mRNA does not occur in root tips, another meristematic tissue, this mRNA is specific for the nodule meristem.

The pattern of nodulin gene expression in soybean root nodule development is rather similar to that in pea (Govers et al., 1985), for also in those plants the majority of the genes are expressed concomitantly with the $L b$ genes whereas the expression of only a few genes is induced before the Lb genes. However, in some respect there is a significant difference in early nodulin gene expression between soybean and pea: in pea nodules the early nodulins are persistent while on the contrary the soybean early nodulins have a transient character. This difference correlates with a difference in meristematic activity during pea and soybean nodule development since in pea a meristem, differentiating into nodule cells, is continuously present while in soybean the meristematic activity comes to an end between 10 and 20 days (Bieberdorf, 1938; Dart, 1977). This observation makes a correlation between early nodulins and the presence of meristematic cells more likely.

For the pea-Rhizobium leguminosarum symbiosis it has been suggested that the nod genes, which are located on the symbiotic plasmid, are involved in the induction of early nodulin genes (Govers et al., 1986), while genes not located on this plasmid but probably on the chromosome, or another plasmid of Rhizobium leguminosarum are required for the induction of the other nodulin genes. It is still unclear which genes of Bradyrhizobium japonicum are involved in nodulin gene expression, but our results show that they are not located in the region in which the nifH,OK genes are located since the mutants F4-6 and 45K-13, despite large deletions covering together about $150 \mathrm{~kb}$ around this nifH,DK region (M. Hahn, personal communication) are still able to induce expression of all nodulin genes. 
Since in HS124 nodules the bacteria are rarely released into the plant cells, and the few infected cells appear to be collapsed, the expression of the subclass of late nodulin genes not expressed in HS124 nodules, seems to be related to the presence of cells invaded by bacteria which sustain infection in nodules. The other late nodulin genes then may be involved in the maintenance of the nodule structure or the actual nitrogen fixation process. In 27-day-old HS124 nodules the level of Ngm-75-2 is relatively high. Whether this is related to a persistent meristem we do not know. Meristematic activity was still visible in these nodules but we have not measured the extent of meristematic activity by serial sectioning. Why the level of expression of the Ngm-38 gene is low and stays low during HS124 nodule development is unclear to us.

Although the mechanism by which nodulin gene expression is regulated is still unclear, it is likely that specific signals from Bradyrhizobium will be involved in this induction. If this is the case the results described in this chapter suggest that at least three different signals from Bradyrhizobium japonicum may be involved in soybean nodulin gene expression. First of all as the early nodulin genes are expressed before the late nodulin genes it is likely that these two classes of genes are regulated in a different manner. The late nodulin genes may be induced by two different signals since the late nodulin genes can be further divided into two subclasses as followed from our analyses of the nodules formed by Bradyrhizobium japonicum mutant HS124. In that case nodule formation was interrupted before completion resulting in some of the late nodulin genes being expressed at wildtype levels while others including the Lb and NOD3 genes were not expressed, or at very reduced levels, in these nodules.

\section{Material and Methods}

Growth conditions for soybean plants and bacteria - Culturing of soybean plants (Glycine max (L.) Merr. cv. Williams) was done as described by Bisseling et al. (1978) for pea plants but at a day/night regime of $16 \mathrm{~h} / 28 \mathrm{C}, 8 \mathrm{~h} / 24 \mathrm{C} ; 70 \%$ relative humidity. The soybean seeds were inoculated at the day of sowing with Bradyrhizobium japonicum USDA1 10 grown as described by Bhuvaneswari et al. (1980). Nodules were either excised from the root by a scalpel (day 7) or picked (day 10 and later) with tweezers directly, frozen in liquid $\mathrm{N}_{2}$ and stored at $-70 \mathrm{C}$ until use. Uninfected plants were grown in the same way and root tips from 2-day-old seedlings or root segments from the main root (5 days old) were harvested. Plants infected with fix Bradyrhizobium japonicum strains were cultured in the same way and the resulting nodules were checked on the Fix phenotype by the acetylene reduction assay.

Pouching technique - Three-day-old seedlings were pouched and inoculated as described by Bhuvaneswari et al. (1980). The position of the root tip (RT) was marked at the time of inoculation. At different times, ranging from 16 hours to 4 days after inoculation, root segments from $2 \mathrm{~cm}$ above the RT mark to $2 \mathrm{~mm}$ below the RT mark were harvested. As a consequence root segments 
harvested 4 days after inoculation are equal with respect to nodule development to gravel cultured plants 7 days after sowing and inoculation. The root segments were frozen in liquid nitrogen and stored at $-70 \mathrm{C}$ until use.

RNA isolation - Total RNA from nodules and roots was isolated as described by Govers et al. (1985) and polyA( $\left.{ }^{+}\right)$RNA was obtained after oligo dT cellulose chromatography according to Maniatis et al. (1982).

In vitro translation and 2-D gel electrophoresis - Total RNA was in vitro translated in a cell free wheat germ extract obtained from BRL. Typically 3 microgram of total RNA or 0.5 microgram of polyA $\left({ }^{+}\right)$RNA was translated in a 15 microliter mixture containing $15-30$ microCi $\left[{ }^{35} \mathrm{~S}\right]$-methionine (NEN) or 6 microCi $\left[{ }^{3} \mathrm{H}\right]$-leucine (NEN) as a radioactive labeled amino acid. In vitro translations were optimized with respect to RNA concentration and incubation time to insure a linear response between the amount of mRNA added and incorporation of labeled amino acids. Incorporated radioactivity was determined by cold TCA precipitation as described in the BRL manual. The in vitro translation products were separated by 2-D gel electrophoresis according to De Vries et al. (1982) and the gels were fluorographed to Kodak XAR-5 films.

RNA transfer blot analysis - Total soybean RNA was denatured in DMSO/glyoxal and electrophoresed, transferred to nitrocellulose and hybridized for $16 \mathrm{~h}$ at $42 \mathrm{C}$ in the presence of $50 \%$ formamide as described by Maniatis et al. (1982). The blots were washed twice for 15 minutes at $42 \mathrm{C}$ in $2 \times S S C$ (1XSSC $=0.15 \mathrm{M} \mathrm{NaCl} / 0.15 \mathrm{M}$ sodium citrate) $/ 0.1 \%$ SDS and twice for 30 minutes at $42 \mathrm{C}$ in $0.5 \times S S C / 0.1 \%$ SDS according to Franssen et al. (1987).

Light microscopy - Nodules were fixed overnight in $3 \%$ glutaraldehyde buffered with phosphate at pH 7.5. After buffer rinsing the nodules were dehydrated in a graded ethanol series and embedded in Kulzer Technovit 7100, cut into 5 micrometer sections, stained with toluidine blue and examined under a light microscope. 


\section{CHAPTER III}

\section{Characterization of Soybean}

\section{Early Nodulin cDNA Clones}

[3.1] Henk J. Franssen, Jan-Peter Nap, Ton Gloudemans, Willem Stiekema, Hans van Dam, Francine Govers, Jeanine Louwerse, Albert van Kammen, and Ton Bisseling. Proceedings National Academy Science USA 84, 4495-4499 (1987)

[3.2] Ben Scheres, Ton Gloudemans, Frans Mulckhuyse, Hans Bluyssen, Albert van Kammen, Ton Bisseling, and Henk J. Franssen. Manuscript in preparation 


\title{
3.1 Characterization of CDNA for nodulin-75 of soybean: a gene product involved in early stages of root nodule development
}

\begin{abstract}
Establishment of a nitrogen fixing root nodule is accompanied by a developmentally regulated expression of nodulin genes, only some of which, the so-called early nodulin genes, are expressed in stages preceding actual nitrogen fixation. We have isolated soybean CDNA clones representing early nodulin genes and have studied clone pGmENOD2 in detail. The cDNA insert of this clone hybridizes to nodule-specific RNA of 1200 nucleotides in length. The RNA that was hybrid-selected by the cloned GmENOD2 DNA was in vitro translated to produce two nodulins with an apparent molecular mass of $75 \mathrm{kDa}$, the Ngm-75 nodulins. These two nodulins differ slightly in charge and one of them does not contain methionine. The amino acid sequence deduced from the DNA sequence shows that proline accounts for $45 \%$ of the 240 residues in these nodulins and the sequence contains at least 20 repeating heptapeptide units. The amino acid composition of none of the (hydroxy)proline-rich (glyco)proteins described in plants resembles the composition of the $\mathrm{Ngm}-75$ nodulins, especially with respect to the high glutamic acid and the low serine content. This suggests that the Ngm-75 nodulins belong to a hitherto unidentified class of presumably structural proteins. The genes encoding the Ngm-75 nodulins were found to be expressed in nodule-like structures devoid of intracellular bacteria and infection threads, indicating that these nodulins do not function in the infection process but more likely function in nodule morphogenesis.
\end{abstract}

\section{Introduction}

The formation of nitrogen fixing nodules on the roots of leguminous plants induced by bacteria of the genera Rhizobium and Bradyrhizobium involves the specific expression of a number of plant genes called nodulin genes (Fuller et al., 1983; Govers et al., 1985; Lang-Unnasch and Ausubel, 1985; Gloudemans et al., 1987). In a description of nodule development, Vincent (1980) distinguishes between three stages in nodule development denoted as 'preinfection', 'infection and nodule formation', and 'nodule function'. In the preinfection stage, the Rhizobium bacteria recognize their host plants and attach to the root hairs, an event that is followed by root hair curling. At the moment nothing is known about specific plant genes that are involved in this stage. In the next stage the bacteria enter the roots by infection threads while concomitantly the dedifferentiation of some cortical cells 
results in the formation of meristems. The infection threads grow towards the meristematic cells; bacteria are released into the cytoplasm of about half of these cells and develop into bacteroids. In the final stage, further differentiation of nodule cells occurs leading up to a nitrogen fixing nodule. Most studies on the expression of nodulin genes so far have been confined to the final stage of root nodule development. But the steps in root nodule formation show that major decisions determining the development of a root nodule are made in the stages preceding the establishment mentof a nitrogen fixing nodule. We have shown that nodulin genes are differentially expressed during development (Govers et al., 1986; Gloudemans et al., 1987) and that in pea at least two nodulin genes are transcribed in the second stage of root nodule formation. These genes are referred to as early nodulin genes. Here we report the detailed analysis of a soybean CDNA clone representing an early nodulin gene.

\section{Results}

\section{Characterization of pGmENOD2}

Out of a cDNA library prepared against polyA $\left(^{+}\right)$RNA of soybean root nodules, 10 cDNA clones were isolated that specifically hybridized with the nodule cDNA probe from 10-day-old plant polyA $\left(^{+}\right)$RNA. These clones represent early nodulin genes and will be designated pGmENOD to distinguish them from pGmNOD clones that represent nodulin genes expressed at later stages of development. Cross-hybridization studies revealed 8 clones with common sequences, of which the clone pGmENOD2 with an insert length of $1000 \mathrm{bp}$ was chosen for further characterization.

On DNA transfer blots of EcoRI-digested soybean genomic DNA, five restriction fragments were found to hybridize with $\left[{ }^{32} \mathrm{P}\right]$-labeled pGmENOD2, whereas no hybridization was observed with Bradyrhizobium japonicum DNA (data not shown). Hence, the cloned pGmENOD2 DNA is encoded by the soybean genome and its gene is probably part of a small gene family.

Clone pGmENOD2 hybridized to a mRNA of 1200 nucleotides; the concentration of GmENOD2 mRNA is highest at day 10 and decreases during further nodule development (figure 3-1A). Thus the GmENOD2 gene is apparently transiently expressed during soybean nodule development, although in some experiments the concentration of GmENOD2 mRNA remained nearly constant between 10 and 21 days. 


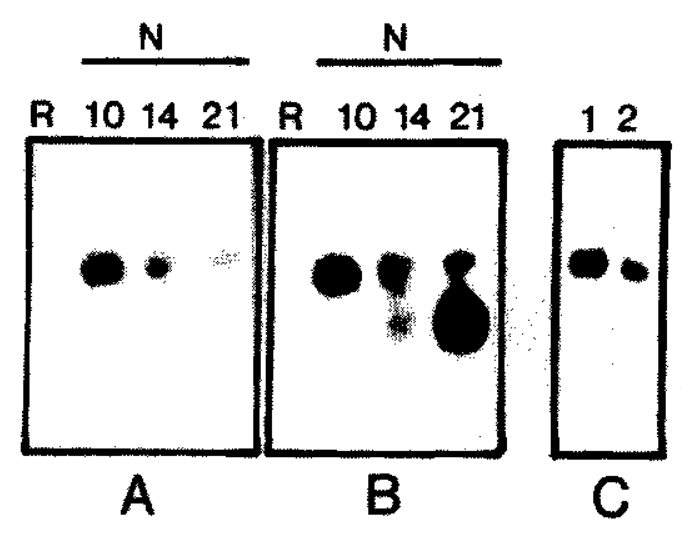

Figure 3-1: Autoradiographs of two identical RNA transfer blots (A and B) containing 15 microgram of total RNA isolated from 5-day-old uninoculated roots $(\mathrm{R})$ and nodules $(\mathrm{N})$ harvested 10 . 14 , and 21 days after sowing and inoculation with Bradyrhizobium japonicum USDA110. (C) Autoradiograph of a RNA transfer blot containing 15 microgram RNA isolated from nodules harvested 14 days after sowing and inoculation with Bradyrhizobium japonicum USDA110 (lane 1) and from nodule-like structures collected four weeks after inoculation with Rhizobium fredii USDA257 (lane 2). The blots were hybridized with [ ${ }^{32} \mathrm{P}$ ]-labeled pGmENOD2 ( $A$ and $C$ ) and with pGmENOD2 and pLb in consecutive order (B).

For comparison of the expression of the GmENOD2 genes with that of nodulin genes expressed later in development, a leghemoglobin (Lb) cDNA clone (pLb), selected from the cDNA library by hybridization with a soybean Lb cDNA clone (Jensen et al., 1981) made available by K. Marcker (University of Århus, Denmark), was used. The difference in time of expression between GmENOD and Lb genes is illustrated in figure 3-1B. The RNA transfer blot was first hybridized with pGmENOD2 and was subsequently probed with pLb. The Lb mRNAs start to appear when the GmENOD2 mRNA concentration is already decreasing.

\section{pGmENOD2 codes for Ngm-75 nodulin}

To identify the early nodulin encoded by pGmENOD2, mRNA was hybrid-selected by $\mathrm{pGmENOD2}$ and translated in vitro in the presence of $\left[{ }^{35} \mathrm{~S}\right]$-methionine. The results showed that the pGmENOD2 encoded polypeptide has an apparent molecular mass of $75 \mathrm{kDa}$ with an isoelectric point around 6.5 (figure 3-2A). In accordance with the nomenclature established hedfor nodulins (Van Kammen, 1984), the identified polypeptide is named $\mathrm{Ngm}-75$. After in vitro translation of the pGmENOD2 selected RNA in the presence of $\left[{ }^{3} \mathrm{H}\right]$-leucine, two polypeptides were found one of which co-migrated with the polypeptide detected after translation with $\left[{ }^{35} \mathrm{~S}\right]$-methionine whereas the other, more prominent, polypeptide was slightly more basic (figure 3-2A). The two polypeptides obtained from hybrid-released translation should be closely related and are each encoded by a different member of the GmENOD2 gene family. The polypeptides, both referred to as Ngm-75, were also easily detectable as nodulins in the 2-D pattern of the polypeptides obtained upon in vitro translation of total nodule mRNA (figure 3-2A, and chapter II). 


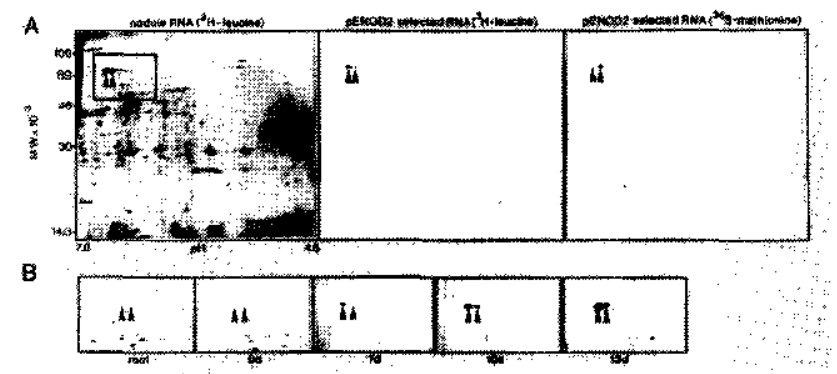

Figure 3-2: Characterization of the early nodulin cDNA clone pGmENOD2 by hybrid-released transiation (A) and time-course analysis of the expression of the Ngm-75 genes during nodule development (B). Total RNA from 16-day-old soybean nodules and RNA eluted from filter-bound pGmENOD2 DNA were transiated in a wheat germ extract in the presence of $\left[{ }^{3} \mathrm{H}\right]$-leucine or $\left.{ }^{35} \mathrm{~S}\right]$-methionine. The products obtained were separated by 2-D gel electrophoresis and fluorographed. The positions of the Ngm-75 nodulins are indicated by arrowheads. In (B) only the fragment of the 2-D gel within the rectangle indicated in $(A)$ is shown that represents the $\left[{ }^{3} \mathrm{H}\right]$-leucine in vitro transiation products obtained from RNA of 5-day-old uninfected soybean root, from root segments of infected soybean plants 6 days after sowing and inoculation with Bradyrhizobium japonicum USDA110, and from soybean nodules 7,10 , and 13 days after sowing and inoculation with the same strain. In (A) the molecular mass of the markers is indicated in $\mathrm{kDa}$.

The translation products of these mRNAs of 1200 nucleotides in length have an apparent molecular mass of $75 \mathrm{kDa}$, whereas mRNA of that length has a coding capacity for a polypeptide of, at most, $45 \mathrm{kDa}$. This notable discrepancy prompted us to sequence the CDNA insert of pGmENOD2 to see if the deduced amino acid sequence could explain the peculiar physical properties of the encoded polypeptides. At the same time information on the structure may provide clues on a possible function of the $\mathrm{Ngm-75}$ nodulins. The sequencing data (figure 3-3) reveal that the Pstl insert of the pGmENOD2 CDNA clone contains 998 nucleotides including a short $3^{\prime}$ poly(A) tail but excluding the dCdG nucleotides generated in the cloning procedure. At most 200 nucleotides of the 5 ' end of the 1200-nucleotide-long MRNA, including the initiation codon and coding sequences for the $\mathrm{N}$-terminus of the polypeptide, are thus missing in this clone. Two open reading frames (ORF) occur in the same strand (figure 3-3). From one ORF, designated ORF-1, 728 nucleotides are found in the cDNA clone (positions 13-741; figure 3-3), and this ORF ends with two successive termination codons. A second ORF, designated ORF-2, not in phase with the first one, comprises 611 nucleotides (positions 14-625; figure 3-3) and ends in a single termination codon. Both ORFs are followed by 3 ' non-translated regions of about 250 (ORF-1) and 375 (ORF-2) nucleotides, respectively, in which two potential poly(A) addition signals are present (figure 3-3). 

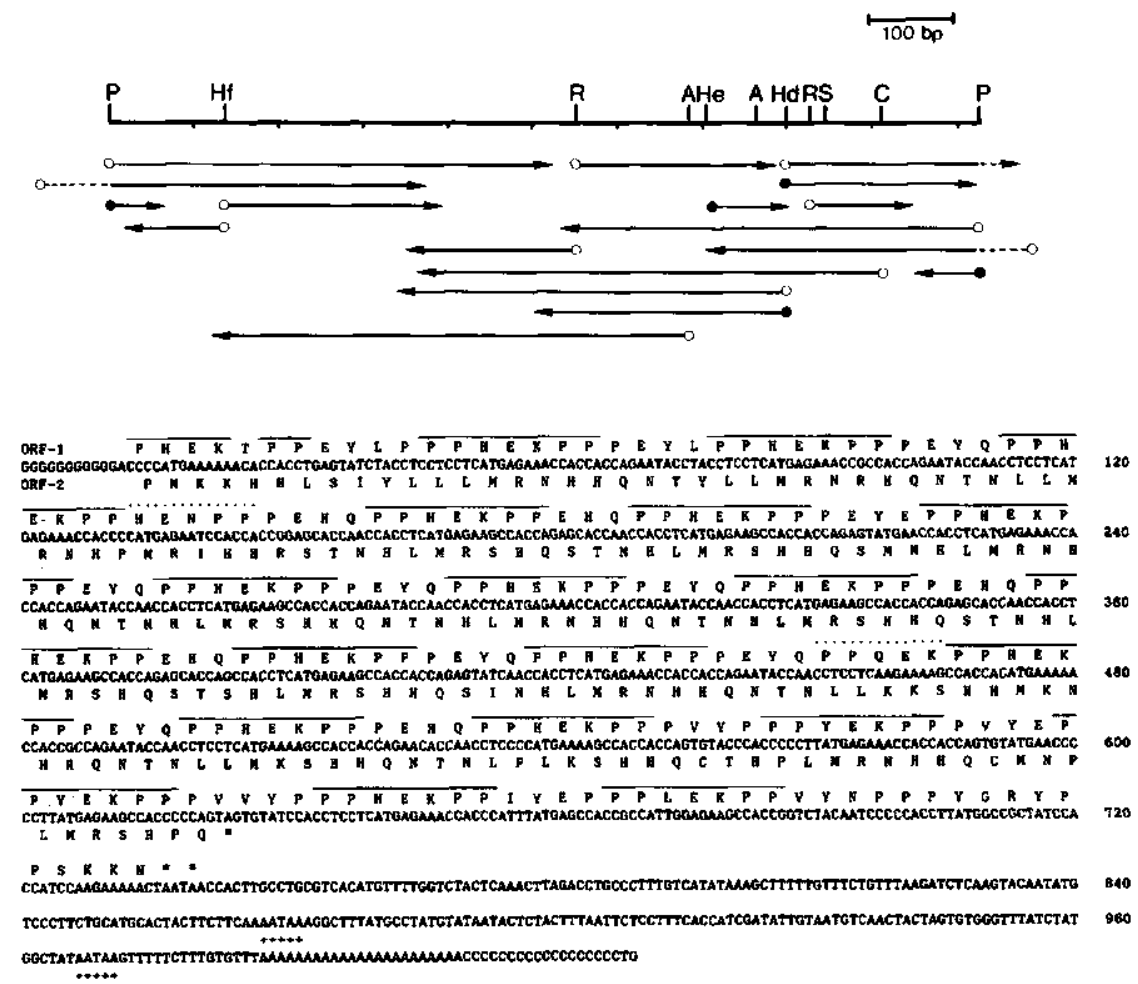

Figure 3-3: Partial restriction map, sequencing strategy, and nucleotide sequence of the Pstl fragment from pGmENOD2. Sequencing was performed by the Maxam-Gilbert method (open circles) and by the dideoxy method (closed circles). The arrows depict the direction and extent of sequencing from the indicated site. The dashed line correspond to sequences originating within the vectors. In the DNA sequence, nucleotides are numbered on the right of the sequence. The predicted amino acid sequence is shown in standard single-letter code for both ORFs and the characteristic heptapeptide is overlined in ORF-1. The two partial repeats are indicated by a dotted line. Termination codons $\left(^{*}\right)$ and potential poly $(A)$ addition sites $(+++)$ are also marked. $P$, Pst; Hf, Himfl; R, Rsal; A, Accl; He, Haelll; Hd, Hindlil; S, Sphl; C, Clal.

Although both ORFs seem to be able to code for a nodulin of about the same size, several lines of evidence indicate that only ORF-1 corresponds to a nodulin N-75. First, ORF-1 gives rise to a completely different polypeptide (241 amino acids of which none is methionine) than ORF-2 ( 203 amino acids of which 20 are methionine). Such entirely different polypeptides will differ in physical properties. The two Ngm-75 in vitro translation products will therefore most likely be related polypeptides with a similar amino acid sequence, derived from two different mRNAs and not from two ORFs of one mRNA. If then one of the Ngm-75 in vitro translation products is shown to contain no methionine (figure 3-2A) the other 
Ngm-75 nodulin may have a low methionine content. However, the ORF-2 derived polypeptide contains 20 methionines, indicating that it is rich in methionine. We therefore deduce that ORF-1 encodes a nodulin $\mathrm{Ngm}-75$. This conclusion is supported by the absence of methionine in the amino acid sequence deduced from this ORF.

Moreover, though both ORFs encode a polypeptide containing repeating peptide sequences, the repetitive amino acid sequence occurring in the polypeptide encoded by ORF-1 are better preserved than those present in the ORF-2 derived polypeptide. This indicates that an evolutionary tendency exists for a functional conservation of the polypeptide encoded by ORF-1. We therefore propose that ORF-1 will exclusively be used for the generation of a nodulin Ngm-75.

ORF-1 shows that the Ngm-75 nodulins are peculiar proline rich proteins. Ngm-75 contains a repetitive sequence of 10 or 11 amino acids that is repeated at least 20 times. Embedded in this repetition a heptapeptide sequence is found that is conserved in 19 of 20 units (figure 3-3). This repeated heptapeptide sequence is Pro-Pro-Xaa-Glu-Lys-Pro-Pro, in which 17 times Xaa = histidine and three times Xaa $=$ tyrosine or leucine. Three or four amino acids that are not as conserved, mainly proline, glutamic acid/glutamine, and tyrosine, flank the heptapeptide repetitive sequence. Two apparent partials of the heptapeptide repeat are found at positions 133 and 451 within the sequence. Neither alpha-helix nor beta-sheet conformations were found using the method of Lim (1974). The high proline content of the Ngm-75 nodulins probably explains the discrepancy between the observed apparent molecular mass of $75 \mathrm{kDa}$ and the coding capacity of a 1200-nucleotide mRNA. A similar aberrant migration behavior on $\mathrm{NaDodSO}_{4} /$ polyacrylamide gels is found for the proline-rich protein collagen (Freytag et al., 1979).

\section{Ngm-75 is involved in nodule morphogenesis}

To form an idea of the process in which the proline rich Ngm-75 protein might be involved, we attempted to correlate the beginning of expression of the $\mathrm{Ngm}-75$ genes with a defined stage in root nodule formation. Total RNA was isolated from tap root segments of 6-day-old inoculated plants, where nodules are not yet visible, and from nodules harvested 7,10 , and 13 days after sowing and inoculation. RNA preparations were analyzed by in vitro translation using $\left[{ }^{3} \mathrm{H}\right]$-leucine followed by 2-D gel electrophoresis. The area of the 2-D gel where $\mathrm{Ngm-75}$ nodulins are found is shown in figure 3-2B. Both Ngm-75 proteins first appear at day 7 and then increase in concentration up to day 13. 


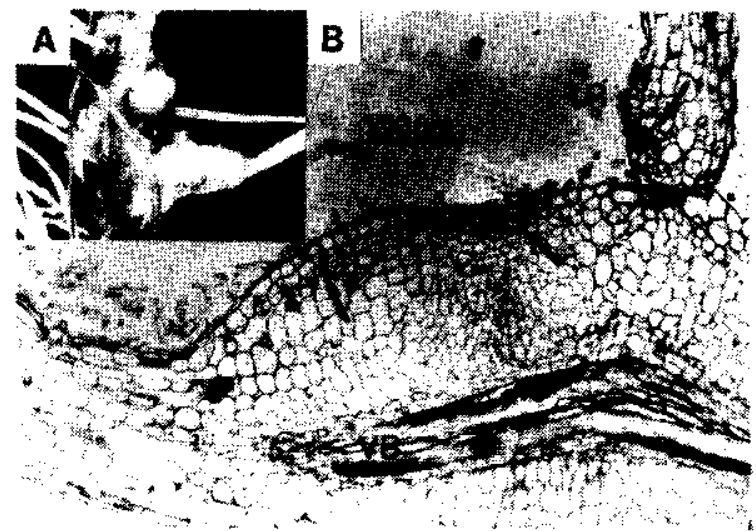

Figure 3-4: (A) Nodule-like structure on soybean roots obtained 4 weeks after inoculation with Rhizobium fredii USDA257. (B) part of a longitudinal section of a nodule-like structure. Cell divisions in the outer and inner cortical cell layers are indicated by arrows. VB, root vascular bundle; LR, lateral root.

By examining the nodule structures formed by Rhizobium fredii USDA257, it proved possible to distinguish between the infection process and the differentiation into a nodule structure. On commercial soybean cultivars, this fast growing Rhizobium strain cannot form nitrogen fixing root nodules but forms nodule-like structures that are not able to fix nitrogen.

Histological examination of these nodule-like structures revealed that they arise from a combination of cell swellings and randomly orientated cortical cell divisions (figure 3-4). In these nodule-like structures, no infected plant cells or infection threads were observed and none of the structures examined had an organization with vascular bundles at the periphery, similar to normal nodules. Apparently the formation of such a nodule-like structure does not require an infection process. By RNA transfer blot analysis, Ngm-75 RNA could be detected in RNA isolated from these nodule-like structures (figure 3-1C).

\section{Discussion}

A cDNA library from soybean root nodules has been analyzed for copies of mRNA transcripts of early nodulin genes. These genes are expressed in the early stage of root nodule development when the nodule structure is being formed. One of the clones, pGmENOD2, was characterized in detail. The nucleotide sequence of the Pstl insert of PGmENOD2 has been determined and the derived amino acid sequence shows that $45 \%$ of the amino acids of $\mathrm{Ngm}-75$ is proline and that the amino acid sequence is organized in highly repetitive units (figure 3-3).

In an effort to derive a function for $\mathrm{Ngm-75}$ in root nodule development from these sequence data, we have surveyed the occurrence of proline-rich proteins in plants and their assumed functions. All proline-rich proteins that have been described in 
plants so far contain hydroxyproline that is posttranslationally formed and in most cases subsequently glycosylated. Although it remains to be established whether the soybean Ngm-75 proteins become hydroxylated and glycosylated in vivo, soybean nodule tissue has been described as extremely hydroxyproline-rich (Cassab, 1986). Also the apparent absence of a class of proline-rich proteins in plants justifies the assumption that the nodulins $\mathrm{Ngm}-75$ belong to one of the classes of hydroxyproline-rich glycoproteins (HRGP). There are four major classes of HRGPs in plants (McNeil et al., 1984): (i) the cell wall structural HRGPs or extensins (Van Holst and Varner, 1984; Chen and Varner, 1985a), (ii) the arabinogalactan proteins (Van Holst et al., 1981), (iii) the solanaceae lectins (Allen et al., 1978), and (iv) hydroxyproline-rich agglutinins (Leach et al., 1983).

Extensins are associated with the cell walls of most dicotyledonous plants (Lamport and Catt, 1981). They are assumed to play a role in maintaining the integrity of the primary cell wall (Cooper, 1984) and they may be important in controlling growth and development. Extensins have been shown to accumulate in plant cell walls upon wounding (Chrispeels et al., 1974) and pathogen attack (Hammerschmidt et al., 1984; Showalter et al., 1985) in what is considered a defense response. The amino acid sequence of extensins are characterized by the occurrence of a repeating Ser-Hyp-Hyp-Hyp-Hyp pentapeptide. Neither this pentapeptide nor the typical high serine content is found in the amino acid sequence of Ngm-75. The nodulins $\mathrm{Ngm}-75$ are therefore not closely related to extensins.

After comparison of the amino acid composition of representatives of each of the classes mentioned above with $\mathrm{Ngm}-75$, it can be concluded that the amino acid composition of none of the HRGPs analyzed so far resembles the amino acid composition derived for Ngm-75. Also Ngm-75 is not homologous to the HRGPs P33 (Chen and Varner, 1985b) and SbPRP1 (Hong et al., 1987), recently identified, using the same criteria as above. We therefore may be dealing with a hitherto unknown class of (hydroxy)proline-rich proteins, characterized by a remarkably low content of serine and a surprisingly high content of glutamic acid. Both the highly repetitive nature of the amino acid sequence and the high proline content suggest that the Ngm-75 nodulins are structural proteins.

To gain a better understanding of the biological function of the Ngm-75 nodulins in root nodule development, we have studied the expression of their genes as a function of time. The expression of the Ngm-75 genes is first detectable at 7 days after sowing and inoculation, when the nodule meristerns just emerge through the root epidermis. We were not able to detect Ngm-75 RNA in 7-day-old tap root pieces with visible nodule structures, whereas we could detect Ngm-75 mRNA in excised nodule structures of the same age. Therefore it cannot be excluded that 
these genes are already expressed earlier than 7 days after sowing and inoculation but in fewer cells and at a similar or lower level than at 7 days.

Irrespective of the possible expression of these genes before 7 days, a strong stimulation of Ngm-75 gene expression occurs from 7 to 13 days. The Ngm-75 proteins should therefore be involved in a developmental event that proceeds during this period. Around day 7 in our growth system the nodules emerged through the root epidermis. This stage of development equals stage VII as described by Calvert et al. (1984), and cytological observations have shown that in this stage the meristems start to differentiate into nodule structures (Calvert et al., 1984). Some of the meristem cells have been invaded by infection threads from which the rhizobia are beginning to be released. To examine whether the induction or stimulation of the expression of the Ngm-75 genes is specifically related to the infection process, on the one hand, or the formation of a nodule structure, on the other, we have looked for Ngm-75 gene expression in nodule-like structures formed by Rhizobium fredii USDA257. This strain induces the formation of nodule structures devoid of intracellular bacteria and infection threads, in which, however, early nodulin Ngm-75 mRNA is detectable. The expression of the Ngm-75 genes in nodules without bacteria or infection threads strongly suggests that Ngm-75 is not involved in the infection process, but more likely in nodule morphogenesis.

Quantitative light microscopical observations on nodule initiation (Calvert et al., 1984) have shown that up to the stage in which the meristems emerge through the epidermis, development can stop. However, when a meristem has reached the 'emergence' stage it will continue to develop into a mature nodule. The stimulation of the expression of the Ngm-75 genes coincides therefore with the moment the soybean nodule meristems have reached an apparently critical developmental stage. The expression of the Ngm-75 genes might therefore reflect the 'commitment' of the meristems to develop into a nodule. The nature of the involvement of the (hydroxy)proline-rich nodulins Ngm-75 in this commitment remains to be established.

\section{Material and methods}

Growth conditions for plants and bacteria - Soybean plants (Glycine max (L) Merr. cv. Williams) were cultured as described by Gloudemans et al. (1987). At the time of sowing the soybean seeds were inoculated with Bradyrhizobium japonicum USDA110 or Rhizobium fredii USDA257. Both strains were cultured as described by Bhuvaneswari et al. (1980).

Isolation of nodules - Nodules were excised from the roots with a scalpel. For samples prior to 6 days after sowing and inoculation, a $4-\mathrm{cm}$ root segment of the upper part of the main root (where 
nodules normally would develop) was harvested. Nodules were frozen in liquid nitrogen and stored at $-70 \mathrm{C}$ until use.

Isolation of nucleic acids - Total RNA from nodules and roots was isolated as described by Govers et al. (1985) and polyA( ${ }^{+}$) RNA was obtained by oligo dT cellulose chromatography (Maniatis ef al., 1982). Plasmid DNA was isolated by the alkaline lysis method (Maniatis et al., 1982).

Construction of CDNA library - DNA complementary to polyA $\left({ }^{+}\right)$RNA isolated from nodules from 21-day-old plants was synthesized with reverse transcriptase (Anglian Biotechnology, Essex, England) and second strand synthesis was performed under standard conditions (Maniatis et al., 1982). The double-stranded cDNA was treated with $S 1$ nuclease and size-fractionated on a sucrose gradient. Double-stranded cDNA with a length of 500 bp or more was tailed with $\mathrm{dC}$ and then annealed to Pstl cut oligo(dG)-tailed pBR322 (Boehringer Mannheim) in a 1:1 molar ratio. The hybridized mixture was used to transform Escherichia coli RR1 (Maniatis et al., 1982). On the average, 5000 transformants were obtained per microgram of polyA ${ }^{+}$) RNA.

Differential screening of the CDNA library - Individual transformants were picked, transferred to 96-well microtiter plates containing LB medium, 15\% glycerol, and 12.5 microgram of tetracycline per $\mathrm{ml}$, and grown for 16 hours at 37C. Two replica filters were made on GeneScreenPlus (New England Nuclear). After 16 hours of bacterial growth on LB agar containing 12.5 microgram tetracycline per $\mathrm{ml}$, the filters were prepared for hybridization according to the GeneScreenPlus manufacturer's manual. Probes for differential screening were prepared from polyA( $\left.{ }^{+}\right)$RNA isolated from segments of 5-day-old, uninfected roots and from nodules 10 and 21 days after inoculation, as in the construction of the cDNA library except that 10 microCi of [ $\left.{ }^{32} \mathrm{P}\right]-\mathrm{dATP}$ (specific activity = $3200 \mathrm{Ci} / \mathrm{mmol} ; 1 \mathrm{Ci}=37 \mathrm{GBq}$; New England Nuclear) was used. the filters were hybridized for 72 hours at $65 \mathrm{C}$ to either root or nodule $\left[{ }^{32} \mathrm{P}\right]$-labeled CDNA in $0.9 \mathrm{M} \mathrm{NaCl} / 90 \mathrm{mM}$ sodium citrate/5X Denhardt's solution (Maniatis et al., 1982)/10 mM EDTA/0.5\% NaDodSO $4 / 100$ microgram of sonicated, denatured calf thymus DNA per $\mathrm{ml} / 20 \mathrm{microgram}$ of poly(A) per $\mathrm{ml}$. The filters were washed twice in $0.3 \mathrm{M} \mathrm{NaCl} / 30 \mathrm{mM}$ sodium citrate/0.1\% NaDodSO 4 for $15 \mathrm{~min}$ at room temperature and twice in $75 \mathrm{mM} \mathrm{NaCl} / 7.5 \mathrm{mM}$ sodium citrate/0.1\% $\mathrm{NaDodSO}_{4}$ for $30 \mathrm{~min}$ at $65 \mathrm{C}$.

In vitro translation of total RNA - Total RNA ( 3 microgram) from roots or nodules was translated in vitro in a wheat germ extract (Bethesda Research Laboratories) in a 15 microliter mixture to which 15-30 microCi of $\left[{ }^{35} \mathrm{~S}\right]$-methionine or 6 microCi of $\left[{ }^{3} \mathrm{H}\right]$-leucine was added (according to the manufacturer's manual). Translation products were separated by two-dimensional (2-D) gel electrophoresis followed by fluorography of the dried gel to preflashed Kodak XAR5 film (Govers $\theta t$ al., 1985).

Hybrid-released translation - For hybrid-released translation, the pGmENOD2 insert (10-15 microgram of DNA) was denatured and applied to $0.5 \mathrm{~cm}$ discs of diazophenytthioether paper (BioRad) essentially as described (Maniatis et al., 1982). Total soybean RNA from 16-day-old root nodules (750 microgram) was then hybridized to the filter-bound DNA in 300 microliter of 50\% (vol/vol) deionized formamide/0.1\% NaDodSO $4 / 0.6 \mathrm{M} \mathrm{NaCl} / 4 \mathrm{mM}$ EDTA/80 mM Tris-HCl, $\mathrm{pH} 7.8$. Hybridization was initiated at $40 \mathrm{C}$ and the temperature was slowly decreased to $37 \mathrm{C}$ over a period of 6 hours. After washing, the bound RNA was eluted (Maniatis et al., 1982) and dissolved in 3 microliter of water; 1.5 microliter was translated and analyzed as above.

RNA transfer blot analysis - Total soybean RNA was denatured in DMSO/glyoxal, electrophoresed in $0.8 \%$ agarose gels (Maniatis et al., 1982), and transferred to GeneScreen (New England Nuclear) as described (Govers et al., 1985). The blots were prehybridized for 6 hours in $50 \%$ (vol/vol) 
deionized formamide/1 $\mathrm{M} \mathrm{NaCl} / 0.05 \mathrm{M}$ Tris-HCl, $\mathrm{pH} 7.5 / 5 \times$ Denhardt's solution/0.1\% $\mathrm{NaDodSO}_{4} / 100$ microgram of denatured salmon sperm DNA per $\mathrm{ml}$ and hybridized with nick-translated (Maniatis et al., 1982) probes. Hybridization was performed for 16 hours at $42 \mathrm{C}$. Blots were washed twice for 15 min at $42 \mathrm{C}$ in $0.3 \mathrm{M} \mathrm{NaCl} / 30 \mathrm{mM}$ sodium citrate/0.1\% $\mathrm{NaDodSO}_{4}$ and twice for 30 min at $42 \mathrm{C}$ in 75 $\mathrm{mM} \mathrm{NaCl} / 7.5 \mathrm{mM}$ sodium citrate/0.1\% $\mathrm{NaDodSO}_{4}$.

DNA sequencing - Standard techniques were used for cloning into M13 and pUC vectors (Messing, 1983), and for dideoxy (Sanger et al., 1977; Biggin et al., 1983) and for Maxam-Gilbert (Maxam and Gilbert, 1980) sequencing. The DNA sequence data were stored and analyzed with programs written by Staden (1984) on a microVAXNMS computer.

Cytology - Nodules were fixed for 16 hours in $3 \%$ glutaraldehyde in $50 \mathrm{mM}$ sodium phosphate buffer (pH 7.2). After fixation the nodules were rinsed with the same buffer, dehydrated in a graded ethanol series, embedded in Technovit 7100 (Kulzer, Wehrheim, F.R.G.), cut into 5 micrometer sections, stained with toluidine blue, and examined under a light-microscope. 


\subsection{Two early nodulin cDNA clones involved in different steps of soybean nodule development}

\section{Introduction}

Upon infection of leguminous plants with bacteria of the genus Rhizobium or Bradyrhizobium a unique organ - the root nodule - is formed, in which symbiotic nitrogen fixation occurs. In this organ plants express a set of genes, the nodulin genes (Van Kammen, 1984), that are only expressed during the stage of formation and functioning of the nodule. Based upon the stage of development in which nodulin genes become expressed they have been divided into early and late nodulin genes (Govers et al., 1985; Gloudemans et al., 1987; Moerman et al., 1987). Early nodulin genes are expressed during infection of the host by the bacteria, and when the nodule structure is formed. Late nodulin genes become first expressed when the nodule structure is already formed: at the onset of nitrogen fixation.

Several late nodulins have been characterized, and a good example is leghemoglobin (Lb) which controls the concentration of free oxygen in the root nodule (Appleby, 1984). Other late nodulins have metabolic functions in assimilation of the fixed nitrogen. Examples are the nodule-specific forms of glutamine synthetase (Lara et al., 1983) and n-uricase (Legocki and Verma, 1979). A large group of soybean late nodulins appears to be localized in the peribacteroid membrane, like Ngm-24 (Fuller et al., 1983), Ngm-26 (Fortin et al., 1987), and Ngm-23 (Jacobs et al., 1987).

In contrast to the number of late nodulins characterized, until now only one early nodulin cDNA clone has been described in more detail; pGmENOD2, coding for Ngm-75 (Franssen et al., 1987; section 3.1). Ngm-75 is built up of repeating pentapeptides each containing two prolines and it is most likely a (hydroxy)proline-rich cell wall protein (Franssen et al., 1987; section 3.1). The ENOD2 gene is highly conserved among legumes since it has also been identified in pea (Govers et al., 1986), vetch (Moerman et al., 1987), bean (Padilla et al., 1988), alfalfa (Dickstein et al., 1988), sesbania (N. Chua, personal communication), clover and birdsfoot trefoil ( $F$. Govers, personal communication). ENOD2 gene expression could be detected in nodules lacking infection threads and intracellular bacteria on alfalfa (Dickstein et al., 1988) and soybean (Franssen et al., 1987), indicating that the ENOD2 gene product is involved in nodule morphogenesis. 
We started to characterize more early nodulin CDNA clones representing genes that are expressed in different steps of the soybean-Bradyrhizobium japonicum interaction. In this paper we report on the characterization of two of these soybean early nodulin CDNA clones: pGmENOD13 and pGmENOD55. Both the ENOD13 and ENOD55 early nodulins appear to be (hydroxy)proline-rich proteins. The ENOD13 early nodulin is correlated with nodule morphogenesis, while the ENOD55 gene is first expressed after release of the bacteria from the infection thread.

\section{Results}

\section{Isolation of pGmENOD13 and pGmENOD55}

Previously we have shown that early nodulin genes have reached their maximum level of expression in nodules on 10-day-old soybean plants (Franssen et al., 1987; Gloudemans et al., 1987). Hence, for isolation of early nodulin cDNA clones, we constructed a cDNA library from polyA $\left({ }^{+}\right)$RNA isolated from nodules on 10-day-old soybean plants (see material and methods).

This 10-day nodule cDNA library and the previously constructed 21-day nodule cDNA library (Franssen et al., 1987) were differentially screened with [ $\left.{ }^{32} \mathrm{P}\right]$-labeled CDNA made from RNA of nodules from 10-day-old plants and with root RNA. In total we isolated 10 nodule specific cDNA clones that might represent different early nodulin genes. One of these clones is pGmENOD2 (Franssen et al., 1987). Here we will describe two early nodulin CDNA clones: pGmENOD13, which cross-hybridizes with pGmENOD2 (data not shown), and pGmENOD55.

\section{Characterization of pGmENOD13 and pGmENOD55}

On DNA transfer blots (Southern, 1975) containing Hindlll digested soybean genomic DNA and Bradyrhizobium japonicum DNA, pGmENOD13 and pGmENOD55 hybridize exclusively with plant DNA. Clone PGmENOD13 hybridizes to 3 fragments of $3.0 \mathrm{~kb}, 20 \mathrm{~kb}$, and $30 \mathrm{~kb}$, suggesting that ENOD13 is a member of a small gene family. The cDNA clone pGmENOD55 only hybridizes to one plant DNA fragment, indicating that in the soybean genome there is only one ENOD55 gene present (data not shown).

To follow the expression pattern of the ENOD13 and ENOD55 genes the CDNA clones were hybridized on RNA transfer blots containing root RNA and RNA from nodules at different stages of development. Clone pGmENOD13 hybridizes to two messengers in nodule RNA of $1200 \mathrm{~b}$ and $1400 \mathrm{~b}$ in length, and not with root RNA 


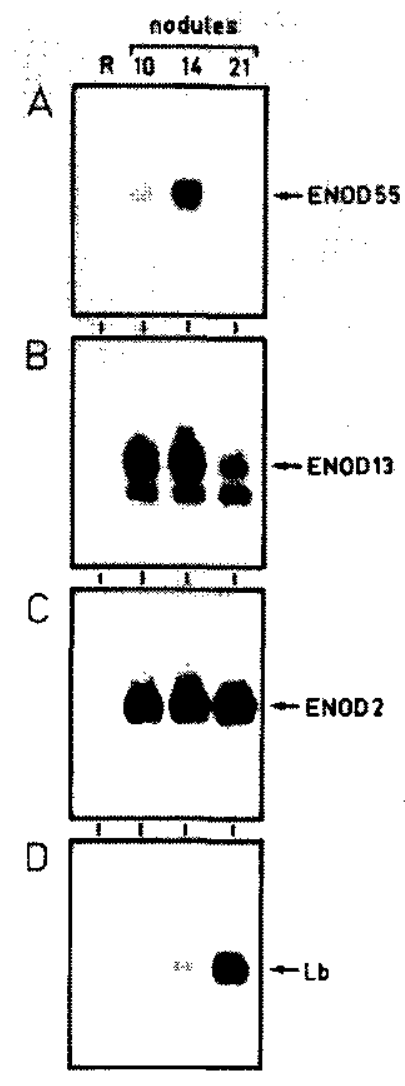

(figure 3-5B). An Rsal-Pstl fragment of the pGmENOD13 insert (see figure 3-6) was subcloned. This subclone only hybridizes to the $1400 \mathrm{~b}$ transcript showing that this mRNA, and not the $1200 \mathrm{~b}$ mRNA, is the ENOD13 transcript (data not shown). Based upon the homology between pGmENOD2 and pGmENOD13, and because the ENOD2 mRNA has a length of $1200 \mathrm{~b}$, it is very likely that the $1200 \mathrm{~b}$ transcript hybridizing with pGmENOD13 is the ENOD2 mRNA. The ENOD13 mRNA concentration is at a maximum in 10-day-old nodules, and the level decreases when the nodule becomes older (figure 3-5B). For comparison, identical RNA transfer blots were also hybridized with the previously described early nodulin CDNA clone PGmENOD2 and with pGmLb, encoding the late nodulin leghemoglobin (Lb) (Franssen et al., 1987). The Lb transcript is absent in 10-day-old nodules, and while its concentration is low in 14-day-old nodules, it is high in 21-day-old nodules. The ENOD2 mRNA is present at a constant level from day 10 to day 21 (figure 3-5C and 3-5D).
Figure 3-5: RNA transfer blots containing 15 microgram total RNA isolated from [R] 5-day-old uninoculated roots, and nodules harvested 10 . 14 , and 21 days after sowing and inoculation with Bradyrhizobium japonicum USDA1 10. The blots were hybridized to [ $\left.{ }^{32} \mathrm{P}\right]$-labeled [A] pGmENOD55, [B] pGmENOD13, [C] pGmENOD2, and [D] pGmLb. 


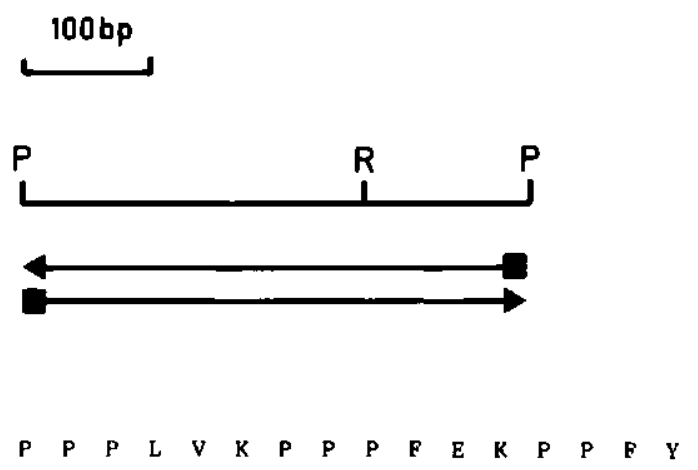

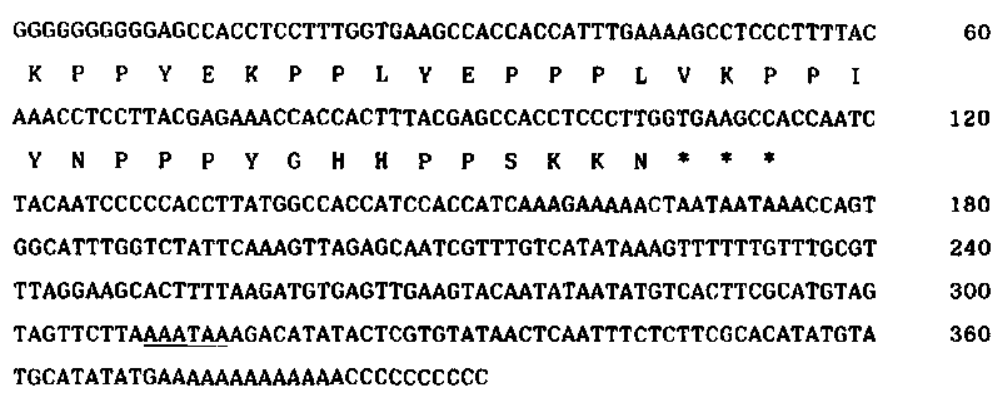

Figure 3-6: Partial restriction map, sequencing strategy, and nucleotide sequence of the Pstl insert of pGmENOD13. The complete insert was sequenced in both directions by the chemical degradation method of Maxam and Gilbert (1980), the arrows indicate the extent and direction of sequencing from the indicated sites; $P=P$ sti $R=R$ sal. The derived amino acid sequence is shown in standard single-letter code above the nucleotide sequence. In the DNA sequence nucleotides are numbered on the right side. Termination codons are denoted by [ $\left.{ }^{\star}\right]$, and a potential poly(A) addition site is underlined.

Clone PGmENOD55 hybridizes to a messenger of $900 \mathrm{~b}$, which is detectable in 10-day-old nodules, so markedly before $\mathrm{Lb}$ gene expression can be observed, reaching a maximum level in 14-day-old nodules after which its level decreases (figure 3-5A).

\section{Nucleotide sequence of pGmENOD13 and pGmENOD55}

In order to find clues on possible functions for the ENOD13 and ENOD55 early nodulins, the nucleotide sequence of the inserts of pGmENOD13 and pGmENOD55 was determined. The insert of the pGmENOD13 clone contains 385 nucleotides, including a short 3' poly(A) tail. Since the mRNA of the ENOD13 gene is $1400 \mathrm{~b}$ in size, only the amino acid sequence of the carboxy-terminal end of the ENOD13 nodulin can be derived from this sequence. One open reading frame of $156 \mathrm{bp}$ is present within the cDNA clone (position 1-156, figure 3-6). The amino 


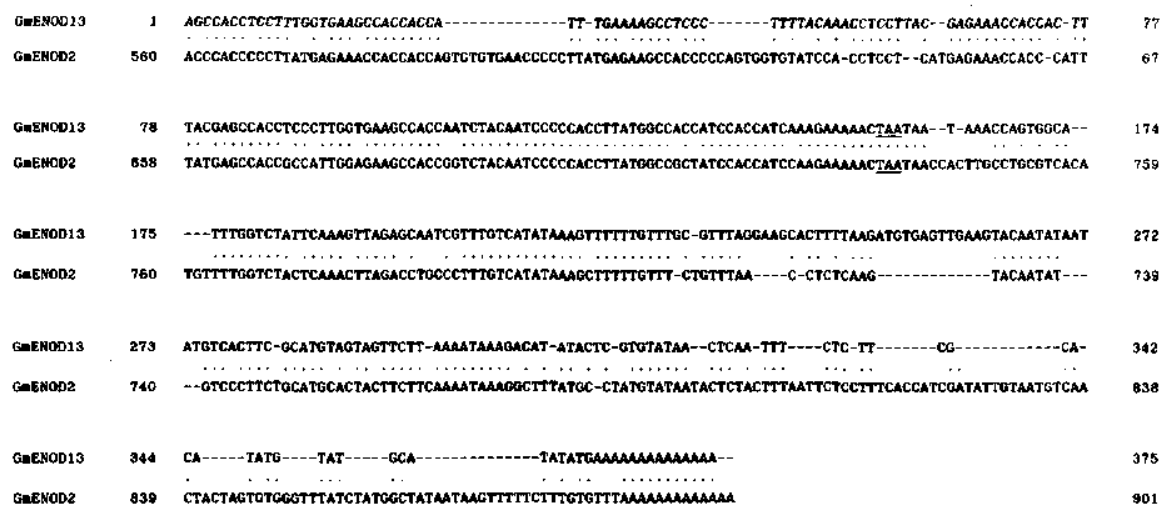

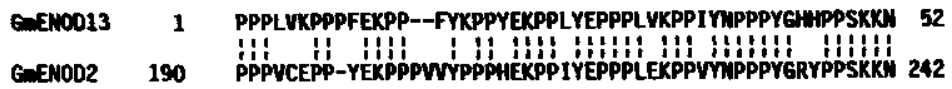

Figure 3-7: Top: alignment of the pGmENOD13 and pGmENOD2 sequences (sense strand). The align program of Staden (1980) was used. Matches are indicated by dots, gaps by dashes, termination codons are underlined. Botom: comparison of the carboxy-terminal amino acid sequences of the ENOD13 and ENOD2 proteins. Matches are indicated by dots, gaps by dashes.

acid sequence derived from this open reading frame contains 22 prolines and is highly homologous to the carboxy-terminal end of $\mathrm{Ngm-75}$, encoded by the GmENOD2 gene (figure 3-7B).

The insert of pGmENOD55 consists of $660 \mathrm{bp}$ including a short poly(A) tail. One large open reading frame from base 1-412 is found and from this open reading frame the partial amino acid sequence of the ENOD55 nodulin was derived (figure 3-8). It is shown that the ENOD55 early nodulin contains an internal domain of alternating proline and serine residues. This domain accounts for $25 \%$ of the amino acid sequence of the part of the ENOD55 polypeptide encoded by this open reading frame. In the amino terminal part three putative $\mathrm{N}$-linked glycosylation sites are present (figure 3-8). 
$100 \mathrm{bp}$

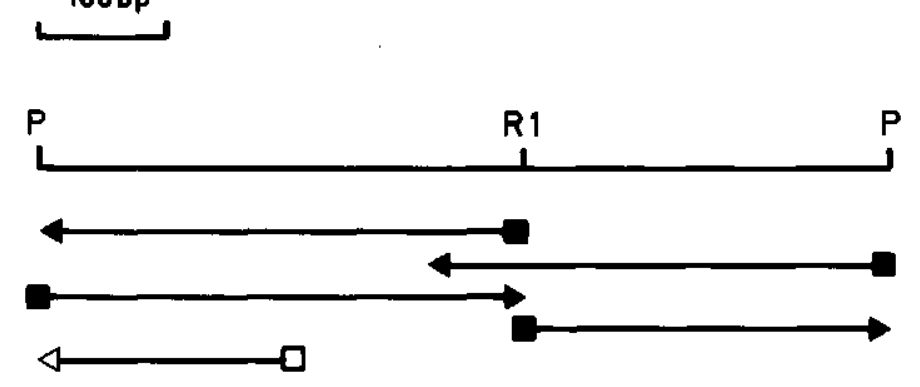

$\begin{array}{lllllllllllllllll}K & Y & D & E & R & T & E & S & V & H & E & V & \underline{N} & E & T & D\end{array}$

GGGGGGGGGTTAAATACGATGAGAGAACAGAGTCAGTGCACGAAGTGAATGAGACGGAT

60

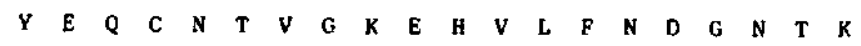

TATGAACAATGCAACACGGTGGgaAaGAACACGTTCTGTTCAACGATGGCAACACCAAG

$\begin{array}{lllllllllllllllllllll}V & M & L & T & K & S & G & F & R & H & F & I & S & G & N & 0 & S & H & C & Q\end{array}$

GTGATGCTTACCAAATCTGGATTCAGACACTTCATTAGTGGAAATCAGAGTCATTGCCAA

$\begin{array}{llllllllllllllllllll}M & G & L & K & L & M & V & V & V & M & S & N & N & T & K & K & K & L & I & H\end{array}$

ATGGGGTTAAAGCTAATGGTAGTTGTCATGTCAAACAACACCAAAAAGAAACTAATTCAT

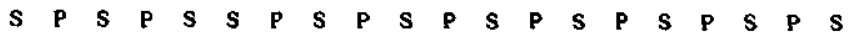

TCACCATCGCCATCATCACCTTCACCATCACCATCACCATCACCTTCACCTTCACCCTCA

$\begin{array}{llllllllllllllllllll}\mathbf{P} & \mathbf{S} & \mathbf{P} & \mathbf{S} & \mathbf{L} & \mathbf{S} & \mathbf{S} & \mathbf{P} & \mathbf{S} & \mathbf{P} & \mathbf{S} & \mathbf{P} & \mathbf{L} & \mathbf{P} & \mathbf{N} & \mathbf{N} & \mathbf{Q} & \mathbf{G} & \boldsymbol{V} & \mathbf{T}\end{array}$

CCTTCACCTTCATTATCATCGCCATCACCTTCACCACTTCCAAATAATCAAGGAGTTACT

$\begin{array}{lllllllllllllllllllll}R & S & S & G & A & E & \text { F } & \text { I } & G & \text { G } & \text { M } & \text { M } & \text { W } & \text { L } & G & \text { G } & \text { M } & \text { M } & \text { L } & \text { L }\end{array}$

CGTAGTTCAGGCGCTGAATTCATTGGAGTTATGATGTGGTTGGGGTGATGATGTTATTG

420

L *

CTTTAAATTAGAGAGTATTGTGTATTTACATGTTAATTTCTCCATACTAATCACTATATA

480

TGCAATATATATTTGTGTGGTTAGTTAATTAGGTCAAGCATGCATTTTCGCTTTCATTTT

540

TGTATTTTTTTAAGTCTGGAAGATTTTCTATTGATTGTGCAATTGTGCCCTTAAACTCCA $\quad 600$

ATGCCTACTCGTTGTAATTTTGAAATTGAATAAGCCATTTGGATTTTTTAAAAAAACCCC $\quad \mathbf{6 6 0}$

Figure 3-8: Partial restriction map, sequencing strategy, and nucleotide sequence of the Pstl insert of pGmENOD55. The arrows depict direction and extent of sequencing from the indicated site. Closed boxes refer to fragments sequenced by the chemical degradation method (Maxam and Gilbert, 1980). Open boxes refer to fragments sequenced by the dideoxy method (Sanger et al., 1977) using the synthetic oligomer 5'-CGATTACCATCAACAGTACA-3' as a primer. $\mathbf{R 1}=\mathbf{E C O R l ;} \mathrm{P}=$ Pst. In the DNA sequence nucleotides are numbered on the right side. The derived amino acid sequence is denoted in the standard single-letter code. Putative $\mathrm{N}$-glycosylation sites are underlined; a termination codon is denoted by [ $\left.{ }^{\star}\right]$, and a potential poly $(\mathrm{A})$ addition site is underlined in the nucleotide sequence. 

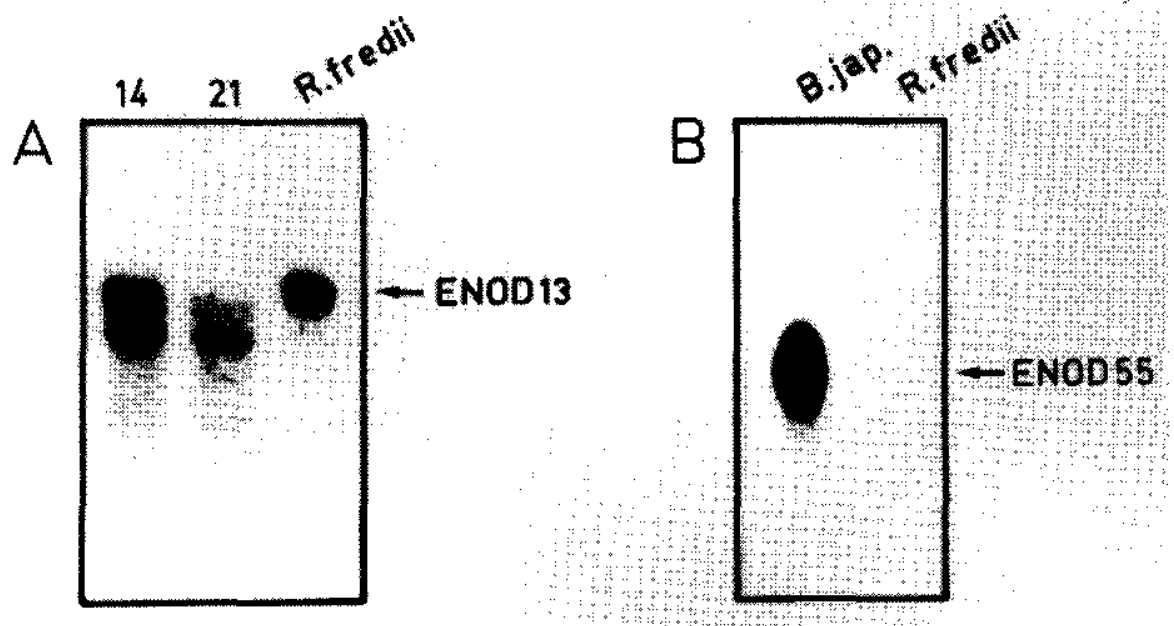

Figure 3-9: RNA transfer blots containing [A] 15 microgram total RNA from nodules on 14- and 21-day-old plants inoculated with Bradyrhizobium japonicum USDA110, and from nodule-like structures harvested from plants 28 days after inoculation with Rhizobium fredii USDA257; [B] 15 microgram total RNA from nodules on 14-day-old plants inoculated with Bradyrhizobium japonicum
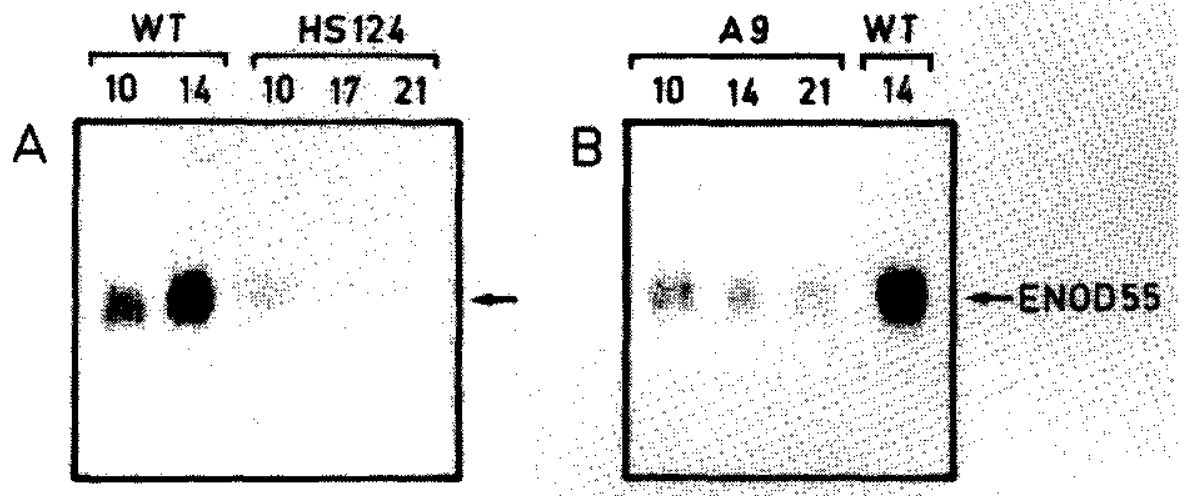

Figure 3-10: RNA transfer blots containing [A] 15 microgram total RNA from nodules on 10- and 14-day-old plants inoculated with Bradyrhizobium japonicum USDA110, and from nodules on 10-, 17-, and 21-day-old plants induced by Bradyrhizobium japonicum HS124; [B] 15 microgram total RNA from nodules on 10-, 14-, and 21-day-old plants induced by Bradyrhizobium japonicum mutant A9 and 14-day-old nodules induced by Bradyrhizobium japonicum USDA110. The blots were hybridized with [ ${ }^{32} \mathrm{P}$ ]-labeled pGmENOD55. 


\section{Expression of ENOD13 and ENOD55 genes in nodules blocked in development}

Rhizobium fredii USDA257 forms nodule-like structures on the roots of commercial cultivars of soybean. These structures are devoid of bacteria and infection threads. They originate from cortical cell divisions and swellings of cortical cells and the organization of these structures is aberrant from wild-type Bradyrhizobium japonicum induced nodules (Franssen et al., 1987). By examining the expression of ENOD13 and ENOD55 genes in these empty nodule-like structures it might be possible to distinguish between a role for the corresponding early nodulins in the infection process or in nodule morphogenesis.

By RNA transfer blot analysis it is shown that the ENOD13 gene, like the ENOD2 gene, is expressed in these empty nodule-like structures. However, no detectable levels of the ENOD55 transcript are found in these structures (figure 3-9). This observation indicates that ENOD13 gene expression does not require the presence of intracellular bacteria or infection threads and hence nodulin ENOD13 is involved in nodule morphogenesis. On the other hand, ENOD55 gene expression can not be addressed to a particular process yet. The ENOD55 gene product could be involved in the infection process or the generation of a normal nodule structure or the expression of the ENOD55 gene is first induced after release of the bacteria into the plant cells.

To discriminate between these possibilities the expression of the ENOD55 gene was studied in nodules induced by a nifA mutant of Bradyrhizobium japonicum, mutant A9 (Fischer et al., 1986), and Bradyrhizobium japonicum mutant HS124 (Noel et al., 1982), respectively. Both mutants induce nodules with an organization similar to nodules induced by wild-type bacteria, but the proliferation of released bacteria is blocked (Studer et al., 1987). In HS124 induced nodules the number of infection threads is comparable to or slightly higher as in wild-type Bradyrhizobium japonicum nodules ( $T$. Gloudemans, unpublished results). By RNA transfer blot analysis it is shown that the ENOD55 gene expression remains at a low level during development of nodules induced by Bradyrhizobium japonicum mutant A9 and HS124 (figure 3-10).

\section{Discussion}

Two soybean early nodulin cDNA clones were analyzed and compared with the previously described early nodulin clone pGmENOD2 (Franssen et al., 1987). Both the ENOD13 and ENOD55 polypeptide are rich in proline. In the ENOD55 nodulin the prolines are confined to an internal domain of 32 amino acids in which proline alternates with serine. This domain is slightly hydrophilic and is flanked by 

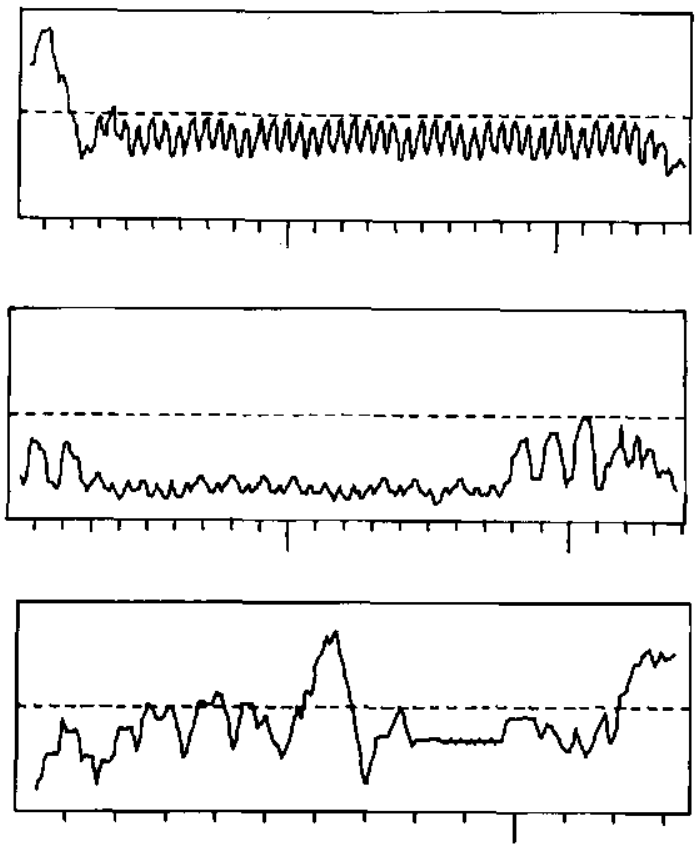

Figure 3-11: Hydropathic plots of deduced amino acid sequences of [top] soybean SbPRP1 (Hong et al., 1987), [middle] partial amino acid sequences of soybean early nodulin Ngm-75 (Franssen et al., 1987), and [bottom] ENOD55. Plots were constructed by the method of Kyte and Doolittle (1982). Hydrophobic regions are plotted above the 0-hydrophilicity line and the hydrophilic regions are below this line.

hydrophobic regions of 25 amino acids (figure 3-11). The hydrophobic stretches can act as membrane anchors and because the amount of amino acids in these stretches is enough to span a membrane they can also act as membrane spanning regions (Kuhn and Leigh, 1985).

The insert of pGmENOD13 encodes 51 amino acids of the carboxy-terminal end of the ENOD13 nodulin. This part of the ENOD13 nodulin contains 22 prolines present in doublets or triplets each interchanged by units of three amino acids in which tyrosine and glutamine are predominant. This makes the carboxy-terminal end of the ENOD13 nodulin homologous to the carboxy-terminal end of Ngm-75, encoded by the ENOD2 gene, and therefore the ENOD13 and ENOD2 genes might be members of the same gene family.

Recently, two soybean cDNA clones have been isolated encoding proline-rich proteins. One clone hybridizes to three different mRNAs and the corresponding genes were shown to be differentially expressed during soybean hypocotyl growth (Hong et al., 1987). The protein SbPRP1, encoded by one of these genes is mainly built up of repeating Pro-Pro-Val-Tyr-Lys units. The other CDNA clone, 1A10, represents a gene expressed in the axis of germinating soybean seedlings (Averyhart-Fullard et al., 1988) and the encoded polypeptide was shown to be built 
up of Pro-Pro-Val-Tyr-Lys units. This protein was proven to be a cell wall protein from which half of the prolines were hydroxylated. Since SbPRP1 is homologous to the 1A10 encoded polypeptide, it is likely that SbPRP1 is also a hydroxylated cell wall protein. Both proteins have a similar structure as the extensins (Chen and Varner, 1985a), which is the best studied hydroxyproline-rich glycoprotein (HRGP). The expression of the genes encoding extensins are developmentally regulated or are induced upon wounding or pathogenic interaction (Cassab and Varner, 1988). So several genes encoding (hydroxy)proline-rich proteins exist in plants and these genes are developmentally regulated.

The amino acid sequence of the ENOD2 protein shows a high degree of homology to the 1A10 polypeptide. In addition the sequence of the ENOD2 gene has revealed that the encoded ENOD2 polypeptide contains a signal peptide $(H . J$. Franssen, in preparation). Based on these observations we hypothesize that ENOD2 also is a cell wall protein and that the prolines will (in part) be hydroxylated. Since at least the carboxy-terminal part of the ENOD13 nodulin is homologous to the ENOD2 nodulin, it is likely that ENOD13 also is a (hydroxy)proline-rich cell wall protein. Hence we speculate that, like other plant organs, also the nodule contains a set of specific hydroxyproline-rich proteins in its cell walls. Whether the ENOD55 nodulin also represents a cell wall protein is not clear, since the amino acid sequence of this early nodulin is different from any other described (hydroxy)proline-rich protein (as was determined by the method of Lipman and Pearson (1985)). Also the hydropathy plot of this early nodulin differs from that of the other (hydroxy)proline-rich proteins, suggesting that the structure of ENOD55 is different (figure 3-11).

The occurrence of a set of plant genes that encode different (hydroxy)proline-rich cell wall proteins which are involved in developmental programs in the plant raises the question why a plant needs this variety of cell wall proteins. Do these proteins have specific functions in the cell walls of different tissues and if so, what is the correlation between function and the amino acid composition of the (hydroxy)proline-rich proteins ?

The group of (hydroxy)proline-rich proteins that are built up of repeating units, i.e. extensin (Chen and Varner, 1985a), SbPRP1 (Hong et al., 1987), 1A10 (Averyhart-Fullard et al., 1988), and the ENOD2 (Franssen et al., 1987) and ENOD13 (this work) early nodulins are rich in proline as well as tyrosine. For extensin it has been shown that intramolecular isodityrosine cross-linkages are formed (Cassab and Varner, 1988). Extensive intra- and intermolecular cross-linking results in the insolubilization of extensin in the cell wall and the insoluble extensin polymers are thought to harden the cell wall. The extent of isodityrosine cross-linking decreases markedly when the $\mathrm{pH}$ is reduced from 7 to 
4, showing that formation of these linkages is $\mathrm{pH}$-dependent. Cooper and Varner (1983) have suggested two mechanisms by which cross-linking could be regulated; (i) The pH of the cell wall might control the level of activity of the enzyme that catalyzes cross-linking, or (ii) at a certain pH the extent of cross-linking is determined by the ratio of acidic and basic amino acids within the (hydroxy)proline-rich protein. Since the second possibility involves the amino acid composition of the (hydroxy)proline-rich cell wall proteins, a comparison of the amino acid composition could indicate the extent of cross-linking of cell wall proteins under particular physiological conditions. Extensin, SbPRP1, 1A10, ENOD2, and ENOD13 are all rich in the basic amino acids histidine and lysine (up to $20 \%$ ). However, only the proline-rich early nodulins contain also a high level of the acidic amino acid glutamic acid. Thus, these (hydroxy)proline-rich proteins have different ratios of acidic and basic amino acids and hence the extent of isodityrosine cross-linking might vary between the different proteins. The ratio of acidic and basic amino acid residues present in the proline-rich proteins also determines the charge of the polypeptide. Depending on this charge these polypeptides will interact with other structural components of the cell wall and this will, of course, lead to different cell wall properties.

The ENOD13 and ENOD2 gene are expressed in empty nodule-like structures formed by Rhizobium fredii USDA257, while the ENOD55 gene is not. This shows that both the ENOD2 and ENOD13 nodulins are most likely involved in a certain step in root nodule morphogenesis. Also the amino acid sequence of these early nodulins shows a high degree of homology. Despite this similarity the ENOD13 and ENOD2 gene seem to be regulated in a slightly different way because during nodule development the ENOD13 mRNA decreases in concentration after day 14 while in the same experiment the ENOD2 mRNA concentration remains at a constant level (see figure 3-5). Furthermore, in nodule-like structures induced by Rhizobium fredii USDA257 the ENOD13 gene transcript is present at wild-type levels whereas the $1200 \mathrm{~b}$ mRNA, that also hybridizes with pGmENOD13 and most likely is the ENOD2 mRNA, is present at lower levels than in wild-type nodules (see figure 3-9).

The absence of ENOD55 mRNA in the empty nodule-like structures shows that this early nodulin is not required for formation of these structures. Since infection threads and intracellular bacteria are absent in these structures, we assumed that this early nodulin has a role in infection thread formation or that the corresponding gene becomes first expressed when cells become invaded by bradyrhizobia. However, the ENOD55 gene is expressed only at a low level in nodules induced by nifA mutant $A 9$ and mutant HS124, respectively, while the ENOD2 gene is expressed at wild type level (Studer et al., 1987; Gloudemans et al., 1987). Since the latter mutant forms nodules with a similar or slightly higher number of infection 
threads than wild-type bacteria (T. Gloudemans, unpublished results) it is not very likely that ENOD55 is involved in infection thread formation and it is more likely that the ENOD55 gene is first expressed when the bacteria are released from the infection thread. In nodules induced by mutant A9 and HS124 the bacteria hardly proliferate after release from the infection thread, and therefore the level of ENOD55 gene expression appears to be correlated to the level of proliferation of the bacteria.

So the two early nodulin sequences pGmENOD13 and pGmENOD55 described here and the early nodulin cDNA clone pGmENOD2 (Franssen et al., 1987) all appear to encode proline-rich proteins, albeit involved in different steps of the plant-bacterium interaction.

\section{Material and methods}

Growth conditions for plants and bacteria - Soybean plants (Glycine max (L) Merr. cv. Williams) were cultured at $28 \mathrm{C}$ as described by Gloudemans et al. (1987). Soybean seeds were inoculated at the day of sowing (day 0) with Bradyrhizobium japonicum USDA110, Bradyrhizobium japonicum nifA mutant strain A9 (Fischer et al., 1986), Bradyrhizobium japonicum mutant strain HS124 (Noel et al., 1982) or Rhizobium fredii USDA257 (Franssen et al., 1987). The bacteria were cultured as described by Bhuvaneswari et al. (1980).

RNA isolation - Nodules were excised from the roots, frozen in liquid nitrogen, and stored at -70C until use. Total RNA was isolated as described by Govers et al. (1985), and polyA $\left(^{+}\right.$) RNA was obtained after oligo dT cellulose chromatography according to Maniatis et al. (1982). Root RNA was isolated from 5-day-old roots.

Construction and differential screening of the cDNA library - A cDNA library was constructed in pBR322 from polyA( ${ }^{+}$) RNA isolated from nodules of 10 -day-old plants, as described by Franssen et al. (1987). This library contained 1500 clones. Probes for differential screening were prepared from polyA ${ }^{+}$) RNA from 5-day-old root segments and from root nodules on 10-day-old plants, using 10 microCi alpha[ ${ }^{32} \mathrm{P}$ ]-dATP (specific activity $3200 \mathrm{Ci} / \mathrm{mmol} ; 1 \mathrm{Ci}=37 \mathrm{GBq}$, New England Nuclear) as radioactive tracer. Individual transformants were subcultured and plasmid DNA was isolated by the alkaline lysis method (Birnboim, 1983).

RNA transfer blot analysis - Total soybean root and nodule RNA was denatured in DMSO/glyoxal and subsequently electrophoresed on $1 \%$ agarose gels (Maniatis et al., 1982). The RNA was transferred to GeneScreen (New England Nuclear) filters and cross-linked to the filters by 1 minute illumination with UV light of $254 \mathrm{~nm}$ (Church and Gilbert, 1984). Hybridizations and washing steps were performed according to the GeneScreen manual. 
DNA sequencing - The inserts of pGmENOD13 and pGmENOD55 were subcloned into pUC vectors using standard techniques (Maniatis et al., 1982). The nucleotide sequences were determined using the chemical degradation method of Maxam and Gilbert (1980) and the dideoxy method of Sanger et al. (1977). The sequence data were analyzed with programs written by Staden (1984), on a microVAXNMS (Digital Equipment Corporation) computer. Hydropathy plots were constructed according to Kyte and Doolittle (1982); homology searches were performed using the method described by Lipman and Pearson (1985). 


\section{CHAPTER IV}

\section{Bacteria Involved in Regulation}

\section{of Late Nodulin Gene Expression}

[4.1] Daniel Studer, Ton Gloudemans, Henk J. Franssen, Hans-Martin Fischer, Ton Bisseling, and Hauke Hennecke. European Journal of Cell Biology 45, 177-184 (1987)

[4.2] Thomas M. Ramseier, Brigitte Kaluza, Daniel Studer, Ton Gloudemans, Ton Bisseling, Peter M. Jordan, Russel M. Jones, Mohammed Zuber, and Hauke Hennecke. Submitted to Archives of Microbiology. 


\title{
4.1 Involvement of the bacterial nitrogen fixation regulatory gene (nifA) in control of nodule-specific host-plant gene expression
}

\begin{abstract}
Nodulation of soybean roots by a Bradyrhizobium japonicum strain (A9) having a mutated nitrogen fixation regulatory gene (nifA) resulted in the formation of highly abnormal nodules. As shown by electron microscopy analysis the infected nodule cells were completely disintegrated. This unusual plant response was specifically seen with the nifA mutant and not with other non-nitrogen fixing mutants. At the molecular level, these nodules were shown to be unaffected in the synthesis of a number of nodulin proteins or mRNAs (glutamine synthetase, uricase, nodulin-75, $-20,-23$, and -42). By contrast leghemoglobin protein and mRNA were present only in trace amounts. It is concluded that the Bradyrhizobium japonicum nifA gene controls the formation of one or several bacterial signals which are then transmitted to, and required in, the soybean host plant (i) to selectively enhance leghemoglobin synthesis, and (ii) to protect the infected nodules against defense reactions.
\end{abstract}

\section{Introduction}

Formation of the nitrogen-fixing root nodule symbiosis by bacteria of the genera Rhizobium and Bradyrhizobium requires a series of interactions between the microsymbiont and the legume host plant. Morphological manifestations of these interactions are root hair curling, infection thread formation and ramification, and development of nodule tissue in which the bacteria occupy about $80 \%$ of the cells. At the molecular level, only a few events in the communication between bacteria and plants are beginning to be understood.

Flavonoid compounds present in alfalfa, clover, and pea root exudates have been identified as inducers of the expression of nodulation (nod) genes in Rhizobium meliloti, Rhizobium leguminosarum biovar trifolii, and Rhizobium leguminosarum (Firmin et al., 1986; Peters et al., 1986; Redmond et al., 1986; Zaat et al., 1987a). Although the exact biochemical functions of the nod gene products have not been elucidated, they are known to induce the earliest detectible host responses such as root hair curling, cortical cell divisions, and infection thread formation (Jacobs et al., 1985; Kondorosi and Kondorosi, 1986). At later stages of development, i.e. differentiation of nodule cells, the response of the plant is accompanied by the 
expression of a specific set of nodulin genes (Van Kammen, 1984). The functions of only a few nodulins in different legumes have been determined: the leghemoglobins (Appleby, 1984), a nodule-specific glutamine synthetase (Lara et al., 1983), uricase-ll (nodulin-35) (Nguyen et al., 1985), and sucrose synthetase (nodulin-100) (Thümmler and Verma, 1986). In pea (Pisum sativum) it has recently been shown that at least two nodulin genes are transcribed in the very early stages of nodule formation, and the synthesis of one of the encoded nodulins, PSENOD2, was directly dependent on the expression of a group of Rhizobium leguminosarum nod genes (nodDABC) (Govers et al., 1986). Little is known about the signals that control, directly or indirectly, the expression of the so called late nodulin genes which encode proteins with proper nodule function (oxygen transport, peribacteroid membrane synthesis, $\mathrm{NH}_{4}{ }^{+}$assimilation etc. (Verma and Nadler, 1984).

In nodules of soybean (Glycine max) up to 40 nodulin genes are differentially expressed in response to infection by Bradyrhizobium japonicum (Verma et al., 1986). The majority of these genes are late nodulin genes (Gloudemans et al., 1987). All of the nodulins are still synthesized at about wild type levels in nodules formed by Bradyrhizobium japonicum Fix mutants containing well characterized deletions or insertions in the nitrogenase genes (Marcker et al., 1984a; Sengupta-Gopalan et al., 1986; Gloudemans et al., 1987). Similarly, electron microscopic analyses have shown that Bradyrhizobium japonicum mutants with mutations in any of the nitrogen fixation genes nifD, nifK, nifE, nifN, nifS, nifB, nifH, fixA, fixB, and fix $C$ induced the formation of relatively normal nodules in which the bacteria differentiated into endosymbiotic bacteroids (Hahn and Hennecke, 1984; Hahn et al., 1984; Gubler and Hennecke, 1986; Lamb et al., 1986). These results have led to the conclusion that nodule and bacteroid development are programmed independent of concomitant nitrogen fixation. However, two Bradyrhizobium japonicum mutants that form ineffective nodules do not follow this generality. Mutant HS124 was shown to induce nodules with few infected cells (Noel et al., 1982) in which several late nodulin genes were expressed at drastically reduced levels (Sengupta-Gopalan et al., 1986; Gloudemans et al., 1987). Unfortunately, the genetic lesion in HS124 (which arose after UV-light mutagenesis) has not been characterized (Noel et al., 1982). The other mutant carries a well defined lesion in the nitrogen fixation regulatory gene, nifA (Fischer et al., 1986), and is the subject of this report. The Bradyrhizobium japonicum nifA mutant was shown to be defective not only in the activation of other nif and fix genes but also in the proper differentiation of soybean nodules: not later than 20 days after infection the nodules assumed an odd necrotic appearance (Fischer et al., 1986) which was reminiscent of a hypersensitive response to infection by non-compatible plant pathogens. In this work we present a more detailed account, by electron microscopic analysis, of the deleterious on the host plant in response 


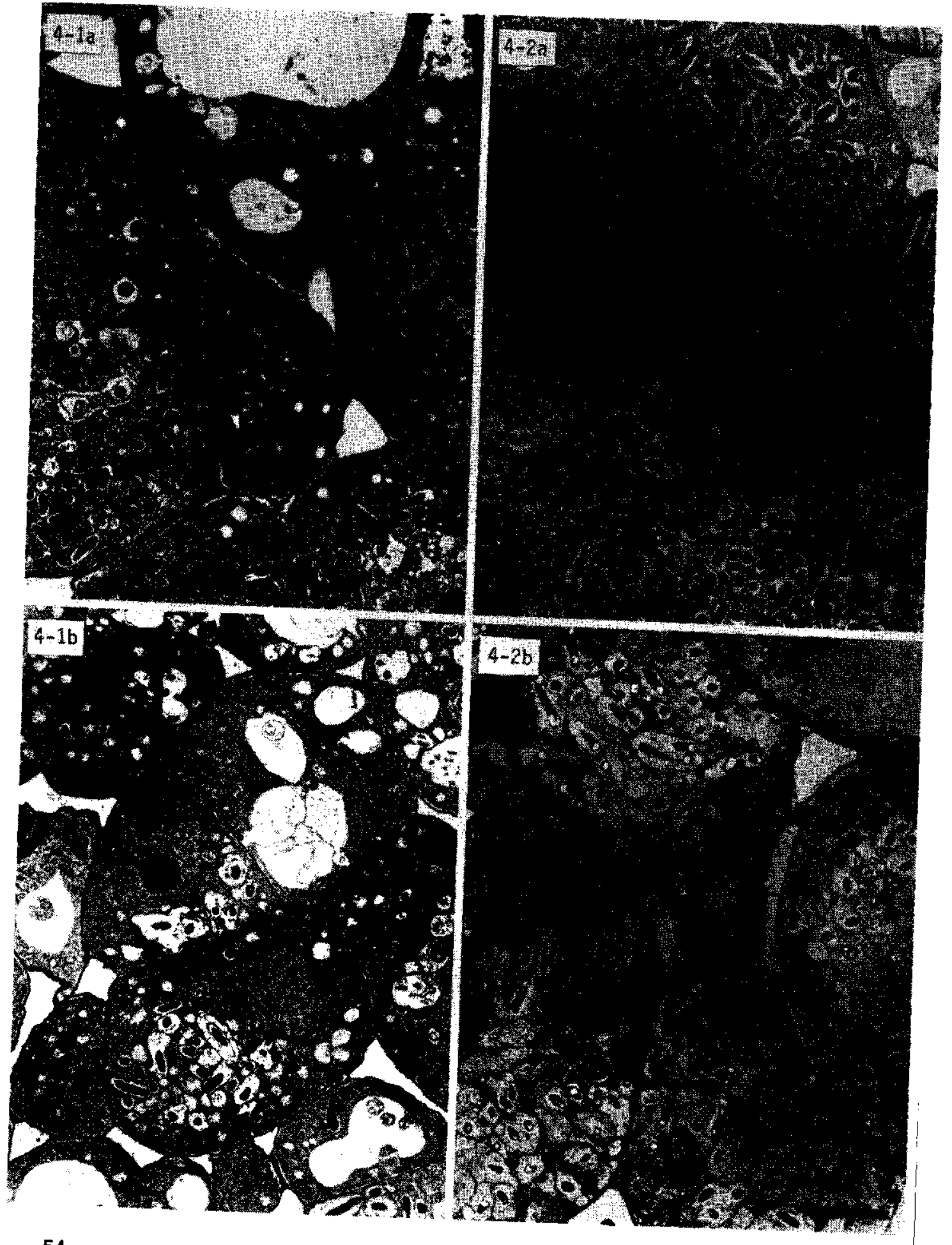

54 


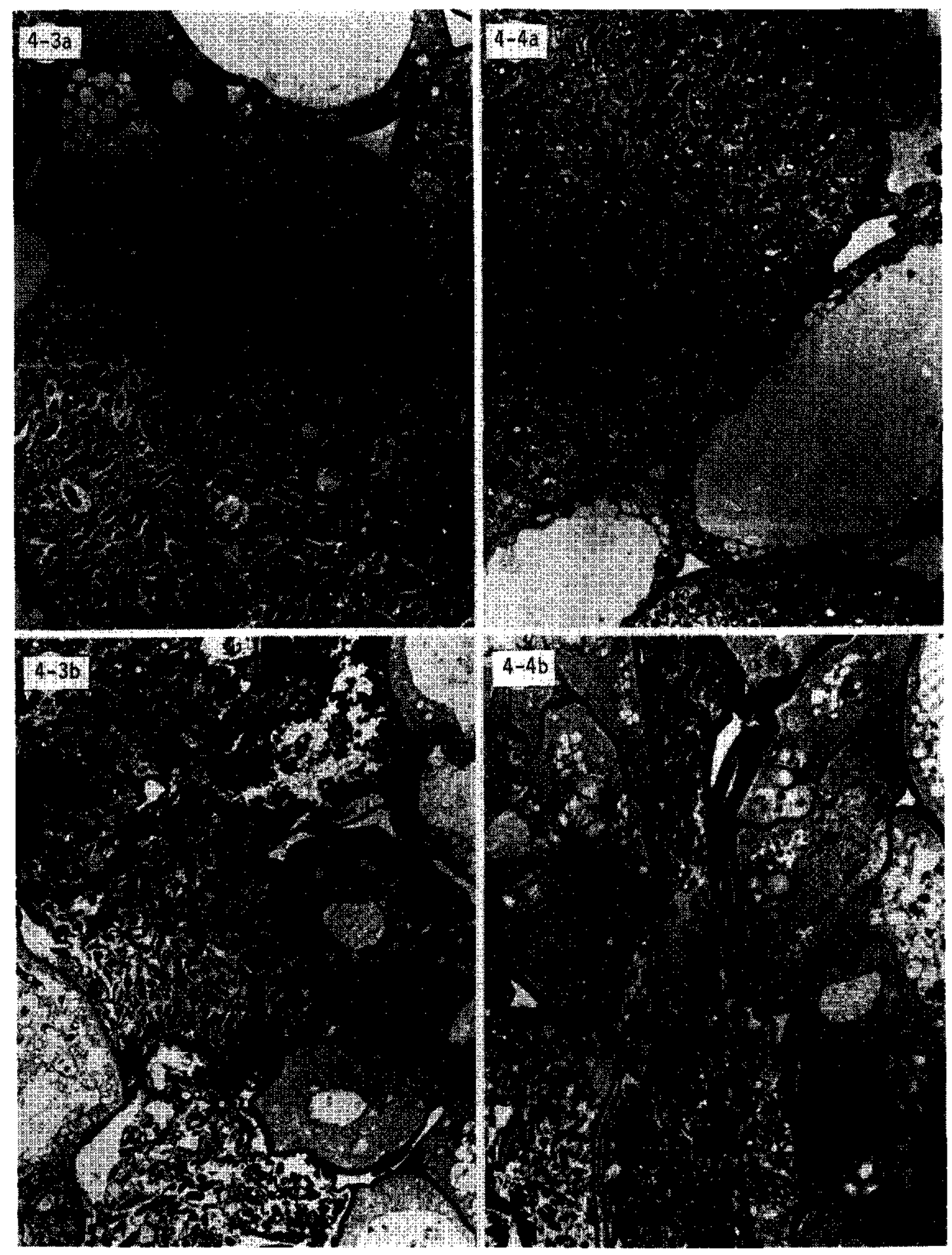


Figures 4-1 to 4-4: Electron micrographs of infected soybean root nodule cells. Samples were taken at days 9 (figure 4-1), 12 (figure 4-2), 16 (figure 4-3), and 20 (figure 4-4) after inoculation. The nodules were infected by the Bradyrhizobium japonicum wild type (series 'a') and by the nifA mutant strain A9 (series 'b'). Bars 5 micrometer (for all figures).

to infection by Bradyrhizobium japonicum nifA mutant. In parallel, the synthesis of a selected number of nodulin mRNAs or nodulin proteins was investigated. The results of this study show that the bacterial nifA mutant specifically and selectively affected the expression of the soybean leghemoglobin genes.

\section{Results}

\section{Dramatic disintegration of nodule cells infected by a Bradyrhizobium japonicum nifA mutant}

The development of endosymbiotic bacteroids and nodule tissue was inspected by electron microscopy. Nodules infected by the Bradyrhizobium japonicum nifA mutant (strain A9) were compared with nodules infected by the wild type (strain USDA110). Figures 4-1, 4-2, 4-3, and 4-4 show samples obtained at days 9,12 , 16 , and 20 after inoculation, respectively. At day 9 (about the time when the bacteria were released from the infection thread) there was hardly any difference between wild type (figure 4-1a) and A9-infected nodule cells (figure 4-1b). Shortly thereafter (day 12), however, a clear difference became obvious: whereas the wild type continued to proliferate (figure 4-2a), the A9 strain ceased to multiply into further bacteroids, and the peribacteroid membrane system exhibited the first symptoms of degradation such as the fusion of the membrane-surrounded compartments (figure 4-2b). Moreover, the A9-infected plant cells generally remained smaller than the wild type-infected cells, and later at days 16 and 20 , collapsed completely (figures $4-3 \mathrm{~b}$ and 4-4b). Many of the disintegrated cells assumed longitudinal shapes squeezed between uninfected cells (figure 4-4b). At this stage the peribacteroid membrane system was not detectable. (It is clear that these (reproducible) phenotypes may have been produced by the sample fixation procedure, but they present ample evidence that significant structural alterations in the nodule cells have taken place). Between days 12 and 16 the nodule did not uniformly degrade because it contained cells of the types shown in figures 4-2b and $3 \mathrm{~b}$ adjacent to each other (not shown). Whether or not the $\mathrm{A} 9$ bacteroids were also subject to equally severe degradation is not known. Although we have been able to reisolate viable bacteria from such nodules, a quantitative assessment of their recovery was not possible. Thus, it can not be excluded that the bacteria converted from endosymbionts to saprophytes. As figures 4-3b and 4-4b show, the nodule occupancy by strain $A 9$ also exerted some influence on the neighboring uninfected cells: these were less intensively vacuolated and their cell 


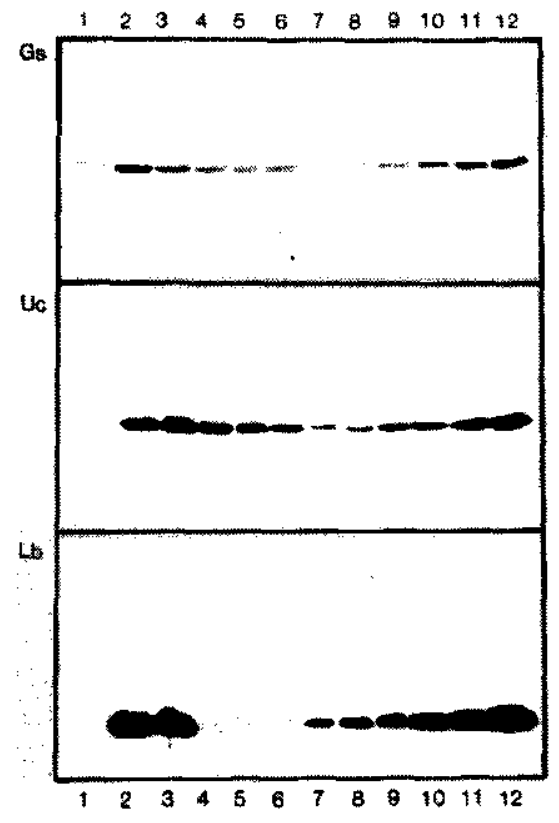

Figure 4-5: Western blot analysis of in vivo proteins from wild type nodules, mutant F4-6 induced-nodules, and mutant A9-induced nodules. Parts of three identical Western blots contain (from left to right) 32 microgram in vivo proteins isolated from 5-day-old uninfected roots (lane 1), 21-day-old nodules induced by Bradyrhizobium japonicum strain USDA110 (lane 2), 21-day-old nodules induced by mutant F4-6 (lane 3), and nodules induced by mutant $A 9,21$ days (lane 4), 16 days (lane 5), and 18 days (lane 6) after sowing and inoculation. Lanes 7-12 contain, from left to right, 1 microgram (lane 7), 2 microgram (lane 8), 4 microgram (lane 9), 8 microgram (lane 10), 16 microgram (lane 11), and 32 microgram (lane 12) in vivo proteins isolated from 21-day-old nodules induced by strain USDA110. Hence, lane 12 is identical to lane 2. [Gs] Western blot incubated with anti-glutamine synthetase serum. [Uc] Western blot incubated with anti-uricase serum. [Lb] Western blot incubated with anti-leghemoglobin serum. All lanes were given the same exposure to the film.

walls became less rigid (compare figures 4-3b/4-4b with 4-3a/4-4a). Parallel to the studies described before we have investigated the capability of wild type and A9-infected nodules to synthesize nodulin proteins and nodulin mRNAs.

\section{In vivo protein analysis}

In these experiments we chose to quantify the amount of product synthesized by a selected number of nodulin genes: (i) uricase, which is specifically synthesized in the uninfected cells (Nguyen et al., 1985; Van den Bosch and Newcomb, 1986), (ii) leghemoglobin (Lb), a representative nodulin in the infected cells (Robertson et al., 1984), and (iii) glutamine synthetase (Gs) which occurs in both infected and uninfected nodule cells. Whether a nodule specific Gs such as in Phaseolus vulgaris beans (Lara et al., 1983) is in fact synthesized in soybeans has recently been questioned (Hirel et al., 1987). The proteins were analyzed in uninfected roots (control), in nodules infected by the wild type (control), by the Fix mutant F4-6 (nifDKEN) which had previously lybeen shown to elicit normal nodule development (Hahn et al., 1984), and by the nifA mutant A9. From A9-induced nodules samples were taken at days 16, 18, and 21 after inoculation. Three identical Western blots were made from soluble protein preparations of these plant 
tissues, and the blots were incubated with antisera specific to Gs, uricase, and $\mathrm{Lb}$ (figure 4-5). To quantify the amounts of these proteins in the mutant-infected nodules, a dilution series of the protein preparations from wild type-infected nodules was included (figure 4-5, lanes 7-12). The following results were obtained:

Glutamine synthetase (figure 4-5, panel Gs) was present in two forms. Two bands of slightly different molecular mass were seen of which the lighter form was present at enhanced levels in the nodules as compared to uninfected roots. In 21-day-old nodules infected by F4-6 there was a slightly reduced amount of Gs (lane 3) and in A9-infected nodules a ca. 50\% reduced Gs level (lane 4-6) compared to wild type-infected nodules (lane 2).

Uricase (figure 4-5, panel UC) was not synthesized in uninfected roots (lane 1) but was strongly derepressed in the nodules. In nodules of all three ages formed by the A9 mutant, more than $50 \%$ of wild type uricase level was seen (lane 4-6), while nodules formed by F4-6 contained uricase levels indistinguishable from the amount present in wild type-infected nodules (compare lane 3 with lane 2).

Leghemoglobin (figure 4-5, panel Lb) was not synthesized in uninfected roots (lane 1) but was equally strongly synthesized in nodules formed by the wild type (lane 2) and by mutant F4-6 (lane 3). In contrast, the amount of Lb in A9-infected nodules was drastically reduced. The intensity of the leghemoglobin band in all three A9 lanes (lane 4-6) was markedly lower than the $3 \%$ level of the dilution series of the wild type nodule proteins (lane 7).

\section{Messenger RNA analysis}

Nodulin mRNA synthesis was analyzed for two reasons: first to see whether the more than 33-fold reduction of $\mathrm{Lb}$ in A9-infected nodules (see previous paragraph) was caused by regulation at the transcriptional or translational level, and second, to extend the spectrum of analyzed nodulins beyond those that were amenable by the available antibodies. For this purpose a Northern blot (figure 4-6) containing total RNA from 5-day-old uninfected roots (control) and from ca. 21-day-old nodules formed by the wild type, or by the mutants $F 4-6$ and $A 9$ was hybridized with an Lb cDNA clone (Franssen et al., 1987). After autoradiography and washing off the radioactivity ('deprobing'), the same blot was again used two times in hybridizations with two other nodulin cDNA clones (pGmENOD2 and pGmNOD7). To quantify the amount of the respective mRNAs we included a dilution series of RNA isolated from wild type-infected nodules (lane 5-10 in figure 4-6). The following results were obtained: 


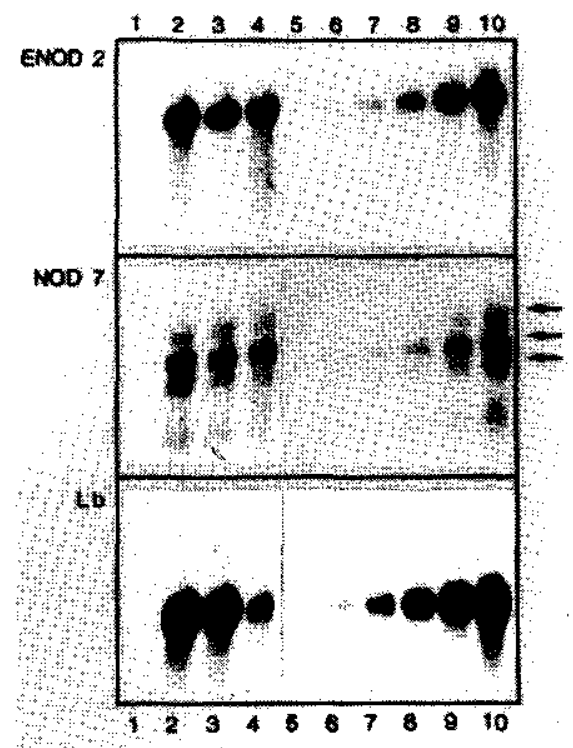

Figure 4-6: Northern blot analysis of total RNA from wild-type nodules, mutant F4-6-induced nodules, and mutant A9-induced nodules. Parts of one Northern blot are shown containing (from left to right) 10 microgram total RNA isolated from 5-day-old uninfected roots (lane 1), 21-day-old nodules induced by strain USDA110 (lane 2), 22-day-old nodules induced by mutant strain F4-6 (lane 3), and 20-day-old nodules induced by mutant A9 (lane 4). Lanes 5-10 contain (from left to right) 0.3 microgram (lane 5), 0.6 microgram (lane 6), 1.2 microgram (lane 7), 2.5 microgram (lane 8), 5 microgram (lane 9), and 10 microgram (lane 10) total RNA isolated from nodules induced by wild type strain USDA110. Hence, lane 10 is identical to lane 2. The size of the RNAs was determined by running lambda $\times$ Hindill markers in the same gel. [ENOD2] Northern blot hybridized with nick-translated insert of CDNA clone pGm-ENOD2. [NOD7] Northern blot hybridized with nick-translated insert of CDNA clone pGm-NOD7; the three mRNA species are indicated by arrows and correspond in size to 1500,1150 , and 1000 nucleotides length. [Lb] Northern blot hybridized with nick-translated insert of cDNA clone pGm-Lb. In [NOD7] a faint Lb mRNA band is seen due to a non-complete deprobing of the Northern blot (see text).

Leghemoglobin mRNA (figure 4-6, panel Lb) was present at similar levels in nodules formed by F4-6 (lane 3) and by the wild type (lane 2); however, a drastic reduction ( to $8 \%$ of wild type level) was seen in A9-infected nodules (lane 4).

GmENOD2 MRNA (figure 4-6, panel ENOD2) was present in similar amounts in nodules infected by the wild type and by the mutants, showing that the early nodulin genes are normally expressed (compare lanes 2-4).

GmNOD7 mRNAs (figure 4-6, panel NOD7) were also present in similar amounts in wild type and mutant-infected nodules. PGmENOD7 hybridizes with mRNAs transcribed from genes of a small gene family encoding PBM nodulins (cf. material and methods). 


\section{Discussion}

The most significant result of this work was the finding that the genetic defect in a single Bradyrhizobium japonicum gene (nifA) leads to a series of dramatic alterations in nodule development of the soybean host plant. This is in clear contrast to the behavior of a number of other Bradyrhizobium japonicum nif and fix mutants (Hahn and Hennecke, 1984; Hahn et al., 1984; Marcker et al., 1984a; Gubler and Hennecke, 1986; Lamb et al., 1986; Sengupta-Gopalan et al., 1986; Gloudemans et al., 1987) which have all been shown to induce normal root nodule and bacteroid development and normal nodulin synthesis; hence it is not the lack of nitrogen fixation per se which causes the effects seen in mutant A9-infected nodules. The Bradyrhizobium japonicum nifA gene is known to code for a positive regulatory protein that is required to activate other nif and fix genes under conditions of low oxygen tensions (Fischer et al., 1986; Fischer and Hennecke, 1987). From the results of this work it must now be concluded that the NifA protein is also involved in the activation of additional genes whose products are vital for further nodule development. It is conceivable that these products (enzymes?) are required for the synthesis of one or several signals that are recognized by the plant and elicit further steps in establishing a nodule and tolerating the invader. We have presented one case which shows that at least one of these NifA-controlled signals is mandatory for the functional expression of a plant gene family, namely the leghemoglobin (Lb) gene family. There are only traces of leghemoglobin mRNA and protein synthesized in nodules infected by the nifA mutant. This shows that it is the enhancement of Lb mRNA accumulation (90\%) rather than its basal level (\%) which is affected. The simplest model would be that the Bradyrhizobium japonicum nifA-controlled signal is a diffusible factor that functions to enhance transcription of the leghemoglobin genes or, alternatively, to stabilize Lb mRNA. In this context, a recent report is of particular interest (O/stergaard-Jensen et al., 1986) because it demonstrated that in a heterologous yeast system the translation of a soybean leghemoglobin mRNA ( $\left.\mathrm{LbC}_{3}\right)$ was dependent on the presence of heme. On the basis of this result heme could be a candidate for the unknown nifA-controlled signal produced in Bradyrhizobium japonicum. Interestingly, heme synthesis in Bradyrhizobium japonicum has been shown to be stimulated under low oxygen partial pressure (Avissar and Nadler, 1978), a condition favoring maximal activity of the NifA protein as transcriptional activator (Fischer and Hennecke, 1987). However, a direct link between the function of the nifA gene product and the expression of some genes involved in heme biosynthesis has yet to be demonstrated.

This work has also shown that nodule cells infected by mutant $A 9$ undergo a dramatic transition from an apparently normal development in the very early stages (up to day 9 after infection) to a completely aberrant morphology ending up in a severe disintegration of the cells. It is not known whether this response is due to 
the lack of the same signal that leads to reduced leghemoglobin formation, or whether this is due to the lack of additional signals controlled by nifA. In the first case the mutant bacteroids (and the nodule cells infected by them?) might suffer from severe anoxia, whereas in the latter case the postulated additional signals might be crucial for the wild type bacteroids to overcome soybean defense mechanisms.

The accumulation of a number of other nodule mRNAs and proteins, irrespective of their location in the infected or uninfected cells, have been shown to be unaffected in nodules formed by the nifA mutant: glutamine synthetase, uricase, GmENOD2 (= Ngm-75) (Franssen et al., 1987), and the GmNOD7 products. The cDNA clone pGmNOD7 contains the 3' end of the gene for nodulin-23 which is a member of a small gene family including nodulin-20 (Sandal et al., 1987), and nodulin-42 (Sengupta-Gopalan et al., 1986). pGmNOD7 hybridizes with mRNAs of 1000,1150 , and 1500 nucleotides in size. We conclude that the 1150 nucleotide RNA is the nodulin-23 mRNA since it is the most abundant mRNA and its size agrees with previously published results (Mauro et al., 1985; Sengupta-Gopalan et al., 1986; Sandal et al., 1987). The 1000 and 1500 nucleotide mRNAs are most likely the nodulin-20 and nodulin-42 mRNAs, respectively. Nodulin-23 has been shown to be a peribacteroid membrane-specific protein, and probably nodulins-20 and -42 are also (peribacteroid) membrane proteins (Jacobs et al., 1987; Sandal et al., 1987). Interestingly, the mRNA concentration for these nodulins is not affected by strain $A 9$, despite the visible degradation of the peribacteroid membrane system. The gene encoding nodulin-23 is expressed in the infected cells (Jacobs et al., 1987), like the genes encoding leghemoglobins. The high levels of nodulin-23 mRNA in A9-infected nodules, in contrast to Lb mRNA, is indicative of an otherwise normal differential gene expression program in the infected cells, i.e., the reduction of L.b mRNA is not the consequence of an unspecific reduction of all nodulin mRNAs in these cells. The unperturbed accumulation of the mRNA for the early nodulin Ngm-75 is consistent with our observation that the morphology of early nodules induced by $A 9$ is hardly distinguishable from wild type nodules.

It is very likely that the unusual host response to infection by a nifA mutant is unique to the Bradyrhizobium japonicum-soybean system, because similar responses using a Rhizobium meliloti nifA mutant (Hirsch and Smith, 1987) or a symbiotic plasmid-free Rhizobium leguminosarum strain carrying a cosmid (plJ1089) with just the nodulation genes (Downie et al., 1983) have not been observed on alfalfa and pea, respectively. It must be kept in mind, however, that the development of the so-called determinate soybean nodule is not directly comparable to the development of indeterminate nodules of temperate legumes. 


\section{Materlals and methods}

Organisms and plant growth - Seeds of soybean (Glycine max L. Merr. cv. Williams) were kindly provided by Jacques Seed company. Prescott, WI/USA. Soybean plants were inoculated with Bradyrhizobium japonicum and grown as described (Hahn and Hennecke, 1984; Gloudemans et al., 1987), and strain USDA110 (wild type) and Fix mutant strains F4-6 and A9 were used for nodulation (Hahn et al., 1984; Fischer et al., 1986). Strain F4-6 carries a large deletion of the entire nifD, $K, E$, and $\boldsymbol{N}$ genes coding for the nitrogenase MoFe protein and for proteins involved in MoFe cofactor synthesis (Hahn et al., 1984; Ebeling et al., 1987). Strain A9 carries a 837 base-pair deletion internal to the nifA gene (Fischer et al., 1986).

Electron microscopy - Soybean nodules were sectioned $(0.5 \mathrm{~mm})$ with a razor blade and then fixed in $3 \%$ glutaraldehyde/sodium cacodylate buffer $(0.1 \mathrm{M}, \mathrm{pH} 7.2)$ at $4 \mathrm{C}$ for $16 \mathrm{~h}$. The sections were washed with pure sodium cacodylate buffer, subsequently postfixed for $4 \mathrm{~h}$ in a $1 \% \mathrm{OsO}_{4} / \mathrm{sodium}$ cacodylate buffer solution, followed by washing twice with double-distilled water and overnight block staining in aqueous $0.5 \%$ uranyl acetate solution at $4 \mathrm{C}$. The samples were washed twice with double-distilled water prior to dehydration with 2,2-dimethoxypropane (Muller and Jack, 1975). Then they were washed twice in acetone, and immersed in 35\% Epon-Araldite/acetone solution at $4 \mathrm{C}$ for $12 \mathrm{~h}$. After infiltration at $4 \mathrm{C}$ for $12 \mathrm{~h}$ in $65 \%$ Epon-Araldite/acetone, the samples were finally immersed overnight $(12 \mathrm{~h})$ in $100 \%$ Epon-Araldite at room temperature. The resin was cured for $36 \mathrm{~h}$ at $60 \mathrm{C}$ (Luft, 1961) prior to thin-sectioning using an Ultracut-Reichert microtome. Thin sections were poststained with uranyl acetate and lead citrate (Reynolds, 1963). The sections were examined under a Hitachi $\mathrm{H}-600$ electron microscope.

Protein isolation and Western blot analysis - Roots from uninfected plants or nodules were harvested in a mortar kept at $0 \mathrm{C}$ and filled with protein isolation buffer $(0.5 \mathrm{M}$ sucrose, $50 \mathrm{mM}$ tris(hydroxymethyl)aminomethane- $\mathrm{HCl}, \mathrm{pH} 7.5,10 \mathrm{mM} \mathrm{MgSO}_{4}, 0.2 \mathrm{mM}$ phenylmethylsulfonyl fluoride). After grinding, the crude material was filtered through two layers of Miracloth (Calbiochem, Amsterdam/The Netherlands) and the filtrate was centrifuged in a SS34 rotor (Sorvall, Newton, CT/USA) at $10,000 \mathrm{rpm}$ for $30 \mathrm{~min}(4 \mathrm{C})$. The supernatant was subsequently centrifuged in a Ti75 rotor (Beckmann, Mijdrecht/The Netherlands) at $35,000 \mathrm{rpm}$ for $30 \mathrm{~min}(4 \mathrm{C})$. The protein concentrations of these soluble (supernatant) protein preparations was determined as described by Bradford (1976). Extracts from roots had a protein concentration of $5 \mathrm{mg} / \mathrm{g}$ fresh weight, and extracts from wild type and A9-infected nodules had protein concentrations of 10 and $8-10 \mathrm{mg} / \mathrm{g}$ fresh weight, respectively.

Soluble proteins were separated on 12.5\% SDS-polyacrylarnide gels (Laemmli, 1970) and subsequently electroblotted onto nitrocellulose (Schleicher and Schuell, Dassel/FRG, BA85) as described (Zabel et al., 1982). The Western blots were incubated with anti-leghemoglobin serum (Glycine max), a gift from C. Sengupta-Gopalan (Sengupta-Gopalan and Pitas, 1986), anti-uricase serum (Ghycine max), a gift from B. Jochimsen (Larsen and Jochimsen, 1986), and anti-glutamine synthetase serum (Phaseolus vulgaris), a gift from J. Cullimore (Cullimore and Miffin, 1984). The bean glutamine synthetase antiserum detects in soybean two forms of glutamine synthetase (Sengupta-Gopalan and Pitas, 1986). Immune complexes on the Western blot were visualized by binding of $\left[{ }^{125} \mid\right]$ protein A from Staphylococcus aureus to the antibodies and subsequent attoradiography to Kodak XAR-5 film (Zabel et al., 1982).

RNA isolation and Northern blot analysis - Total RNA from roots $(0.4 \mathrm{mg} / \mathrm{g}$ fresh weight) or nodules $(0.8-1 \mathrm{mg} / \mathrm{g}$ fresh weight) was isolated (Govers ot al., 1985), denatured in dimethylsulfoxide/glyoxal, separated on $1 \%$ agarose gels in $10 \mathrm{mM}$ sodium phosphate buffer, $\mathrm{pH}$ 
7.0, and blotted onto GeneScreen paper (New England Nuclear, Doorn/The Netherlands) with 25 $\mathrm{mM}$ sodium phosphate, pH 7.0, as blotting buffer (Maniatis et al., 1982). The RNA was cross-linked to the GeneScreen filter by 1 min illumination with UV light (Church and Gilbert, 1984).

The blot was hybridized to three different cDNA clones. (i) pGmLb is a leghemoglobin cDNA clone (Franssen et al., 1987). (ii) pGmENOD2 (Franssen et al., 1987) is an early nodulin cDNA clone coding for nodulin Ngm-75 for which the mRNA is 1200 nucleotides in size. (iii) pGmNOD7 is a nodulin cDNA clone; it was sequenced by the Maxam and Gilbert (1980) method which showed that the insert has a length of 409 nucleotides preceding the poly(A) tail. The insert of pGmNOD7 is identical to the 3' end of the nodulin-23 cDNA clone described by Mauro et al. (1985) and therefore homologous to the 3' ends of nodulin-42 (Sengupta-Gopalan et al., 1986) and nodulin-20 (Sandal et al., 1987). Hence, pGmNOD7 will hybridize with at least the nodulin-20, -23 , and -42 mRNAs. 


\title{
4.2 Cloning of a DNA region from Bradyrhizobium japonicum encoding pleiotropic functions in heme metabolism and respiration
}

\begin{abstract}
Random and site-directed Tn5-induced mutagenesis of Bradyrhizobium japonicum yielded two mutations, one in strain 2960 and the other in strain 2606::Tn5-20, which mapped close to each other but in separate genes. The corresponding wild-type genes were cloned, and their approximate location on the cloned DNA was determined. Mutant 2960 was $\mathrm{Fix}^{-}$and formed green nodules on soybean, whereas 2606::Tn5-20 had ca. $4 \%$ of wildtype Fix activity and formed white nodules. Cytochrome oxidase assays (Nadi tests) showed a negative reaction with both mutants, indicating a functional deficiency of cytochrome $c$ or its terminal oxidase, or both. However, the mutants grew well under aerobic conditions on minimal media with different carbon sources. Furthermore, mutant 2960 had a reduced activity in hydrogen uptake, was unable to grow anaerobically with nitrate as the terminal electron acceptor, and 2960 infected soybean nodules contained little, if any, functional leghemoglobin. Southern blot analysis showed that a Bradyrhizobium japonicum heme biosynthesis mutant (strain L0505: O'Brian et al, 1987a) had its mutation close to the Tn5 insertion site of our mutant $2606:: \operatorname{Tn} 5-20$. This finding, combined with the observed phenotypes, suggested that the genes affected in the mutants 2960 and $2606:$ Tn5-20 were involved in some steps of heme biosynthesis thus explaining the pleiotropic respiratory deficiencies of the mutants. Similarly to strain LO505, the mutant 2606::Tn5-20 (but not 2960) was defective in the activity of protoporphyrinogen IX oxidase which catalyzes the penultimate step in the heme biosynthesis pathway. This suggests that one of the two cloned genes may code for this enzyme.
\end{abstract}

\section{Introduction}

Bradyrhizobium japonicum, a member of the slow-growing group of the rhizobia, is able to elicit root nodules on soybean (Glycine max L. Merr.) in which it lives endosymbiotically as bacteroids and fixes atmospheric nitrogen. Until today, most of the genetic work performed with Bradyrhizobium japonicum has focussed on the analysis of genes involved in early steps of nodulation and in the formation of nitrogenase activity (nod genes: Lamb and Hennecke, 1986; So et al., 1987; Nieuwkoop et al., 1987; Hahn and Hennecke, 1988; nif and fix genes: Fischer et al., 1986; Ebeling et al., 1987; Hennecke et al., 1987). Symbiotic nitrogen fixation, 
however, not only depends on genes directly concerned with the establishment of an active nitrogenase but, more indirectly, also on genes concerning metabolic functions in bacteroids (see below). Bradyrhizobium japonicum mutants with lesions in these genes are defective in symbiotic nitrogen fixation (Fix) because either the bacteroids do not fully proliferate in the nodules or the missing function creates a physiological state specifically unfavorable to the reduction of $\mathrm{N}_{2}$ while bacteroid development remains unaffected. These statements find support in the following examples: (i) Bradyrhizobium japonicum mutants lacking the high affinity molybdate uptake system are Fix obviously because nitrogenase suffers from inadequate supply of Mo (Maier et al., 1987). (ii) Respiration-defective Bradyrhizobium japonicum mutants have been described in which the concomitant Fix phenotype was caused by starvation of the costly nitrogenase reaction for ATP or the inability to metabolize $\mathrm{O}_{2}$ which inhibits nitrogenase (EI Mokadem and Keister, 1982; O'Brian et al., 1987a). Some of the mutations may have affected the structural genes of protein components in the electron transport to the high-affinity terminal oxidase, others the biosynthesis of cofactors (such as heme) required in this process. (iii) In Rhizobium meliloti and Rhizobium leguminosarum biovar viciae, mutations have been reported which affect genes (dct) required for the uptake of C4-dicarboxylates (succinate, fumarate, malate). The corresponding mutants form nodules that contain bacteroids but do not fix nitrogen (reviewed by Ronson and Astwood, 1985). Evidently, the bacteroids depend on transport of C4-dicarboxylates for using these metabolites as energy substrates. It is possible that a similar transport system also exists in Bradyrhizobium japonicum (Humbeck and Werner, 1987).

With the exception of the dct genes, the genes involved in the aforementioned processes are either not at all or only poorly characterized. In our laboratory we have previously obtained a considerable number of symbiotically defective transposon Tn5-induced Bradyrhizobium japonicum mutants (Regensburger et al., 1986). A preliminary analysis has revealed that three mutants have most interesting, pleiotropic phenotypes with regard to bacteroid development and symbiotic nitrogen fixation. This report provides a more thorough phenotypic description of one of these mutants, strain 2960, in which the lesion was shown to affect pleiotropically several respiratory pathways (hydrogen activation, anaerobic nitrate reduction, microaerobic respiration). The corresponding wild-type DNA region was cloned, the location of the gene in question delimited by marker exchange mutagenesis and a new, adjacent gene detected. At least one of the two genes appeared to determine a step in heme biosynthesis. 


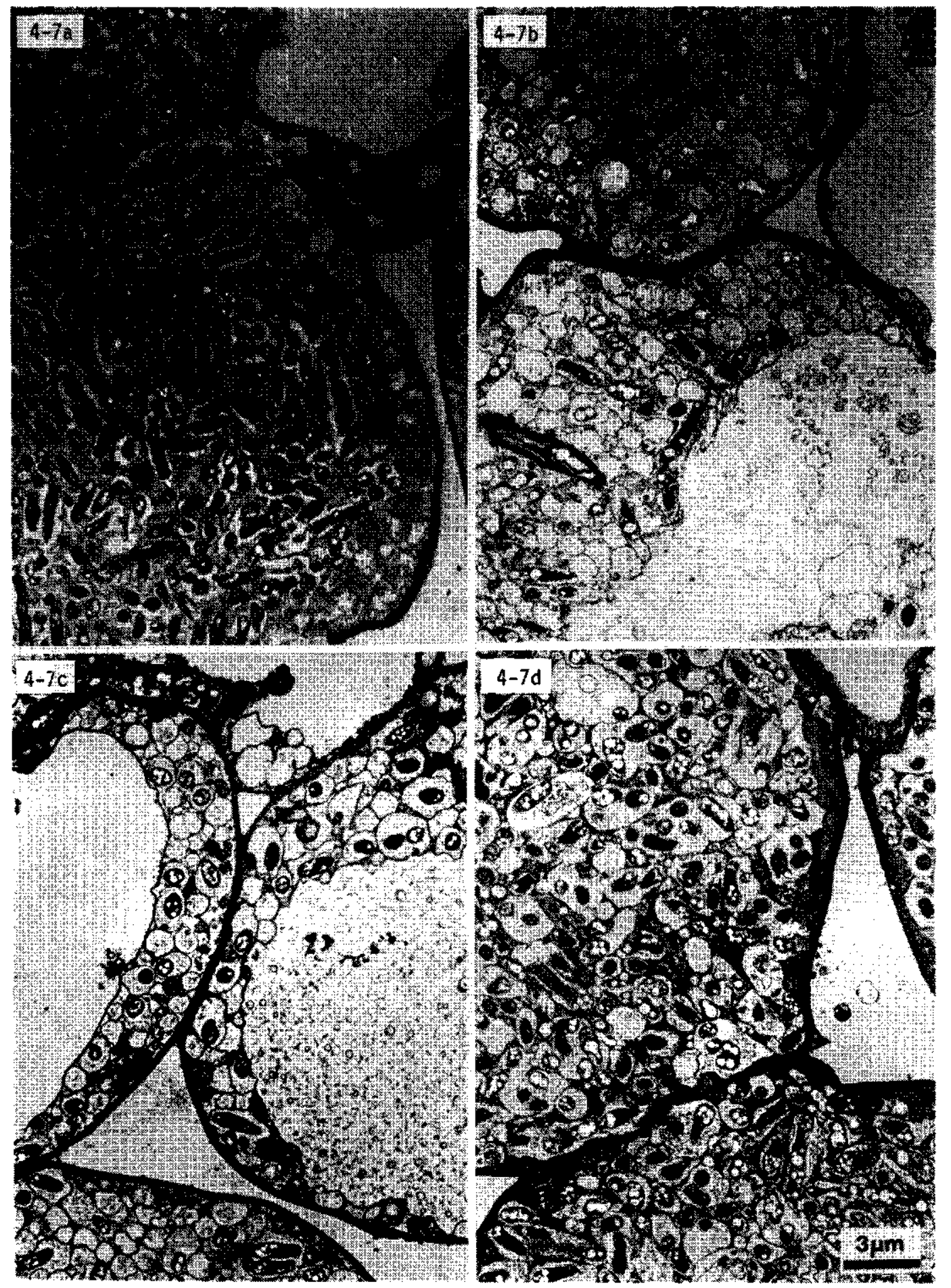


Figure 4-7 a-d: Electron microscopic examination of infected soybean root nodule cells. Photographs were taken from nodules infected by the wildtype [a], strain 2960 [b], LO505 [c], and 2606::Tn5-20 [d]. The 3 micrometer bar in [d] stands for all figures. The age of the nodules was 20 days after inoculation.

\begin{tabular}{|c|c|c|}
\hline \multirow[t]{2}{*}{ Examined phenotype } & \multicolumn{2}{|c|}{ B. japonicum strains } \\
\hline & $\begin{array}{l}\text { 110rif15 } \\
\text { (wi Tdtype) }\end{array}$ & $\begin{array}{l}2960 \\
\text { (mutant) }\end{array}$ \\
\hline Nodulation of Glycine max & $\mathrm{Nod}^{+}$ & Nod ${ }^{+}$ \\
\hline $\begin{array}{l}\text { Nodule color } \\
\text { externally } \\
\text { internally }\end{array}$ & $\begin{array}{l}\text { reddish } \\
\text { red }\end{array}$ & $\begin{array}{l}\text { greenish } \\
\text { green }\end{array}$ \\
\hline Bacteroid content & high & low \\
\hline $\begin{array}{l}\text { Acetylene reduction } \\
\text { in symbiosis } \\
\text { in free-living state }\end{array}$ & $\begin{array}{l}130^{a} \\
\mathrm{Nif}^{+}\end{array}$ & $\begin{array}{l}0.41^{\mathrm{a}} \\
\mathrm{Nif}\end{array}$ \\
\hline Leghemoglobin concentration & $2.94^{b}$ & $0.46^{b}$ \\
\hline $\begin{array}{l}\text { Aerobic growth on minimal medium } \\
\text { supplemented with one of these } \\
\text { carbon sources: D-glucose, } \\
\text { D-mannito1, L-arabinose, } \\
\text { pyruvic acid, L-glutamate }\end{array}$ & + & + \\
\hline Anaerobic growth with nitrate & + & - \\
\hline $\begin{array}{l}\text { Hydrogenase activity } \\
\text { amperometrically } \\
\text { methylene blue colony assay }\end{array}$ & $\begin{array}{c}163.6^{\mathrm{C}} \\
+\end{array}$ & $\begin{array}{c}57.4^{\mathrm{C}} \\
+\end{array}$ \\
\hline Oxidase reduction (Nadi test) & + & - \\
\hline
\end{tabular}

a symbiotic acetylene reduction activity is expressed in umoles ethylene $\times \mathrm{h}^{-1} \times \mathrm{g}^{-1}$ (nodule dry weight)

$b$ Leghemoglobin (Lb) concentration is expressed in $\mathrm{mg} L b \times g^{-1}$ (nodule fresh weight)

c Hydrogen uptake activity is expressed in $\mathrm{H}_{2} \times \min ^{-1} \times \mathrm{mg}$ protein ${ }^{-1}$ 
Table 4-1: Phenotypes of Bradyrhizobium japonicum mutant strain 2960.

\section{Results}

\section{Phenotypic description of mutant 2960}

Mutant 2960 originated from random Tn5-induced mutagenesis of the genome of Bradyrhizobium japonicum 110rif15 (Regensburger et al., 1986). This mutant still nodulated soybean $\left(\mathrm{Nod}^{+}\right.$), but was unable to fix dinitrogen either symbiotically (Fix) or in the free-living state under microaerobic growth conditions (Nif) (Table 4-1). The nodules from 2960-infected plants were green internally, as well as externally. The differentiation of the nodules into core and cortex zones was similar as in wildtype-infected nodules (data not shown). The infected plant cells harbored only few bacteroids, and contained many vesicles which appeared to represent empty peribacteroid membranes (figure 4-7b).

Nodulin gene expression in the plant cells was investigated by analyses of total RNA on RNA transfer blots (figure 4-8) and soluble protein preparations on Western blots (figure 4-9). Figure 4-8 shows that wild-type and 2960-infected nodules contained approximately the same amounts of mRNA transcribed from ENOD2, NOD7, and leghemoglobin (Lb) genes. By contrast, 2960-infected nodules contained only a very low level of Lb polypeptide (between $3-6 \%$ of that in wild-type nodules; figure 4-9). The levels of n-uricase (a representative tativeprotein of uninfected nodule cells) and glutamine synthetase (a representative tiveprotein occurring in all nodule cells) were also comparatively low (between 6 to $12 \%$ and 12 to $25 \%$, respectively; figure $4-9$ ). Unfortunately, uricase and glutamine synthetase cDNA clones were not available to test their corresponding mANA quantities. Therefore, although nodulation by strain 2960 had the strongest negative effect on Lb synthesis, it is not clear whether this is a specific and selective effect on Lb mRNA translation, or protein stability. The low amount of $L b$ apoprotein in 2960-induced nodules was consistent with the detection of only $16 \%$ of heme-containing holoenzyme in these nodules, as determined by spectrophotometric techniques (table 4-1). It is even possible, that this value just represents the background in nodule extract. A proper control would have been to measure authentic nodule tissue without any $L b$, but this is so far not available.

On plates, colonies of 2960 gave a negative reaction in the cytochrome oxidase assay (table 4-1), whereas aerobic growth rates of 2960 in liquid minimal medium with different carbon sources were hardly distinguishable from the growth rates of the wild-type (measured by optical density and viable cell counts). By contrast, mutant 2960 was unable to grow anaerobically in the presence of $10 \mathrm{mM}$ nitrate as terminal electron acceptor (table 4-1). Uptake hydrogenase activity in 

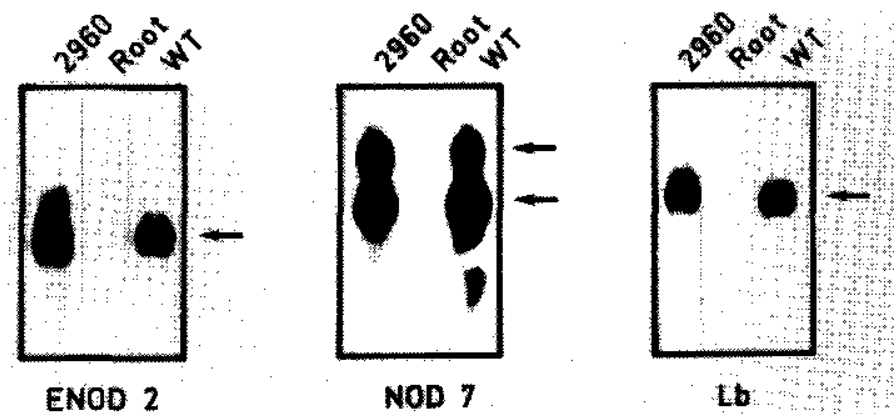

Lb

Figure 4-8: RNA transfer blot analysis of total RNA from wildtype nodules [WT], mutant 2960-infected nodules [2960], and uninfected roots [Root]. Nick transiated pENOD2, pNOD7, and pLb inserts were used as probes $(L b=$ leghemoglobin), which detect the mRNA species indicated by arrows.

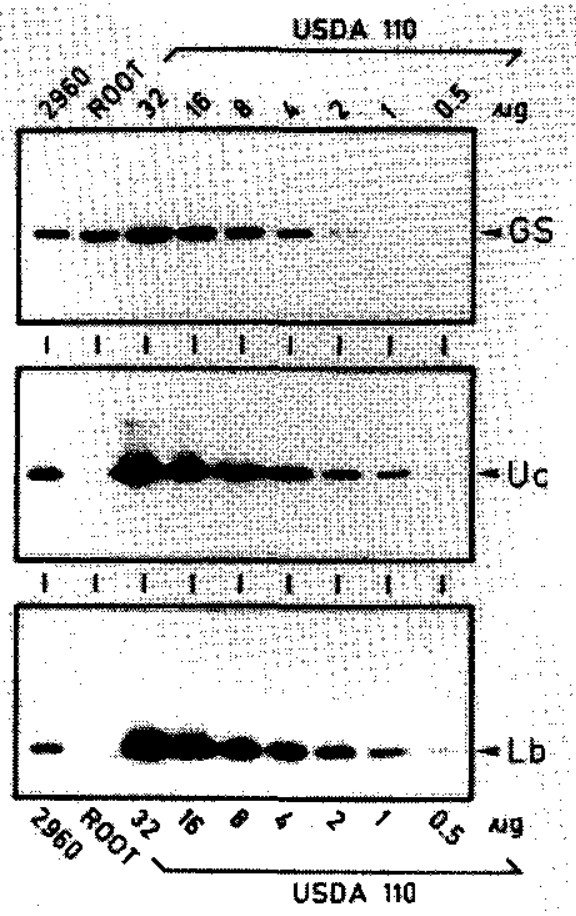

Figure 4-9: Western blot analysis of in vivo proteins from nodules infected by the Bradyrhizobium japonicum wildtype [USDA110], from mutant 2960-infected nodules [2960], and from uninfected roots [ROOT]. Parts of three identical Western blots are shown which were incubated with antibodies specific to glutamine synthetase [GS], n-uricase [Uc], and leghemoglobin [Lb]. The first three lanes from the left contain 32 microgram each of total in vivo protein. The bracket designated 'USDA110' embraces lanes containing a dilution series of total wildtype nodule protein from 32 to 0.5 microgram.

2960 was strongly reduced as compared to the wild-type (table 4-1), but this reduced activity was still detectable by the methylene blue colony assay. Taken together, these data suggested that mutant 2960 was pleiotropically defective in cellular reactions involving respiratory electron flow. 
A
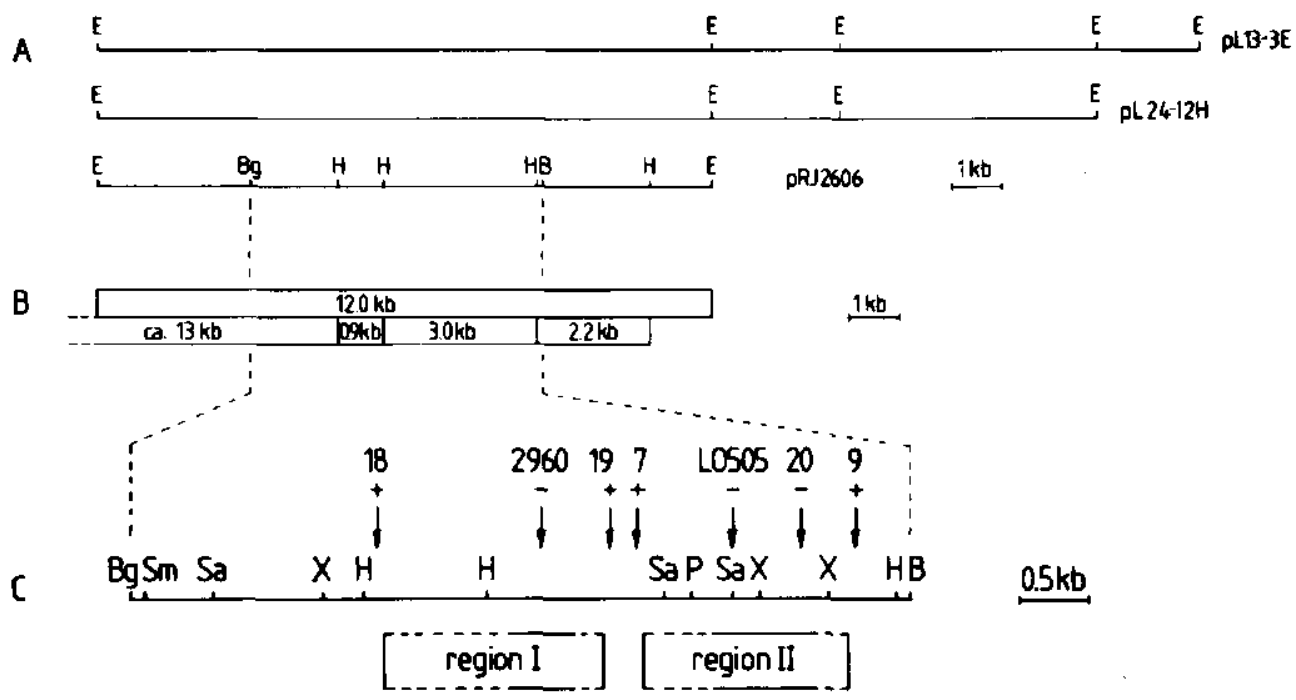

Figure 4-10 A-C: Physical maps of Bradyrhizobium japonicum DNA surrounding the site of Tn5 insertion in mutant 2960. [A] Maps of isolated cosmids and of subclone pRJ2606. [B] Sizes of EcoRI (top) and Hindll! fragments (bottom) relevant for the interpretation of figure 4-11. [C] Genomic $5.8 \mathrm{~kb}$ Bghl/BamHI fragment showing the sites of different Tn5 insertions (vertical arrows). The Fix phenotypes are indicated below the mutant numbers (+, wildtype Fix activity; -, 4\% Fix activity).

\section{Cloning of the Tn5-containing fragment and of the corresponding wildtype DNA region}

The Tn5-containing EcoRI fragment from genomic DNA of mutant 2960 was cloned into pSUP202 resulting in recombinant plasmid pRJ2600 (table 4-4). This plasmid had previously been used in a marker-exchange experiment with the wildtype to create the identical mutation as in strain 2960 and it was proven that the Tn5 insertion was the sole cause of the observed phenotypes (Regensburger et al., 1986). A pLAFR1 cosmid clone library of Bradyrhizobium japonicum (kindly provided by H.-M. Fischer) was probed with the [ ${ }^{32} \mathrm{P}$-labeled insert of pRJ2600 in a colony hybridization experiment. Two cosmids were thus identified, pL13-E and pL24-12H, containing cloned DNA of $21.5 \mathrm{~kb}$ and $19.5 \mathrm{~kb}$, respectively (figure 4-10a). In Southern blot hybridizations the cosmid inserts were proven to be colinear with the restriction patterns (BamHI, Pstl) of genomic DNA (data not shown). The $12 \mathrm{~kb}$ EcoRl fragment was identified as the one that had been mutated in strain 2960; it was subsequently lycloned in pSUP202 to give pRJ2606. Thereof, a $5.8 \mathrm{~kb} \mathrm{Bg} / \mathrm{ll}-\mathrm{BamH}$ I fragment (figure 4-10c) was subcloned into the EcoRI site of pNS1 using EcoRI linkers. This resulted in plasmid pRJ2608. 


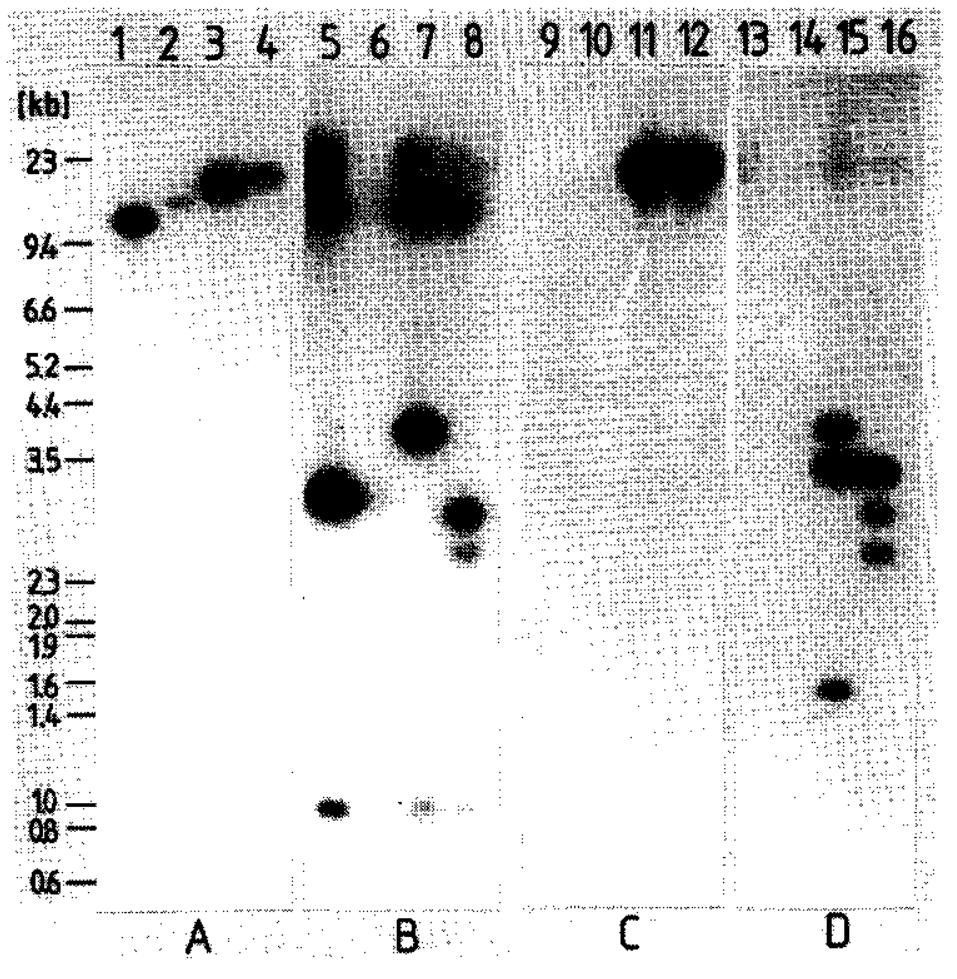

Figure 4-11 A-D: Comparison of mutants 2960 and 20505 by Southern blot hybridizations. [A and C] DNAs were digested with EcoRI. [B and D] DNAs were digested with HindIII. The $5.8 \mathrm{~kb}$ DNA region shown in figure $5 \mathrm{C}$ was used as a probe in sections [A] and $[B]$, whereas $a$ Tn5-specific probe (see text) was used in sections [C] and [D]. The DNAs were from Bradyrhizobium

japonicum 110rif15 (lanes 1, 5, 9, 13), USDA122 (lanes 2, 6, 10, 14), mutant 2960 (lanes 3, 7, 11, 15), and mutant LO505 (lanes 4, $8,12,16)$. The left margin shows the sizes of a mixture of lambda DNA digested with Hindill, and EcoRI plus Hindlll.

\section{Identification of at least two fix loci}

Plasmid pRJ2606 was transformed into Escherichia coli 294cys::Tn5 for Tn5 mutagenesis. Five plasmid derivatives (pRJ2606::Tn5-7, -9, -18, -19, and -20) were chosen for marker exchange mutagenesis of the wildtype (Bradyrhizobium japonicum 110rif15), because in these plasmids the Tn5 insertion sites were mapped close to the site of the Tn5 insertion in mutant 2960 (figure 4-10c). The resulting mutants were tested for symbiotic nitrogen fixation (acetylene reduction assay) activity. Mutants 2606::Tn5-18, $-19,-7$, and -9 were Fix ${ }^{+}$like the wildtype, but mutant 2606::Tn5-20 had only $4 \%$ Fix activity (figure 4-10c). Since the original 2960 mutation and Tn5-20 are separated by Fix ${ }^{+}$insertions (Tn5-19 and Tn5-7), it is likely that the two Fix insertions are located in two separate gene regions. The Fix ${ }^{+}$insertions delimit the maximal extension of these gene regions (regions I and II in figure 4-10c). 
The phenotype of strain 2606::Tn5-20 was further tested for a number of the criteria used in table 4-1 to describe mutant 2960. The new mutant was also found to be Nif in free-living culture and cytochrome oxidase negative in the standard Nadi colony test, but in contrast to 2960 , it was able to utilize $\mathrm{NO}_{3}{ }^{-}$as electron acceptor for anaerobic growth. Soybean nodules infected by strain $2606:: \operatorname{Tn} 5-20$ were white or only feebly pink, and contained less bacteroids than in wildtype induced nodules but more than in 2960-infected nodules (figure 4-7d). This intermediary phenotype is consistent with the observed $4 \%$ residual Fix activity.

\section{The Tn5 insertion in heme biosynthesis mutant L0505 maps to region II}

While this work was in progress, O'Brian et al., (1987a and 1987b) reported that a Bradyrhizobium japonicum Tn5 mutant (strain LO505) was defective in the activity of protoporphyrinogen IX oxidase which catalyzes the penultimate step in heme biosynthesis. Several phenotypic characteristics reported for LO505 were strikingly similar to our mutant 2960 , e.g. the green nodules which were Fix-, and the negative oxidase reaction. This prompted us to investigate into the possibility that the Tn5 insertion of LO505 mapped to the DNA regions cloned in our laboratory. Strain LO505 was kindly provided by R.J. Maier. The original parent of LO505, strain USDA122, was included as control. Genomic DNA of both strains were analyzed by Southern blot hybridization and compared with DNA of mutant 2960 and its parent 110rif15. The $5.8 \mathrm{~kb}$ DNA insert of pRJ2608 (figure 4-10c) was used as a probe in the hybridization shown in figure 4-11a and 4-11b, and a $2.5 \mathrm{~kb}$ Xhol fragment isolated from pSUP202::Tn5-3 was used as Tn5-specific probe in the hybridizations shown in figure 4-11c and 4-11d.

The wildtype EcoRl fragments of the two parental strains hybridizing with the pRJ2608 probe were not of equal lengths (figure 4-11, lanes 1 and 2), but both carried a Tn5 insertion in the corresponding mutants. This was evident from the enlargement of the band in figure 4-11, lanes 3 and 4 , and from the fact that these enlarged bands both hybridized with the Tn5 probe (figure 4-11, lanes 11 and 12). The HindIII digests of the two parental DNAs were similar, showing three hybridizing bands of $13,3.0$, and $0.9 \mathrm{~kb}$ (figure $4-11$, lane 5 , and very faintly in lane 6). This coincides with the map presented in figure 4-10b for wildtype strain 110rif15. The pRJ2608 probe overlapped by about $0.1 \mathrm{~kb}$ with a fourth Hindll fragment of $2.2 \mathrm{~kb}$ (see figure 4-10b) which, however, was only seen on a long exposure of the autoradiogram (not visible in figure 4-11b). In the two mutants, 2960 and LO505, the $3.0 \mathrm{~kb}$ HindllI fragment was missing, indicating that in both mutants the Tn5 insertion had taken place in the same Hindll fragment. Due to the presence of additional Hindlli sites in Tn5, this $3.0 \mathrm{~kb}$ wildtype Hindlll fragment was split into two other hybridizing bands of 3.9 and $1.6 \mathrm{~kb}$ in strain 2960 (figure 
4-11, lane 7) and of 2.9 and $2.5 \mathrm{~kb}$ in LO505 (figure 4-11, lane 8). These same bands also hybridized with the Tn5 probe in addition to the Tn5-internal fragments (figure 4-11, lanes 15 and 16). In conclusion, these data show that the Tn5 insertions in strains 2960 and LO505 have occurred in the same $3.0 \mathrm{~kb}$ HindIII fragment but at different positions within it. Similar Southern blot hybridizations were also performed with Xhol-and BamHI/Pstl-digested DNAs (data not shown). All data have led to the determination of the exact map positions of both insertions as shown in figure 4-10c. Interestingly, the Tn5 insertion in LO505 is located more closely to the position of Tn5-20, i.e. in region II, although the phenotype of mutant LO505 resembles more that of mutant 2960 (see also the electronmicroscopic analysis in figure 4-7c). The implications of these findings will be discussed below.

The close proximity of the Tn5 insertions of strains LO505 and 2606::Tn5-20 within region II prompted us to test the latter strain for protoporphyrinogen IX oxidase activity. For comparison, strain LO505 described as being defective in this enzyme (O'Brian et al., 1987b) was included in this analysis, and Bradyrhizobium japonicum strains 110rif15 (wildtype) and 2960 were also tested. Table 4-2 shows that mutants 2606::Tn5-20 and LO505 had very low, albeit detectable, levels of enzyme activity. This suggests that the insertions of both mutants are in fact in a gene (or genes) determining the activity of protoporphyrinogen IX oxidase. The relative activity of strain LO505 as shown in table 4-2 is considerably higher than the value reported by O'Brian et al. (1987b). Furthermore, the activity of 2606::Tn5-20 consistently was higher than that of LO505. These results will be discussed in relation to the other phenotypes of these mutants (see below). Mutant 2960 did not appear to be drastically affected in protoporphyrinogen IX oxidase activity (table 4-2).

\section{Interspecies hybridization of cloned regions I and II to DNA of related bacteria}

The $0.9 \mathrm{~kb}$ and $3.0 \mathrm{~kb}$ Hindill fragments covering regions I and II (see figure 4-10b and c) were used as probes to possibly detect homologous DNA fragments in other bacteria. Figure 4-12 shows that hybridizing EcoRI fragments were detected in other Bradyrhizobium strains $(9.0 \mathrm{~kb}$ band in strain $61-\mathrm{A}-76$, lane $2 ; 15$ and 13 kb bands in strain $32 \mathrm{H} 1$, lane 3 ) and in the closely related, non-symbiontic diazotroph Rhodopseudomonas palustris (5 kb band, lane 4). Conserved regions also appeared to be present in fast-growing rhizobia such as Rhizobium fredii (4.2 $\mathrm{kb}$ band, lanes 5 and 6) and Rhizobium meliloti (2.6 kb band, lane 7). DNA in lane 6 of figure 4-12 was from a Rhizobium fredii strain cured of its symbiotic plasmid; it had the same band as the symbiotic plasmid-containing wildtype strain, which showed that the homologous DNA regions were located on the chromosome. Positive but weak hybridization signals were also detected in Azotobacter 


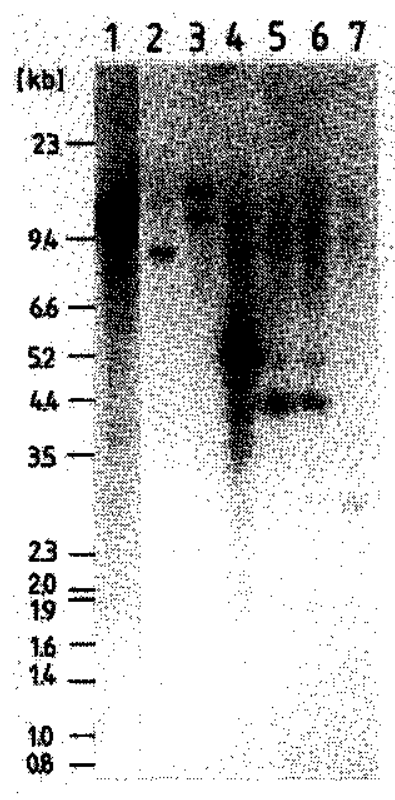

Figure 4-12: Interspecies hybridization using the 0.9 and $3.0 \mathrm{~kb}$ DNA fragments of regions 1 and II as probes. Genomic DNAs were digested with EcoRI before electrophoresis and blotting. The DNAs were from the following sources: Bradyrhizobium japonicum 110rif15 (lane 1), Bradyrhizobium japonicum 61-A-76 (lane 2), Bradyrhizobium sp. strain $32 \mathrm{H} 1$ (lane 3), Rhodopseudomonas palustris (lane 4), Rhizobium fredii USDA191 str (lane 5), Rhizobium fredii USDA191 C3 (lane 6), Rhizobium meliloti AK631 (lane 7). The left margin shows the sizes of a mixture of lambda DNA digested with HindIII, and EcoRI plus Hindlll.

\begin{tabular}{l|c|c}
\hline Strain & $\begin{array}{l}\text { Specific activity } \\
\text { nmole } \times \mathrm{mg}^{-1} \times \mathrm{h}^{-1}\end{array}$ & \% Activity \\
\hline & 1.90 & 100 \\
110 $\mathrm{rif15}$ & 1.40 & 74 \\
2960 & 0.28 & 15 \\
$2606:: \operatorname{Tn} 5-20$ & 0.13 & 7 \\
L0505 & & \\
\hline
\end{tabular}

Table 4-2: Solubilized membrane pellet protoporphyrinogen IX oxidase activity.

vinelandii (4.1 kb band, data not shown) and in the non-nitrogen fixing Escherichia coli (5.1 kb band, data not shown). All these data suggest that homologous regions may be present in a wide variety of bacteria, among them non-symbiotic or even non-diazotrophic ones. Thus, regions I and II may neither be directly concerned with symbiosis nor with nitrogen fixation.

\section{Discussion}

Starting out from a Bradyrhizobium japonicum Fix mutant, strain 2960, we have cloned and characterized a new Bradyrhizobium japonicum DNA region encoding essential functions for symbiotic nitrogen fixation. After an extensive phenotypic analysis it became clear that these functions are concerned with respiratory 
pathways because, in vivo 2960 was completely defective in cytochrome $c$ oxidase activity and anaerobic nitrate respiration, and partly affected in the oxidation of molecular hydrogen by the uptake hydrogenase activity. Paradoxically, aerobic growth was hardly affected.

The precise function of the gene mutated in 2960 is not known. However, since it maps in a region (region I) close to another gene region (region II) in which we were able to locate the position of a hem mutation (O'Brian et al., 1987b), it is tempting to assume that region I may also code for a function in heme biosynthesis. This assumption is corroborated by a number of phenotypic properties that strain 2960 and the region-II-mutant LO505 have in common. One of these similarities is the elicitation of green nodules, which may be explained by the formation of unknown products derived from the porphyrinoid intermediates accumulating in the mutants; heme $d$ may be a candidate, but this suggestion requires further exploration.

Strain LO505 had recently been shown to have a lesion in the penultimate step of heme biosynthesis, i.e. the reaction catalyzed by protoporphyrinogen IX oxidase (O'Brian et al., 1987b). This finding was confirmed by our own experiments except that we detected a higher residual enzyme activity as compared to the values reported by O'Brian et al. (1987b). Similarly, the other region II mutant, strain 2606::Tn5-20, was also found to have a low protoporphyrinogen IX oxidase activity. Thus region II contains either the structural gene for that or a regulatory gene governing its expression.

The maximal extent of both region I and region II allows the accommodation of one average-size gene in each. The presence of more than one gene in each region, however, cannot be excluded, but this would require that those genes are small. The fact that the Tn5 insertion in mutant 2606::Tn5-20, although being close to the LO505 insertion, leads to a considerably different phenotype from LO505 would be consistent with the presence of two adjacent genes in region II. Alternatively, Tn5-20 and the insertion in LO505 may both be in the same gene but the LO505 mutation disrupts its function more severely than the Tn5-20 mutation. The latter interpretation is supported by the observation that strain 2606::Tn5-20 had a higher residual protoporphyrinogen IX oxidase activity (15\% of the wildtype activity) than strain LO505 (7\%). Results obtained from DNA sequencing will hopefully clarify this point.

A defect in heme biosynthesis would certainly explain the pleiotropic deficiencies observed in strains 2960 and L0505, and partly also in strain 2606::Tn5-20 because this results in the defective formation of heme-containing cytochromes. An unsolved problem is, however, why different respiratory processes are affected 
to different extent: for example, aerobic growth of strain 2960 is unaffected, $\mathrm{H}_{2}$ oxidation is partly defective, and nitrate respiration and in vivo cytochrome oxidase (Nadi test) are completely defective. The ability to grow aerobically in liquid medium and the Nadi-negative phenotype are not necessarily two conflicting observations, because the Nadi test uses colonies in which the cells are known to be in microaerobic rather than aerobic state (Peters et al., 1987). As far as mutants L0505 and 2606::Tn5-20 are concerned, they both have residual protoporphyrinogen IX oxidase activity; i.e. these mutants are leaky. Futhermore, O'Brian et al. (1987b) have argued that the oxidation of protoporphyrinogen IX to protoporphyrin IX may to some extent occur nonenzymatically in the presence of oxygen. These activities may help the mutants produce enough heme to support respiration during aerobic growth. However, under microaerobiosis - a condition that prevails in endosymbiontic root nodule bacteroids - respiration may be hampered more severely. This interpretation is in line with the observation that strains LO505 and 2960 are Nif and Fix (starvation for ATP ?) and that soybean nodules infected by them contain only a few proliferated bacteroids. It has been known for some time that microaerobic and aerobic Bradyrhizobium japonicum cells contain different terminal oxidases and, hence, a branched respiratory chain, but little is known of which proteins they are composed and what their demands are for herne as constituent cofactors of cytochromes (Appleby, 1984). It is interesting to note in this context that a heme-containing cytochrome bc1 complex of Bradyrhizobium japonicum has recently been shown to be dispensable for aerobic growth whereas it was essential for this bacterium to form $\mathbf{N}_{2}$-fixing root nodules (Meyer, 1988). It is thus possible that a higher threshold level of heme production is required for microaerobic than for aerobic energy metabolism. This postulate is consistent with the finding that strain 2606::Tn5-20 with its $15 \%$ protoporphyrinogen IX oxidase activity produces more bacteroids and even some Fix activity (4\% of wild-type activity) as opposed to strain LO505.

It was shown in this work that mutant 2960 -infected nodules exhibited an aberrant pattern of nodulin biosynthesis. In particular a strong reduction in Lb polypeptide formation was observed in spite of the presence of normal amounts of $L b$ mRNA. Furthermore, several peribacteroid membrane proteins were found to be missing in preparations from nodules formed by mutant 2960 (D. Werner, personal communication). In order to propose a meaningful interpretation for these interesting observations it will clearly be necessary to precisely identify the enzymatic defect in strain 2960. 
Table 4-3: Bacterial strains.

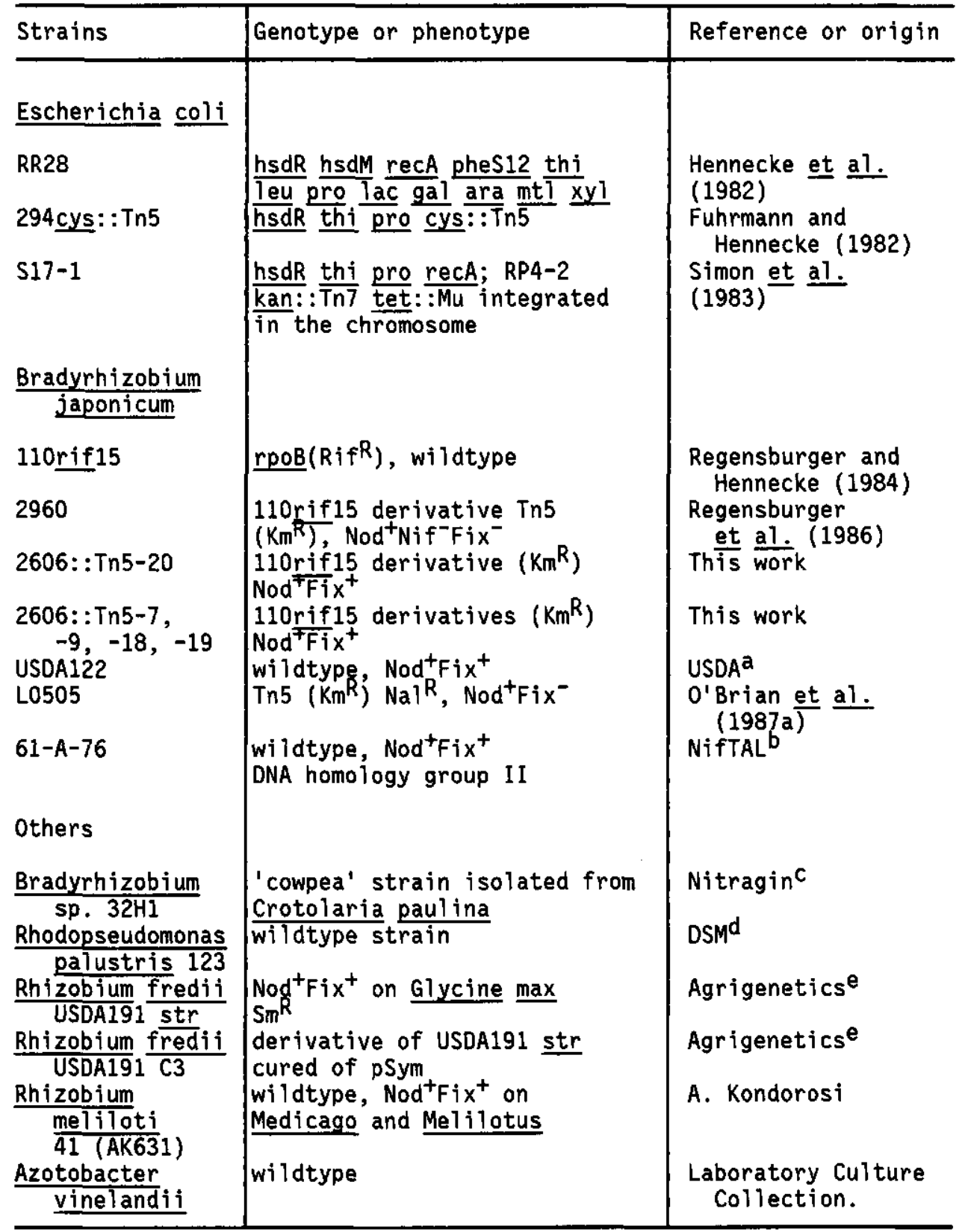

a U.S. Department of Agriculture, Beltsville MD, USA

b Rhizabium Germplasm Resource Center, NifTAL Project, Paia, Hawaii, USA

c Nitragin Co., Mi Iwaukee WI, USA

d Deutsche Sammlung für Mikroorganismen, Göttingen, FRG

e Agrigenetics Advanced Science Co., Madison WI, USA 
Table 4-4: Vectors and recombinant plasmids.

\begin{tabular}{|c|c|c|}
\hline & Genotype or phenotype & Reference or origin \\
\hline \multicolumn{3}{|l|}{ Vectors: } \\
\hline $\begin{array}{l}\text { pSUP202 } \\
\text { pNS1 }\end{array}$ & $\operatorname{Mop}_{A}^{+}$(oriT of RP4) $A p^{R} T c^{R}$ & $\begin{array}{l}\text { Simon et al. } \\
\text { Nikolnikov et al. } \\
(1984)\end{array}$ \\
\hline PLAFR1 & $T c^{R} \underline{\cos }$ & Friedman et al. \\
\hline pSUP202: :Tn5-3 & $\mathrm{Km}^{\mathrm{R}} \mathrm{Ap} \mathrm{p}^{\mathrm{R}} \mathrm{T} c^{\mathrm{R}}$, cam: :Tn5-3 & $\underset{(1986)}{\operatorname{Regensburger}}$ et al. \\
\hline \multicolumn{3}{|l|}{$\begin{array}{l}\text { Recombinant } \\
\text { plasmids: }\end{array}$} \\
\hline $\mathrm{pRJ} 2600^{\mathrm{a}}$ & $\begin{array}{l}\mathrm{Km}^{\mathrm{R}} A \mathrm{p}^{\mathrm{R}} T \mathrm{c}^{\mathrm{R}} \text { (pSUP202) } \\
\text { Tn5 containing EcoRI fragment } \\
\text { from B. japonicum } 2960\end{array}$ & This work \\
\hline$p L 13-3 E^{a}$ & $\begin{array}{l}T c^{R} \text { (pLAFR1) } 21.5 \mathrm{~kb} \\
\text { B. japonicum wildtype DNA }\end{array}$ & This work \\
\hline $\mathrm{pL} 24-12 \mathrm{H}^{\mathrm{a}}$ & $\begin{array}{l}T C^{R} \text { (pLAFR1) } 19.5 \mathrm{~kb} \\
\text { B. japonicum wildtype DNA }\end{array}$ & This work \\
\hline pRJ2606 ${ }^{a}$ & 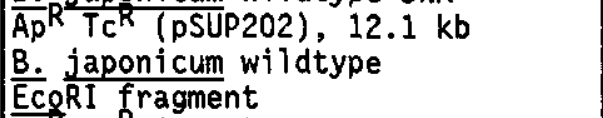 & This work \\
\hline pRJ2608a & $\begin{array}{l}\mathrm{Ap}^{R} \mathrm{Tc}^{\mathrm{R}}(\mathrm{pNS} 1), 5.8 \mathrm{~kb} \\
\mathrm{~B} \text {. japonicum } \mathrm{Bgl} I \mathrm{I} / \mathrm{BamHI} \text { fragment } \\
\text { cloned with } \mathrm{ECORI} \text { inkers into } \\
\text { EcgRI site of pNS1 }\end{array}$ & This work \\
\hline $\begin{array}{l}\text { pRJ2606: : } \operatorname{Tn} 5-7, \\
-9,-18,-19, \\
-20 b\end{array}$ & $\begin{array}{l}\overline{\mathrm{Km}^{R}} A p^{R} T c^{R} \text { (pSUP202) } \\
\text { Tn5-containing derivatives } \\
\text { of pRJ2606 }\end{array}$ & This work \\
\hline
\end{tabular}

a The inserts of these plasmids are shown in figure 4-10

$b$ The positions of the Tn5 insertions are shown in figure 4-10

\section{Material and methods}

Bacterial strains, vectors and recombinant plasmids - These are listed in tables 4-3 and 4-4. Bradyrhizobium japonicum 110rif15, a rifampicin resistant derivative of strain 311b110 (U.S. Department of Agriculture, Beltsville, MD, USA) is called the wildtype throughout this manuscript. Strain LO505 is a Tn5 induced mutant of Bradyrhizobium japonicum strain LO (a nalidixic acid resistant derivative of strain USDA DES122; O'Brian et al., 1987a). Escherichia coli strain 294cys::Tn5 was used as the source of Tn5 in the mutagenesis of cloned DNA, and strain S17-1 served as the donor strain for the mobilization of pSUP202 derivatives. Strain RR28 was used for transformations. The use of other strains is mentioned in the text. 
Media and growth conditions for Escherichia coli and Bradyrhizobium japonicum - Escherichia coli was routinely grown in LB medium (Miller, 1972). Bradyrhizobium japonicum was grown aerobically in PSY medium (Regensburger and Hennecke, 1983). Minimal medium HM (Cole and Elkan, 1973) was used to determine aerobic growth on different carbon sources (1 g/l of separately sterilized D-glucose, D-mannitol, D-gluconate, L-arabinose, pyruvic acid or L-glutamate, with purity degrees 98\%). Microaerobic (ex planta) cultures were grown as described previously (Scott et al., 1980; Regensburger et al., 1986). Anaerobic growth in the presence of $10 \mathrm{mM} \mathrm{KNO} 3$ was performed at $28 \mathrm{C}$ in $10 \mathrm{ml}$ YEM medium (Daniel and Appleby, 1972) under 1 bar of argon in $120 \mathrm{ml}$ stoppered serum flasks inoculated with approximately $10^{7}$ cells. Prior to derepression for hydrogenase activity cells were grown on plates containing $\mathrm{H}_{2}$ uptake medium (Maier et al., 1978, with modifications of Cantrell et al., 1983). The cultures were derepressed for 10 days in a gas atmosphere maintained at $89.5 \% \mathrm{~N}_{2}, 5 \% \mathrm{H}_{2}, 5 \% \mathrm{CO}_{2}$, and $0.5 \% \mathrm{O}_{2}$ (Lambert et al., 1985).

DNA work - Cloning, restriction endonuclease site mapping, nick translation, Southern blotting, and transformation were performed using established protocols (Maniatis et al., 1982). In the interspecies Southern blot hybridization experiment, different stringency conditions were used: prehybridization, hybridization, and washing of the filter blots were performed at $60 \mathrm{C}$. The wash solution contained $2 \times S S C / 0.1 \%$ SDS (medium stringency). Total genomic DNA from Bradyrhizobium japonicum was prepared as described (Hahn and Hennecke, 1984).

Tn5-induced mutagenesis, and matings between Escherichia coll and Bradyrhizobium japonicum - Recombinant plasmids were mutagenized in Escherichia coll 294cys::Tn5 essentially as described (Fuhrmann and Hennecke, 1982) except that after transformation the cell pool was distributed into twelve 100 microliter samples (to avoid formation of too many siblings) which were then grown in $4.9 \mathrm{ml}$ LB for 12 to $15 \mathrm{~h}$. Tetracycline (10 microgram/ $\mathrm{ml}$ ) was added for plasmid maintenance, and to prevent Tn5-insertion into the major hotspot of the tet gene (Berg et al., 1983). The mutagenized pSUP202 based plasmids were transformed into Escherichia coli S17-1. Matings were done essentially as described by Hahn and Hennecke (1984). Bradyrhizobium japonicum exconjugants were selected on PSY agar plus kanamycin (200 microgram/ $/ \mathrm{ml})$, and chloramphenicol (10 microgram/ml) was used to counterselect against the Escherichia coli donor. The genomic structure of the kanamycin-resistent (due to Tn5-insertion) and tetracycline-sensitive exconjugants (due to loss of the pSUP202 vector after double cross-over) were verifled by appropriate Southern blot hybridizations.

Assays for nitrogen fixation activity in symbiosis (Fix) and in tree-living cultures (Nii) - Surface sterilization of soybean seeds (Glycine max L. Merr. cv. Williams), inoculation with Bracyrhizobium japonicum strains, plant cultivation, acetylene reduction assay, and bacteroid reisolation were performed as described previously (Hahn and Hennecke, 1984; Lamb and Hennecke, 1986). To measure Nif activity in free-living Bradyrhizobium japonicum cultures, the strains were grown under microaerobic conditions. $\mathrm{N}_{2}$ fixation activity was determined by the acetylene reduction assay (Turner and Gibson, 1980).

Soybean nodulin mRNA and protein synthesis - Total RNA was isolated from 5-day-old root tips, 21-day-old nodules induced by the Bradyrhizobium japonicum wildtype, and 28-day-old nodules induced by mutant strain 2960 . Individual RNAs were quantitated by RNA transfer blot hybridization using specific cDNA probes ( $p L b$, coding for leghemoglobin; pENOD2, coding for early nodulin Ngm-75; pGmNOD7, representing a member of a small gene family hybridizing to RNAs of 1100 and 1500 nucleotides in size which encode the late peribacteroid membrane nodulins $\mathrm{Ngm}-23$ and $\mathrm{Ngm}-42$, respectively). Total protein was isolated from the same tissue samples as were used for the 
RNA isolation. Individual proteins were quantitated by Western blot analysis using antisera specific to leghemoglobin, $n$-uricase, and glutamine synthetase (the respective antisera were gifts of $C$. Sengupta-Gopalan, B. Jochimsen, and J. Cullimore). All isolation techniques and the RNA transfer blot and Western blot analyses have been described in detail (Studer et al., 1987).

Enzymatic assays - Cytochrome oxidase activity was determined using either a $1 \%$ solution of $N, N, N$ ', N'-tetramethyl-p-phenylenediamine dihydrochloride in water or the classical Nadi-reagent, a 1:1 mixture (vol:vol) of $1 \%$ alpha-naphthol in $95 \%$ ethanol and $1 \%$ aqueous N,N-dimethyl-p-phenyienediamine (Smibert and Krieg, 1981). The Lb concentration of an unfractioned nodule crude extract was determined by measuring the absorption difference of the reduced minus oxidized Lb at 556 and $539 \mathrm{~nm}$ as described by Appleby and Bergersen (1980). The expression of hydrogenase activity was determined in the methylene blue colony assay (Haugland et al., 1983). $\mathrm{H}_{2}$-uptake rates of free-living Bradyrhizobium japonicum cells were measured amperometrically using oxygen as the electron acceptor (Hanus et al., 1978).

Protoporphyrinogen IX oxidase activity from the solubilized membrane fractions of Bradyrhizobium japonicum was determined by following the change in absorbance at $408 \mathrm{~nm}$ over a period of 40 minutes. The cell pellets, $1 \mathrm{~g}$ wet cells, were resuspended in $4 \mathrm{ml} 50 \mathrm{mM} \mathrm{Tris} / \mathrm{HCl}, \mathrm{pH} 8.0$ and broken by sonication, using a soniprep 150 sonicator, over a period of $1 \mathrm{~min}$ in $30 \mathrm{sec}$ bursts allowing an equal time for cooling. An amplitude of 8 micrometer was used for each and cooling was provided by means of crushed ice. The membrane pellets were prepared by centrifugation of the crude cell extract at $140,000 \times \mathrm{xg}$ for $15 \mathrm{~min}$. The resulting membrane pellets were then solubilized in $1 \mathrm{ml} 50 \mathrm{mM}$ Tris $/ \mathrm{HCl}$, pH 8.0 containing $1 \%$ Tween20. Solubilization was aided by sonication for $10 \mathrm{sec}$. The protoporphyrinogen oxidase activities were measured in $1 \mathrm{ml}$ cuvettes containing 50 microliter of the membrane fraction and 100 microliter protoporphyrinogen IX, made up to $1 \mathrm{ml}$ using $50 \mathrm{mM}$ Tris $/ \mathrm{HCl}, \mathrm{pH}$ 8.0. The protoporphyrinogen IX was prepared from protoporphyrin IX as described by Poulson and Polglase (1975) and was added to start each assay. The change in optical density at $408 \mathrm{~nm}$ was recorded over $\mathbf{4 0} \mathrm{min}$ at $5 \mathrm{~min}$ intervals. The protein content of each sample was calculated using the method described by Bradford (1976). Each reaction was accompanied with an appropriate blank to measure non-enzymic auto-oxidation of the protoporphyrinogen IX. The specific activities for each sample were calculated from the initial rates using a $\mathrm{mM}$ extinction coefficient of 262.

Light and electron microscopy - For inspection of the overall nodule morphology, 20-day-old nodules from soybean plants were cut into slices and examined under a Wild \& Leitz stereomicroscope M3. Electron microscopy of nodule ultrastructure was penformed as described previously (Hahn $\theta t$ al., 1984) using a Hitachi H-600 electron microscope. 


\section{CHAPTER V}

\section{Identification of Plant Genes Involved}

\section{in Rhizobium-Root Hair Interactions}

[5.1] Ton Gloudemans, Marja Moerman, Joke van Beckum, Jens Gundersen, Albert van Kammen, and Ton Bisseling. In: Bothe, H., de Bruyn, F.J., and Newton, W.E. (eds) Nitrogen Fixation, A Hundred Years After. Gustav Fischer Verlag, Stuttgart pp 611-616 (1988)

[5.2] Ton Gloudemans, T.V. Bhuvaneswari, Marja Moerman, Ton van Brussel, Albert van Kammen, and Ton Bisseling. Plant Molecular Biology, in press. 


\subsection{In vivo proteins of root hairs}

\section{Introduction}

The formation of legume root nodules is accompanied by the differential expression of nodulin genes. The synthesis of the majority of the detectable nodulins starts shortly before the onset of nitrogen fixation, when the nodules with their specific structural features have already been formed (Gloudemans et al., 1987; Moerman et al., 1987). Similar nodulins to which we refer as late nodulins, are found in different legumes e.g. Soybean (Legocki and Verma, 1980; Sengupta-Gopalan et al., 1986; Gloudemans et al., 1987), pea (Govers et al., 1985), alfalfa (Lang-Unnasch and Ausubel, 1985), vetch (Moerman et al., 1987), and yellow lupin (Strózycki et al., 1985). The corresponding genes are the late nodulin genes. Besides these genes for late nodulins, a few nodulin genes have been identified that are expressed at markedly earlier stages of root nodule development (Govers et al., 1985; Gloudemans et al., 1987; Moerman et al., 1987). These genes code for so called early nodulins which are thought to be involved in nodule morphogenesis (Franssen et al., 1987), infection thread formation, and release of bacteria from the infection thread (B. Scheres, in prep). Most early nodulins characterized so far are (hydroxy)proline-rich proteins, which may be cell wall constituents.

In the interaction with their hosts Rhizobium bacteria bring about the deformation of root hairs. In addition Rhizobium bacteria induce cortical cell divisions, which results in the formation of nodule meristems, differentiating into nodules. The involvement of nodulins in the formation of nitrogen fixing nodules is well established. However, to date it has not been studied whether phenomena occurring in the root hair after inoculation (i.e. deformation, curling, infection thread formation) are accompanied by changes in gene expression. In this chapter we describe our first analyses on the identification of plant gene products that are involved in the interaction between Rhizobium and root hairs.

\section{Analyses of root hair proteins}

Root hairs were isolated by freezing roots in liquid nitrogen and scraping them off with a paint brush (Röhm and Werner, 1987). Pea root hair proteins were extracted by heating the root hairs for $5 \mathrm{~min}$ at $100 \mathrm{C}$ in sample buffer (2\% SDS, $5 \%$ 2-mercaptoethanol, $10 \%$ glycerol, $50 \mathrm{mM}$ Tris- $\mathrm{HCl} \mathrm{pH} \mathrm{6.8)} \mathrm{followed} \mathrm{by} 5 \mathrm{~min}$ centrifugation at $10,000 \times \mathrm{xg}$. The resulting supernatant contained the root hair proteins. Root proteins from 3-day-old pea seedlings were isolated in a similar way. The roots were ground in sample buffer, passed through miracloth, and heated for $5 \mathrm{~min}$ at $100 \mathrm{C}$ followed by centrifugation. The root and root hair protein 


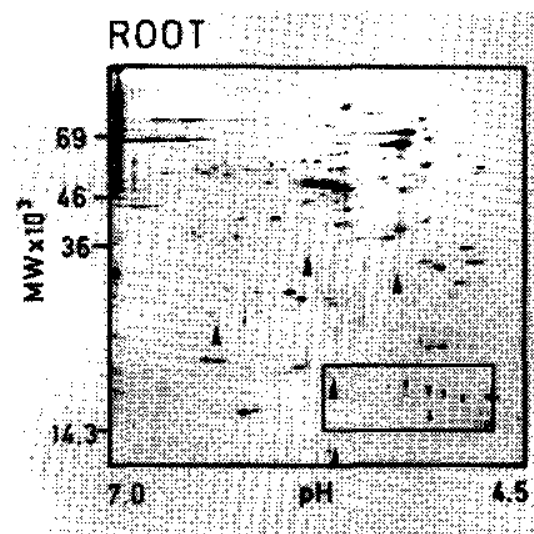

ROOI HAIR

NOCULATED

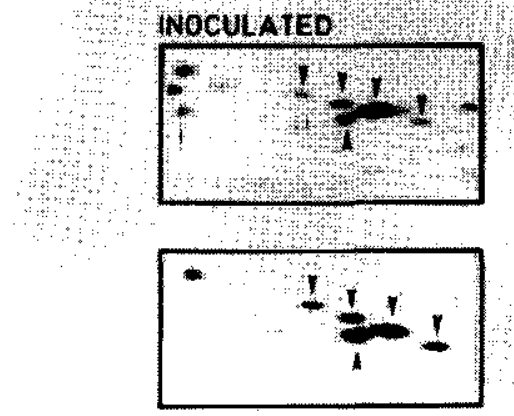

4
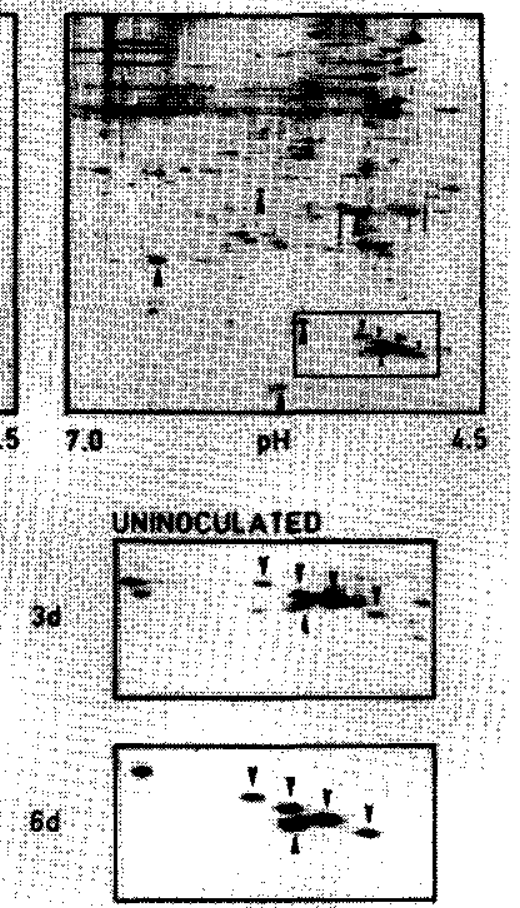

Figure 5-1: Root and root hair proteins from pea. Silver stained 2-D gels of proteins isolated from 3-day-old pea roots and root hairs of 6-day-old pea seedlings (top), and root hairs from 3- and 6-day-old pea seedlings either uninoculated or inoculated with Rhizobium leguminosarum (bottom). Root hair specific proteins are indicated by arrowheads and the $14 \mathrm{kDa}$ proteins by small arrowheads. At the bottom only the in the top encircled part of the 2-D gel is shown.

preparations were separated by 2-dimensional gel electrophoresis, as described by De Vries et al. (1982), and the proteins were stained with silver (Morrissey, 1981).

Comparison of the 2-D patterns obtained from root and root hair proteins from pea showed that the majority of the proteins is identical in both preparations (figure 5-1, top). However, about 10 polypeptides (indicated by arrowheads in figure 5-1, top) have a markedly higher concentration in root hairs compared to roots. This suggests that these proteins are specifically present in root hairs. Besides these root hair specific proteins there are other proteins which are only detectable in root protein preparations (not indicated). 

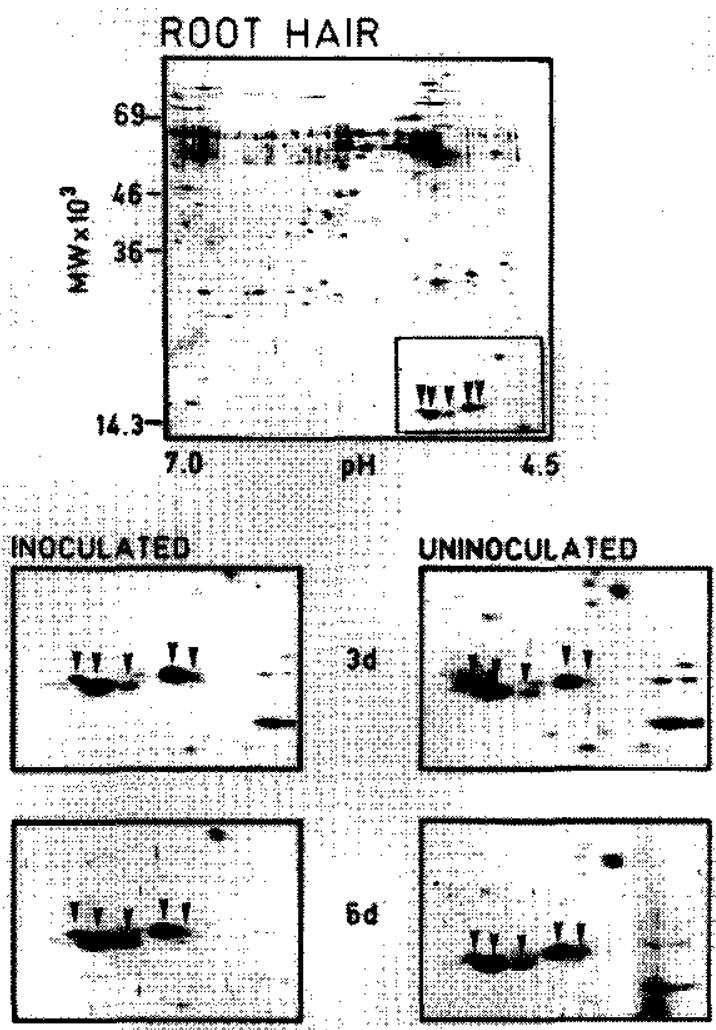

Figure 5-2: Root hair proteins from soybean. Silver stained 2-D gels of proteins isolated from root hairs of 6-day-old soybean seedlings (top), and root hairs from 3- and 6-day-old soybean seedlings either uninoculated or inoculated with Bradyrhizobium japonicum (bottom). The $14 \mathrm{kDa}$ proteins are indicated by small arrowheads. At the bottom only the in the top encircled part of the 2-D gel is shown.

The most abundant root hair specific proteins in pea is a group of 5 polypeptides with apparent molecular masses of about $14 \mathrm{kDa}$ and isoelectric points of approximately 4.8 (rectangle in figure 5-1, top). A similar comparison of root and root hair protein preparations from soybean revealed the presence of a group of root hair specific polypeptides that migrates to the same position in the gel as the $14 \mathrm{kDa}$ pea root hair specific proteins (figure 5-2). This suggests that both pea and soybean have similar root hair specific proteins.

Root hairs are only susceptible to infection by Rhizobium during a certain phase of their development. In soybean the root hairs that are formed after inoculation with Bradyrhizobium japonicum are the ones that are most susceptible to infection (Calvert et al., 1984). The emerging root hairs are only poorly infected. In pea, however, the root hairs emerging at the time of infection with Rhizobium leguminosarum are efficiently infected (T.V. Bhuvaneswari, personal communication). Neither in pea, nor in soybean mature root hairs are infectible. To determine whether the concentration of root hair specific proteins correlates with 


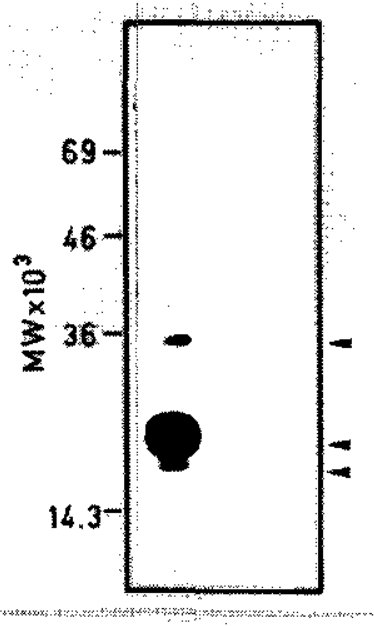

$1: 2$
Figure 5-3: Western blot analysis of in vivo proteins from root hairs of 6-day-old pea seedlings (lane 2) and tobacco leaves treated with Ethral A (lane 1). The Western blot is incubated with antibodies directed against the $2 b$ class of PR proteins from tobacco.

the susceptibility towards infection of the root hairs, we analyzed the root hair proteins from 3- and 6-day-old pea and soybean seedlings. On day 3 all root hairs on pea seedlings as well as on soybean seedlings are still growing, while at day 6 the majority of the root hairs is fully developed. The concentrations of the $14 \mathrm{kDa}$ root hair specific proteins appeared to be significantly higher in root hair preparations from 6-day-old pea seedlings compared to those from 3-day-old plants (figure 5-1, bottom). In soybean, however, the concentration of the $14 \mathrm{kDa}$ root hair specific proteins is at a high level in root hairs from both 3- and 6-day-old seedlings (figure 5-2, bottom). In both plant species, inoculation with Rhizobium leguminosarum and Bradyrhizobium japonicum, respectively, does not affect the concentration of the $14 \mathrm{kDa}$ proteins (figures 5-1 and 5-2, bottom). Assuming that the $14 \mathrm{kDa}$ root hair specific proteins in soybean and pea are related proteins this observation indicates that there is a correlation between the concentration of the $14 \mathrm{kDa}$ root hair specific proteins and the susceptibility of the root hairs towards infection. Only root hairs containing low levels of these proteins can be infected.

Because of this correlation and the fact that the molecular masses and isoelectric points of the $14 \mathrm{kDa}$ proteins are identical to those of pathogen related (PR) proteins of for example tobacco (Van Loon, 1981), it was attractive to speculate that the $14 \mathrm{kDa}$ root hair specific proteins are in fact PR proteins. To test this hypothesis, we analyzed whether antibodies directed against tobacco PR protein class $2 \mathrm{~b}$ (generous gift of Dr L.C. Van Loon) bind to the $14 \mathrm{kDa}$ root hair proteins. A Western blot, containing tobacco proteins from leaves treated with Ethral A (an 
ethylene precursor that induces the synthesis of PR proteins in tobacco leaves) and root hair proteins from 6-day-old pea seedlings, was incubated with the PR antibodies. In figure 5-3 it is shown that the tobacco PR proteins are recognized. However, a binding to the pea $14 \mathrm{kDa}$ root hair proteins is not observed. Since we did not study whether antibodies directed against tobacco PR proteins cross-react with pea PR proteins, this experiment neither supports nor disproves our hypothesis.

\section{Changes in root hair gene expression induced by Rhizobium}

A comparison of the patterns of root hair proteins from uninoculated pea plants and pea plants inoculated with Rhizobium leguminosarum, after 2-D gel electrophoresis, revealed several changes as a result of infection (results not shown). Since such analyses do not allow to discriminate between proteins from the bacteria and proteins from the host plant it is not possible to determine whether the changes in protein pattern are indeed changes of plant proteins in root hairs. The effect of Rhizobium infection on gene expression in root hairs can however be determined by in vitro translation of mRNA isolated from root hairs in a rabbit reticulocyte lysate (Pelham and Jackson, 1976) followed by separation of the translation products by 2-D gel electrophoresis. In such eukaryotic cell-free translation system Rhizobium RNA is not translated (Govers et al., 1985; Gloudemans et al., 1987). The experiments and results will be described in the next section. 


\title{
5.2 Involvement of Rhizobium leguminosarum nodulation genes on gene expression in pea root hairs
}

\begin{abstract}
The mRNA population in pea root hairs was characterized by means of in vitro translation of total root hair RNA followed by 2-dimensional gel electrophoresis of the translation products. Root hairs contain several mRNAs not detectable in total RNA preparations from roots. Most of these root hair specific mRNAs occur in elongating root hairs at higher levels than in mature root hairs. The expression of some genes in pea root hairs is typically affected by inoculation with Rhizobium leguminosarum. One gene, encoding $\mathrm{RH}-42$, is specifically induced while the expression of another gene, encoding $\mathrm{RH}-44$, is markedly enhanced. Using Rhizobium leguminosarum mutants it was shown that the nodC gene is required for the induction and enhancement of expression of the RH-42 and $\mathrm{RH}-44$ genes, respectively, while the Rhizobium chromosomal gene pss1, involved in exopolysaccharide synthesis, is not essential. After induction of the nod genes with apigenin the bacteria excrete into the culture medium a factor that causes root hair deformation. This deformation factor stimulates the expression of the RH-44 gene but does not induce the expression of the gene encoding RH-42. For expression of the RH-42 gene just as for marked root hair curling both the presence of Rhizobium leguminosarum and nod gene products are required. However, whether RH-42 is really involved in marked root hair curling remains to be studied. Nevertheless, RH-42 can be used as a marker in studies involving the interactions between Rhizobium and root hairs, while the RH-44 mRNA is an excellent tool to identify active deformation factor fractions during purification of this factor.
\end{abstract}

\section{Introduction}

In the interaction between leguminous plants and Rhizobium bacteria that can lead to formation of nitrogen fixing root nodules, root hairs are the first target of rhizobia. The bacteria cause root hairs to deform and curl and induce in about $0.1-1 \%$ of the root hairs development of infection threads which carry the Rhizobium bacteria into the root cortex (Bauer, 1981).

Bacterial genes essential for the interactions with root hairs are the nodulation genes and genes involved in exopolysaccharide (EPS) synthesis. The common nod genes (nodABC) are required in all three phases of root hair interaction, 
namely deformation, curling and infection thread formation (Debellé et al., 1986; Downie and Johnston, 1986). Genes involved in determining host-specificity are also required for infection thread formation (Debellé et al., 1986; Horvath et al., 1986; Van Brussel et al., 1988). All known Rhizobium leguminosarum nod genes are located on a plasmid, the so-called Sym plasmid. The presence of the nodD gene product, in cooperation with a flavone excreted by the host plant, is essential for synthesis of all other nod gene products (Rossen et al., 1985; Firmin et al., 1986; Peters et al., 1986; Redmond et al., 1986; Zaat et al., 1987b). A culture of free living rhizobia with induced nod genes excretes into the medium a not yet identified product that is capable of deforming root hairs (Zaat et al., 1987a). For marked curling and infection thread formation, however, the presence of live bacteria is required (Bhuvaneswari, 1984).

In addition to nod genes, genes for EPS synthesis are necessary for infection thread formation (Finan et al., 1985; Downie and Johnston, 1986). This is illustrated by Rhizobium meliloti mutants which lack the ability to synthesize EPS (Norris et al., 1988). These mutants can curl root hairs but infection threads are not produced. EPS mutants of Rhizobium trifolii induce small ineffective nodules which rapidly senesce, but it is not clear if infection threads are present in such nodules (Djordjevic et al., 1987).

Studies on involvement of nodule specific proteins, nodulins, and regulation of host genes encoding nodulins have become of major importance in understanding ingthe role of the plant in root nodule formation. Up to the present changes that occur in gene expression in root hairs due to interaction with Rhizobium have, however, not been investigated, probably due to the fact that methods for isolating sufficient quantities of root hair material were lacking until recently. Using the root hair isolation method described by Röh and Werner (1987) we have examined changes in gene expression in root hairs induced by Rhizobium and by the extracellular compound produced by the bacterium after induction of the nod genes. We call this compound deformation factor; probably this factor is similar to the branching factor previously described by Bhuvaneswari and Solheim (1985). As a first step in understanding gene expression in root hairs in relation to interaction with Rhizobium, we studied: (i) Gene expression during root hair development, (ii) Changes in root hair mRNA population induced by Rhizobium, (iii) Bacterial genes involved in eliciting these changes, and (iv) The RNA composition of root hairs from seedlings exposed to deformation factor. 


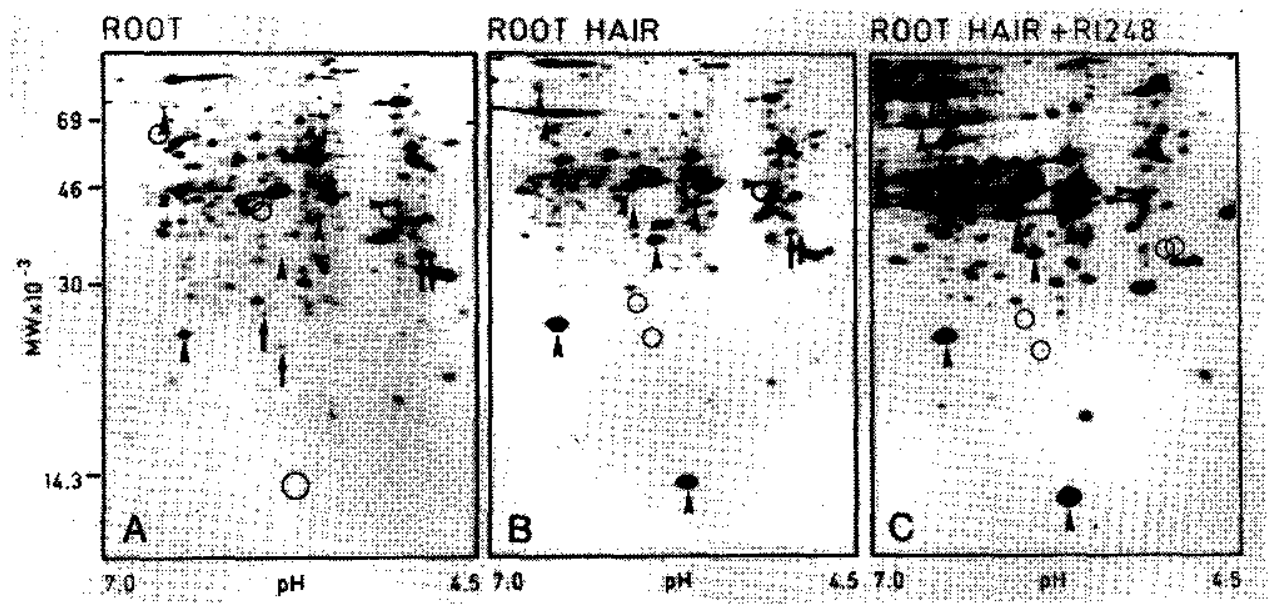

Figure 5-4: Two-dimensional gels of in vitro translation products from RNA of A [root] 4-day-old root segments; B [root hair] root hairs of 4-day-old uninoculated seedlings; C [root hair + RI248] root hairs of 4-day-old seedlings inoculated with Rhizobium leguminosarum 248. Root hair specific translation products are indicated by arrowheads. Translation products present in roots, but present at strongly reduced levels in root hairs, are indicated by arrows. Circles indicate the absence of translation products indicated by arrows or arrowheads.

\section{Results}

\section{Translation products of root hair RNA}

The in vitro translation products of pea root hair RNA after separation by 2-D gel electrophoresis are shown in figure 5-4B. Such polypeptide patterns are highly reproducible with different root hair RNA preparations and always include polypeptides with molecular masses up to $200 \mathrm{kDa}$. This illustrates that degradation of root hair RNAs during isolation is negligible.

Comparison of the in vitro translation products of root hairs with those obtained with RNA from root segments reveals substantial differences. Root hair specific in vitro translation products are indicated by arrowheads in figure 5-4A and 5-4B. Apparently some mRNAs present at high levels in root hairs are hardly present in root RNA. On the other hand there are root RNAs that are not detectable in root hairs. The corresponding root specific translation products are indicated in figure $5-4 A$ and $5-4 B$ by arrows. 

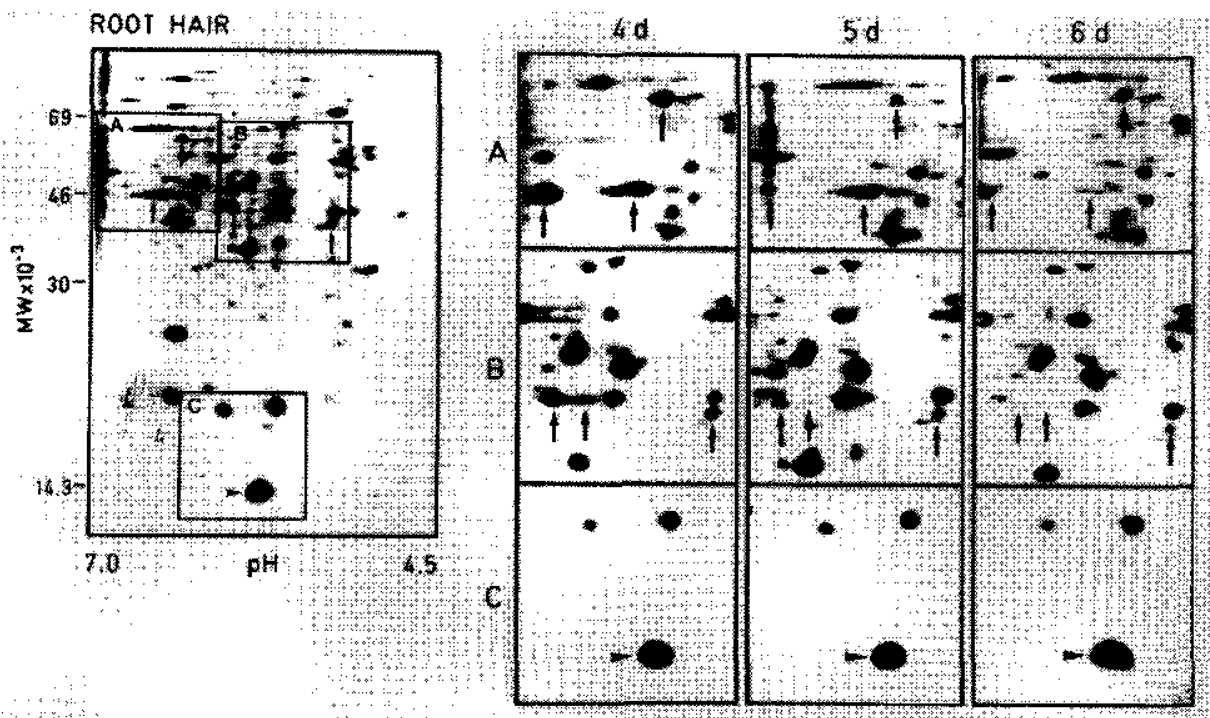

Figure 5-5: In vitro translation products of root hair RNA from 4-, 5-, and 6-day-old uninoculated pea seedlings. The area of 2-D gels indicated by the rectangles A, B, and C in the 2-D gel on the left is shown. Root hair specific transiation products decreasing in concentration during root hair development are indicated by arrows in panels A and B. A root hair specific translation product encoded by a mRNA present at a constant concentration during development of the root hair is indicated by an arrowhead in panel $C$.

\section{Gene expression during root hair development}

Root hair cells gradually loose their ability to get infected by Rhizobium as they develop into mature root hairs (Bhuvaneswari et al., 1980). Therefore we first analyzed RNA of root hairs from uninoculated plants at different stages of development before studying gene expression in root hairs from inoculated plants.

Under our growth conditions Rhizobium forms nodules on the upper 3 centimeter part of the tap root. Roots of 4-day-old seedlings only carry growing root hairs in this region, while at day 6 this same region of the root only contains mature root hairs. Root hair RNA from this part of the tap root of uninoculated 4-, 5-, and 6-day-old pea seedlings was isolated and in vitro translated as before.

The 2-D gel patterns of the in vitro translation products show that during root hair development the concentration of several mRNAs changes considerably (figure 5-5). Most changes are in the root hair specific mRNAs whose translation products are indicated in figure 5-4B. The changes in concentration of some root hair specific mRNAs during root hair development are illustrated in figure 5-5. This 


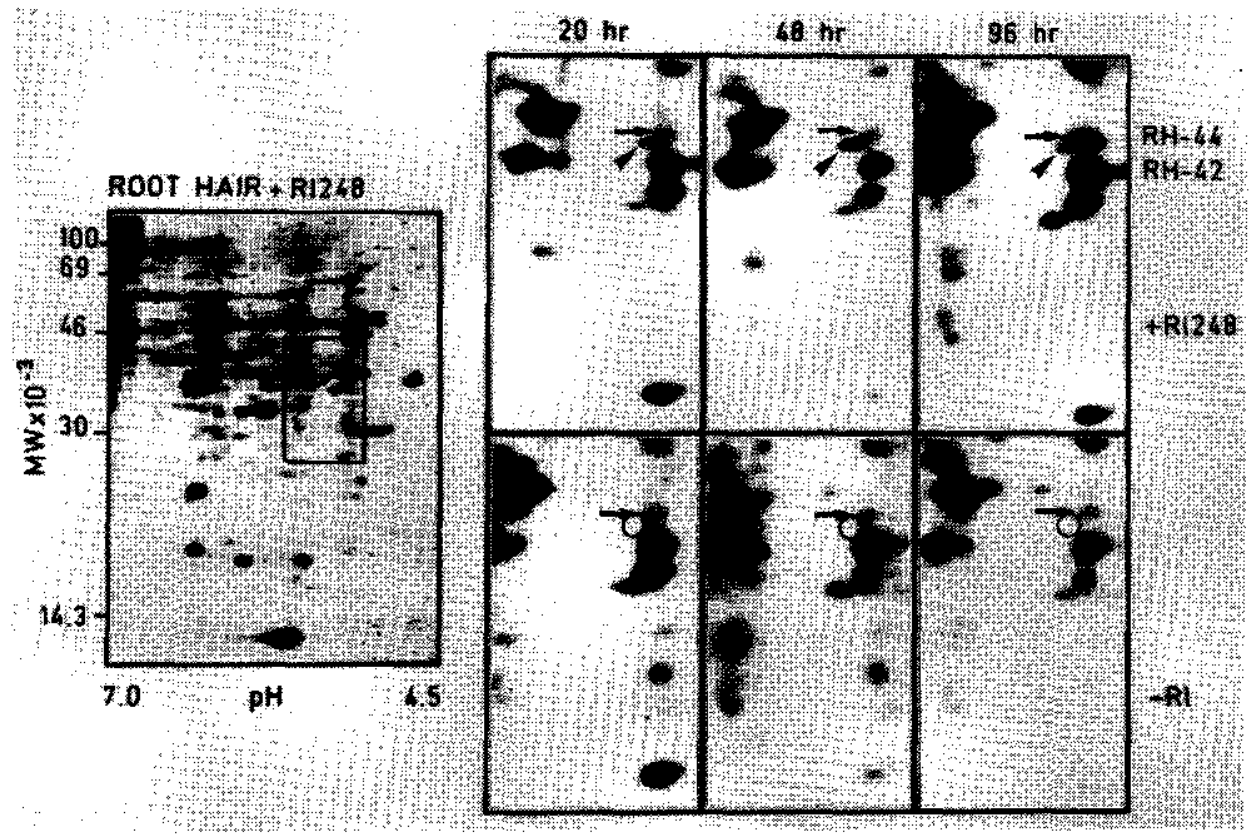

Figure 5-6: In vitro translation products of root hair RNA from seedlings 20, 48, and 96 hours after inoculation with Rhizobium leguminosarum 248 [ + Ri248]; [-RI] uninoculated seedlings of the same age. At the right side enlargements of the part of 2-D gels indicated by the rectangle are shown. $\mathrm{RH}-42$ is indicated by an arrowhead. $\mathrm{RH}-44$ is indicated by an arrow. Absence of RH-42 is indicated by a circle.

figure presents a composite of regions of 2-D gels indicated in the 2-D gel on the left by rectangles. It can be seen that the level of some root hair specific mRNAs decreases during root hair development (figure 5-5, panel A and B), while others remain constant (figure 5-5, panel C).

\section{Gene expression in root hairs after inoculation with Rhizoblum}

To study whether Rhizobium induces changes in gene expression in root hairs we analyzed RNA isolated from hairs of inoculated seedlings and from YEM treated control plants. Previously it has been established that in the in vitro translation system we used, bacterial mRNAs are not translated (Govers et al., 1985). The 2-D pattern of the in vitro translation products obtained with RNA from root hairs treated with sterile YEM is identical to the 2-D pattern of uninoculated root hairs (data not shown). The in vitro translation products of root hair RNA from plants inoculated with Rhizobium leguminosarum 248 is shown in figure 5-4C. This figure reveals an elevated level of several mRNAs after inoculation with Rhizobium. 
However, the majority of these mRNAs are root hair specific mRNAs that occur also at higher levels in growing root hairs than in mature root hairs (arrowheads in figure 5-4B).

Two changes specifically induced by Rhizobium in root hairs are not related to a developmental stage of the root hairs. A polypeptide with an apparent molecular mass of $42 \mathrm{kDa}$ and an isoelectric point of approximately 5 is only produced upon in vitro translation of RNA from root hairs of inoculated plants but not with RNA from root hairs of uninoculated plants of any age, nor with RNA from roots (figure 5-4A), or nodules. This polypeptide indicated in figure 5-6 by an arrowhead, will be referred to as RH-42. Another mRNA encoding a polypeptide with an apparent molecular mass of $44 \mathrm{kDa}$ and an isoelectric point of approximately 5 , is present at markedly increased levels in root hairs after inoculation with Rhizobium in comparison to uninoculated roots (figure 5-4A) and nodules. The $44 \mathrm{kDa}$ in vitro translation product, indicated in figure $5-6$ by an arrow, will be referred to as RH-44.

With pea seedlings grown in gravel deformation and curling of root hairs is observed 24-48 hours after inoculation with Rhizobium. To study whether the changes in expression of the genes encoding RH-42 and $\mathrm{RH}-44$ correlate with the deformation and curling of root hairs we have analyzed root hair RNA populations at different times after inoculation. Six hours after inoculation with Rhizobium leguminosarum 248 no changes in RNA from root hairs could be observed (data not shown). RH-42 was first detectable upon translation of RNA from root hairs harvested 20 hours after inoculation. The concentration of RH- 44 mRNA increases from 20 hours on.

\section{Rhizobium genes involved in regulation of expression of RH-42 and $\mathrm{RH}-\mathbf{4 4}$ genes}

The involvement of nod genes in regulation of expression of RH-42 and RH-44 genes was demonstrated using a Rhizobium leguminosarum cured of its Sym plasmid, strain RBL1387, and a Rhizobium leguminosarum nodD mutant, strain RBL1402 (see table 5-1). In figure 5-7 the regions of 2-D gels of the in vitro translation products containing $\mathrm{RH}-42$ and $\mathrm{RH}-44$ are shown. $\mathrm{RH}-42$ mRNA is not detectable among the translation products of root hair RNA from seedlings inoculated with the cured strain RBL1387 or the nodD mutant RBL1402. Also the concentration of RH-44 mRNA is not enhanced in these cases. Hence it is clear that bacterial nod genes are essential both for the induction of expression of the gene encoding $\mathrm{RH}-42$ and the enhancement of expression of the gene encoding RH-44. 

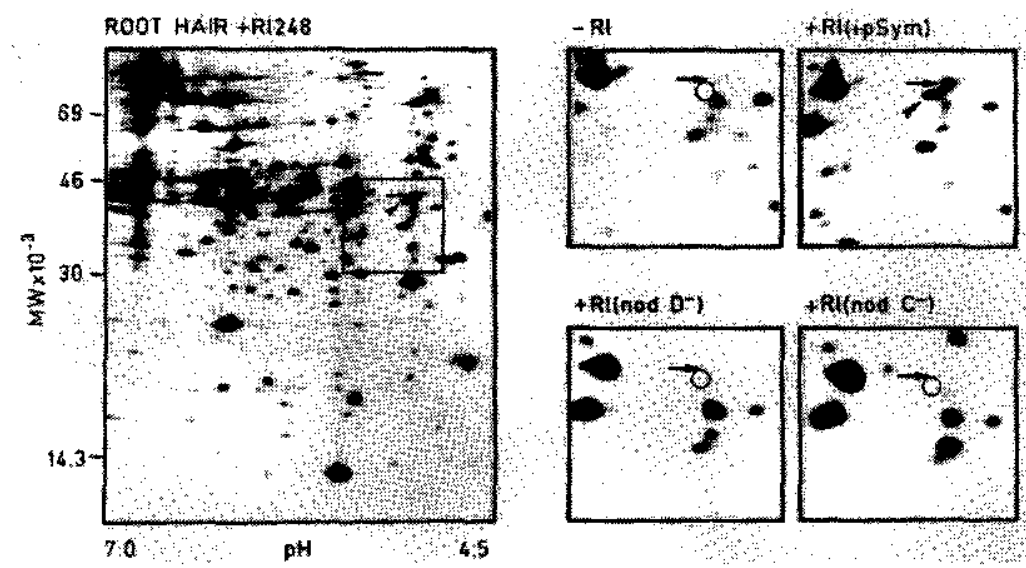

+ RA OSym)
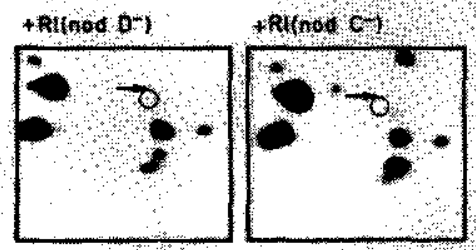

\& Rlossil

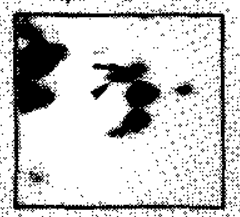

Figure 5-7: In vitro translation products of root hair RNA from uninoculated pea seedlings [-RI] and from seedlings inoculated with [ + Ril + pSym)] Rhizobium leguminosarum 248, [+RI(-pSym)] strain RBL1387, [+ RI(nodD')] strain RBL1402, [+ Rl(nodC)] strain RBL1412, or [+RI(pss1)] strain 8401 pRL1Ji:pss1::Tn5, respecthely. An enlarged part of 2-D gels is shown which is indicated by a rectangle on the left. $\mathrm{RH}-42$ is indicated by an arrowhead. $\mathrm{RH}-44$ is indicated by an arrow. The circle indicates absence of RH-42.

The involvement of common nod genes, nodABC, in expression of the RH-42 and $\mathrm{RH}-44$ genes was studied with a Rhizobium leguminosarum nodC mutant, strain RBL1412. Inoculation of root hairs with RBL1412 did not trigger the induction of the gene encoding RH-42, nor did it cause an enhanced level of RH-44 mRNA (figure 5-7). Hence we conclude that at least nod $C$ is involved in the induction and enhancement of the genes encoding $\mathrm{RH}-42$ and $\mathrm{RH}-44$ respectively. Whether the nodA and nod $B$ gene products are essential for regulation of expression of the $\mathrm{RH}-42$ and $\mathrm{RH}-44$ genes has not been studied.

The root hair specific mRNAs present at higher levels in growing root hairs than in mature root hairs (figure 5-4B, arrowheads), are also present at higher levels in root hairs from plants inoculated with the Sym plasmid cured strain RBL1387 and from plants inoculated with the nodD mutant strain RBL1402 or nodC mutant RBL1412. This illustrates that the Sym plasmid with the nod genes is not essential for the regulation of these genes in pea root hairs.

When pea seedlings were inoculated with the Rhizobium leguminosarum mutant pss 1 which does not produce exopolysaccharides, the gene encoding RH-42 is induced in inoculated root hairs and expression of the gene encoding $\mathrm{RH}-44$ is enhanced as well (figure 5-7). This result indicates that exopolysaccharides are not required for regulation of the expression of the genes encoding $\mathrm{RH}-42$ and $\mathrm{RH}-44$. 

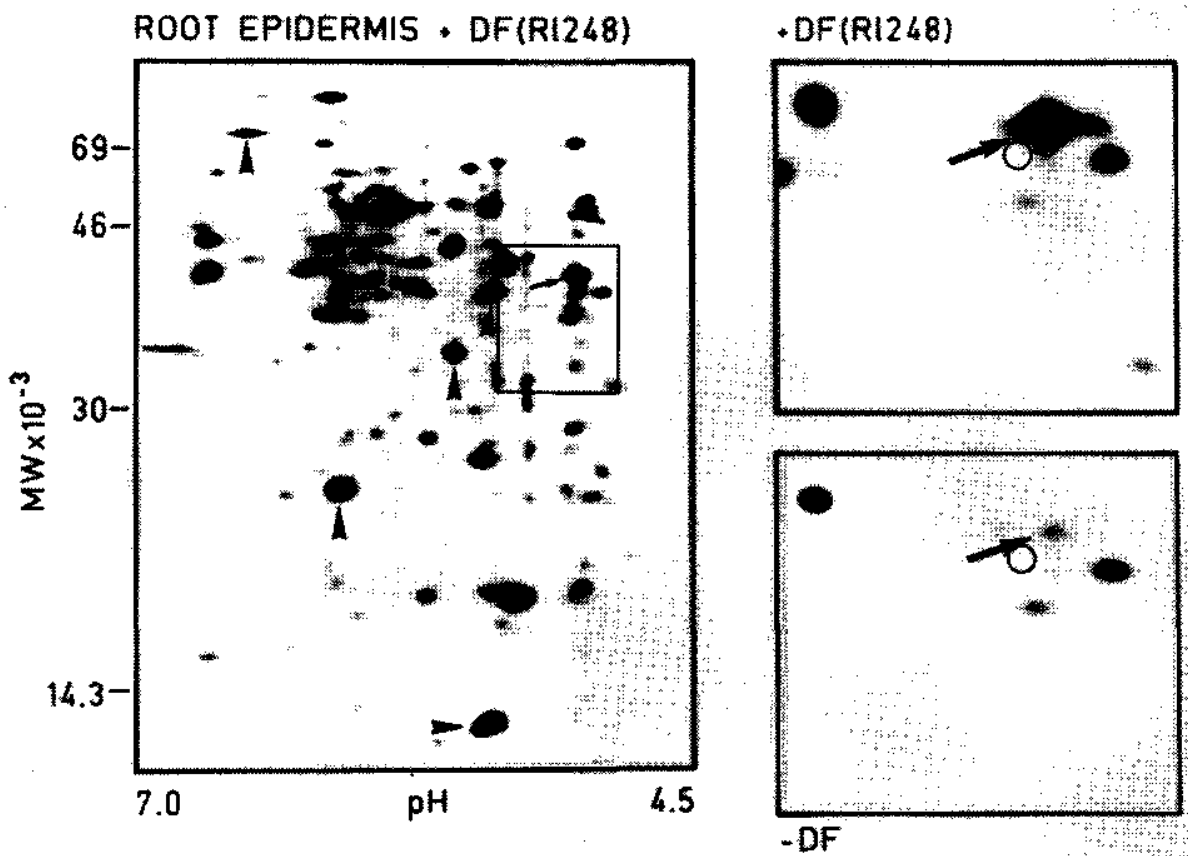

Figure 5-8: In vitro translation products of root epldermis RNA isolated from five-day-old seedlings treated for 16 hours with a deformation factor preparation from Rhizobium leguminosarum 248 [+DF(RI248)], or with sterile medium [-DF]. From the 2-D gels only the part indicated by the rectangle in the 2-D gel on the left is shown. $\mathrm{RH}-44$ is indicated by an arrow. The circle indicates absence of $\mathrm{RH}-42$.

\section{Effect of deformation factor on gene expression in root hairs}

Deformation factor is excreted by rhizobia upon induction of nod genes by a flavone (Zaat et al., 1987a; Bhuvaneswari and Downie unpublished results). If four-day-old pea seedlings were incubated overnight in a deformation factor preparation the roots were covered with a layer of ice after freezing them in liquid nitrogen which prevented normal isolation of root hairs. Lyophilization of roots to remove this ice layer resulted in our hands in degradation of root hair RNA. To circumvent this problem we isolated epidermis strips from the root region containing the root hairs. The 2-D pattern of in vitro translation products of RNA extracted from epidermis of YEM treated seedlings is similar to that of root hair RNA from uninoculated plants and shows that root hair specific mRNAs are also present at relatively high levels in epidermis RNA preparations (figure 5-8, indicated by arrowheads). 
Pea seedlings were incubated in deformation factor produced by Rhizobium leguminosarum 248 for 16 hours. The 2-D pattern of in vitro translation products of RNA from epidermis from these seedlings shows that expression of the RH-42 gene is not detectable, but expression of the gene encoding RH-44 is dramatically enhanced (figure 5-8).

\section{Discussion}

Molecular events taking place in the root hair during the legume-Rhizobium interactions have until now not been studied. Root hair specific proteins have been identified in clover and alfalfa (Gerhold et al., 1985), in soybean (Werner and Kuhlmann, 1985; Gloudemans et al., 1988a) and pea (Werner and Röhm, 1985; Röhm and Werner, 1987; Gloudemans et al., 1988a). However, in all these cases the effect of Rhizobium on gene expression in root hairs was not studied. In the present study we have employed in vitro translation of RNA from root hairs and found that Rhizobium induces considerable changes in the RNA composition of root hairs. Root hairs from inoculated pea seedlings contain several RNAs at a markedly higher level than hairs from uninoculated control plants and they are much more abundant in root hairs than in total roots. Most of the corresponding pea genes appear to be expressed at a high level in an early stage of root hair development. Besides these genes two other pea genes in root hairs are specifically regulated by Rhizobium leguminosarum. These are the gene encoding RH-42, a gene not expressed in root hairs of uninoculated pea seedlings, and the RH-44 gene. The latter gene is expressed at a markedly higher level in root hairs from inoculated plants. The genes encoding $\mathrm{RH}-42$ and $\mathrm{RH}-44$ are not related to early stages of root hair development.

The observation that Rhizobium stimulates the expression of plant genes that are transcribed at much higher levels in still elongating root hairs suggests that Rhizobium either stimulates formation of new root hairs, or transfers existing root hairs to a younger stage of development. In our study we have observed that the yield of root hair RNA from inoculated plants is always $10-40 \%$ higher than from uninoculated plants. Hence the bacteria might produce a factor that stimulates new root hair growth. Since also a Rhizobium leguminosarum cured of its Sym plasmid can induce these changes in gene expression, this factor is not encoded by the Sym plasmid. The existence of a similar compound is suggested by preliminary data of Dazzo et al. (1987). This group showed that even when the nod genes of Rhizobium are not induced by the addition of a flavone, the bacteria excrete a factor that stimulates formation of new root hairs.

To identify Rhizobium genes required for the regulation of the genes encoding $\mathrm{RH}-42$ and $\mathrm{RH}-44$ and to provide clues towards the role of these genes in defined 
stages of Rhizobium-root hair interactions we used Rhizobium strains mutated in the nod genes and the gene pss1, which is involved in exopolysaccharide synthesis.

Exopolysaccharides of Rhizobium leguminosarum are not essential for regulation of expression of the genes encoding $\mathrm{RH}-42$ and $\mathrm{RH}-44$, since the strain mutated in the pss1 gene still induced and enhanced the expression of the genes encoding $\mathrm{RH}-42$ and $\mathrm{RH}-44$, respectively. The pss 1 mutant does not form nodules on pea and in analogy with similar mutants in other Rhizobium species might not form infection threads (Norris et al., 1988). On the other hand root hairs still deform and curl after inoculation with this pss 1 mutant (Borthakur et al., 1986). Young nodules contain a high number of infection threads and RH-42 is absent and the gene encoding RH-44 is not enhanced. However, only in $0.1-1 \%$ of inoculated root hairs an infection thread is observed (Bauer, 1981) and RH-42 is present and the expression of the $\mathrm{RH}-44$ gene is enhanced. This supports that $\mathrm{RH}-42$ and $\mathrm{RH}-44$ are not involved in infection thread formation.

We showed that from the common nod genes at least the nodC gene is essential for the induction and stimulation of expression of the genes encoding RH-42 and RH-44 respectively. We further demonstrated that a Rhizobium leguminosarum culture, treated with apigenin, excretes compound(s) in the medium enhancing the expression of the gene that codes for RH-44. Hence it is likely that rhizobia stimulate the expression of the RH-44 gene by the excreted deformation factor(s).

The expression of the gene encoding $\mathrm{RH}-42$ is not induced by deformation factor, but nodC is required. The apparent contradiction that the common nod genes are essential for induction of the gene coding for $\mathrm{RH}-42$, whereas the deformation factor is not sufficient to elicit expression of this gene, also exists for marked root hair curling. Both root hair curling and expression of the gene encoding RH-42 appear to require nod gene products as well as the presence of live bacteria. This suggests that besides the compounds excreted by Rhizobium after treatment with flavones, other molecules might be essential for induction of this pea gene, or that the physical presence of Rhizobium bacteria is required for these two processes. Whether RH-42 is really involved in curling reactions remains therefore to be established.

The enhanced expression of the gene encoding RH-44 appears to be coupled to root hair deformation. Deformation of root hairs and stimulation of expression of the RH-44 gene occur practically simultaneously, and Rhizobium mutants that do not induce deformation of the hairs also do not enhance the expression of the $\mathrm{RH}-44$ gene. In addition deformation factor stimulates the transcription of the $\mathrm{RH}-44$ gene. These observations suggest that there is a correlation between the 
increased expression level of the $\mathrm{RH}-44$ gene and deformation of root hairs. However, whether $\mathrm{RH}-44$ is involved in a process induced by the same factor as root hair deformation, or there is a causative relationship between $\mathrm{RH}-44$ and root hair deformation, can not be concluded yet.

Although specific functions could not be assigned to RH-42 and $\mathrm{RH}-44, \mathrm{RH}-42$ gene expression can be used as a characteristic feature in the study of interactions between Rhizobium and root hairs. In addition, the coupling between root hair deformation and the stimulation of $\mathrm{RH}-44$ gene expression makes the increased RH-44 mRNA an excellent molecular marker in the purification of bacterial deformation factor.

Table 5-1: Bacterial strains.

\begin{tabular}{|c|c|c|c|}
\hline $\begin{array}{l}\text { Rhizobium } \\
\text { Teguminosarum }\end{array}$ & Genotype & $\begin{array}{l}\text { Phenotype } \\
\text { on pea }\end{array}$ & Reference \\
\hline 248 & wildtype & $\mathrm{had}^{+} \mathrm{hac}^{+} \mathrm{nod}^{+}$ & Josey et al. \\
\hline RBL1387 & $248\left(\mathrm{pSym}^{-}\right)$ & had $^{-}$hac $^{-}$nod- $^{-}$ & Van Brusse 1 \\
\hline RBL1402 & $\begin{array}{l}\text { RBL1387 (pRL602) } \\
=\text { pRL1JI (nodD::Tn5) }\end{array}$ & $\underline{\text { had }^{-}} \underline{\text { hac }^{-}} \underline{\text { nod }^{-}}$ & $\begin{array}{l}\text { Wijffileiman } \\
\text { et al. (1985) }\end{array}$ \\
\hline RBL1412 & $\begin{array}{l}\text { RBL1387 (pRL615) } \\
=\text { pRL1JI (nodC::Tn5) }\end{array}$ & $\mathrm{had}^{-} \mathrm{hac}^{-} \mathrm{nod}^{-}$ & $\begin{array}{l}\text { Wijffelman } \\
\text { et al. (1985) }\end{array}$ \\
\hline $\begin{array}{l}8401 \text { pRL1JI: } \\
\text { pSS1: }: \operatorname{Tn5} \\
\left(\mathrm{EPS}^{-}\right)\end{array}$ & $8401(p R L 1 J I)$ & $\mathrm{had}^{+}$hac $^{+}$nod $^{-}$ & $\begin{array}{l}\text { Borthakur } \\
\text { et a1. (1986) }\end{array}$ \\
\hline
\end{tabular}




\section{Material and methods}

Growth conditions for plants and bacteria - The bacterial strains used are listed in table 5-1. Pea seeds (Pisum sativum (L.) cV. Rondo) were obtained from Cebeco, the Netherlands. The seeds were sown in gravel (Bisseling et al., 1978) and four days later the seedlings were inoculated with Rhizobium bacteria cultured in yeast extract mannitol (YEM) medium to an OD600 of 1.0 (Bhuvaneswari et al., 1980) or, as a control, treated with sterile YEM medium. The upper 3 centimeter part of the roots containing the root hairs were harvested and frozen in liquid nitrogen for root hair isolation. Root segments, including root hairs, were harvested from 4-day-old pea seedlings and immediately frozen in liquid nitrogen for isolation of root RNA. Harvested plant material was stored at $-70 \mathrm{C}$ until use.

Root hair isolation - Root hairs were harvested from roots essentially as described by Röhm and Werner (1987). Roots were frozen in a container filled with liquid nitrogen and root hairs were broken off by stirring. Since root hairs float in liquid nitrogen they could be collected by decanting into a prechilled container. The remaining roots were washed with liquid nitrogen which was added to the liquid nitrogen containing the root hairs. Residual root pieces in the root hair preparation were removed with forceps and then the liquid nitrogen was allowed to evaporate at $-70 \mathrm{C}$. Root hair preparations harvested in this way are free from contaminating pieces of root, cortex, epidermis, and root cap cells (figure 5-9 and cover photo), while root segments from which root hairs had been removed were essentially free from root hairs. Residual ice was removed from the root hairs by freeze drying and the root hairs were stored at $-70 \mathrm{C}$.

Epidermis isolation - The epidermis of roots of 4- and 5-day-old seedlings was stripped off from the root hair containing region with forceps \#5 (A. Dumont \& Fils, Switzerland). Care was taken not to include cortex material. Epidermis strips were randomly checked for purity by light microscopy. Pieces of epidermis were frozen immediately in liquid nitrogen and stored at -70C.

Production of deformation factor - Rhizobium leguminosarum bacteria were grown in minimal medium (Beringer, 1974) at $29 \mathrm{C}$ to an optical density of 1.0 at $600 \mathrm{~nm}$, and subsequently diluted with 10 volumes deposit free, nitrogen free Fahraeus medium (Vincent, 1970) containing 10 microM apigenin. The bacteria were cultured for an additional 48 hours at $29 \mathrm{C}$, and then they were centrifuged for 30 minutes at $20,000 \times$ g. The supernatant was passed through a 0.2 micrometer fitter to remove bacteria left behind. The supernatant which contains the deformation factor was tested on roots of Vicia sativa according to Bhuvaneswari and Solheim (1985). The presence of deformation factor induces within three hours characteristic tip swellings, lateral bulging, and branching of the 200-300 micrometer root hairs in a $2-5 \mathrm{~mm}$ zone from the tip of the root. Deformation factor was applied to pea seedlings by placing them in sealed pasteur pipettes filled with deformation factor preparation.

RNA isolation - Total RNA was extracted as described by Govers et al. (1985). Usually 500 plants were used to isolate root hairs and the yield of total root hair RNA was about 1 microgram per 100 plants. Contaminating polysaccharides were removed by heating RNA preparations for 5 minutes at $60 \mathrm{C}$ followed by centrifugation at $40,000 \times \mathrm{g}$ for 30 minutes. The supernatant contained the RNA which was then precipitated by addition of $1 / 3$ volume of $8 \mathrm{M} \mathrm{LiCl}$ and left overnight at $4 \mathrm{C}$. The RNA was collected by centrfugation $(15,000 \times g, 30$ minutes) and dissolved in sterile water to a final concentration of 4 microgram/microliter.

In vitro translation and 2-D gel electrophoresis - Two microgramg total RNA was in vitro translated in 6 microliter cell free rabbit reticulocyte lysate containing 5 microCi [ ${ }^{35} \mathrm{~S}$ ]-methionine for 60 
minutes at $30 \mathrm{C}$ (Pelham and Jackson, 1976). The amount of $\left[{ }^{35} \mathrm{~S}\right]$-methionine incorporated into protein was determined after precipitation of 1 microliter reaction mixture in $10 \%$ trichloroacetic acid on Whatmann 3MM filters (Pelham and Jackson, 1976). Addition of root hair RNA resulted in a 20-50 fold stimulation of $\left[{ }^{35} S\right]$-methionine incorporation compared to a control to which no RNA was added. In vitro translation products were separated by 2-D gel electrophoresis according to De Vries et al. (1982) and the gels were fluorographed to preflashed Kodak XAR-5 films.

Figure 5-9: Phase contrast photomicrograph of a root hair preparation isolated by freeze-fracturing. $(100 \mathrm{x})$.

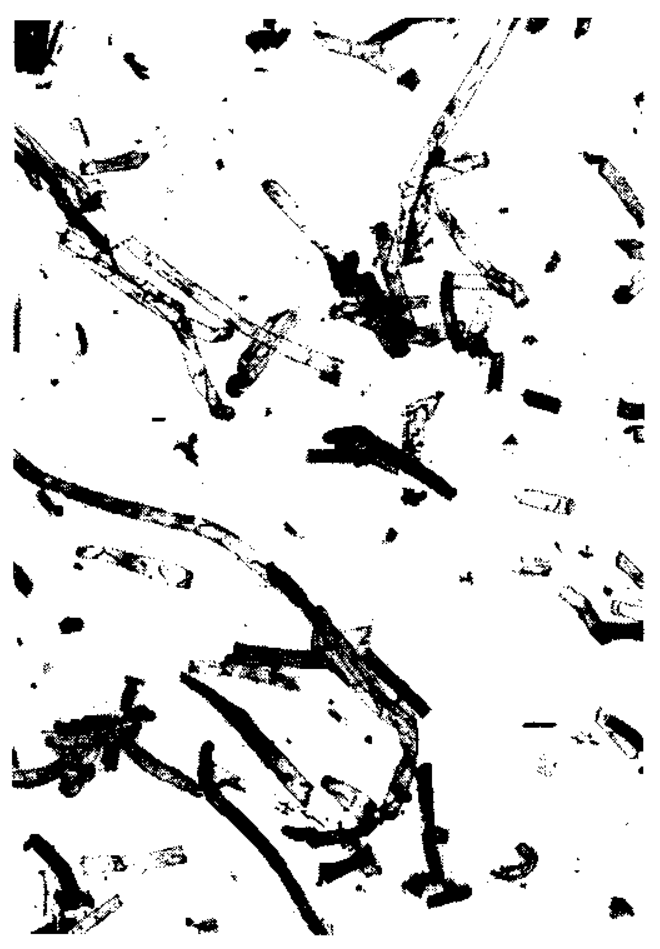




\section{CHAPTER VI}

\section{Plant Gene Expression in Early Stages}

\section{of Rhizobium-Legume Symbiosis \\ DISCUSSION}

Ton Gloudemans and Ton Bisseling. Plant Science, in press 


\subsection{Introduction}

The sequence of events leading to a mature nitrogen fixing nodule on the roots of leguminous plants starts with the interaction of rhizobia with root epidermis cells in the regions where root hairs are emerging (Bhuvaneswari et al., 1980; Bauer, 1981; Turgeon and Bauer, 1982). The bacteria attach to the root hair surface (Vincent, 1980) and in reaction the root hairs deform and curl in a short 360 turn, forming a so called shepherds crook, thereby entrapping the bacteria in a kind of pocket (Turgeon and Bauer, 1982 and 1985). The bacteria then enter the root hair by partly dissolving the cell wall (Callaham and Torrey, 1981; Ridge and Rolfe, 1985; Turgeon and Bauer, 1985). The host deposits new cell wall material at the site of infection forming a tubular structure, called the infection thread, which grows into the root hair. The infection thread with the bacteria inside grows towards the cortex (Bauer, 1981). In the infection thread the bacteria proliferate and become surrounded by mucopolysaccharides (Newcomb and Mcintyre, 1981). Independently of the infection process locally in the cortex cells dedifferentiate and meristematic centers are formed at several places within the cortex (Newcomb et al., 1979; Libbenga and Harkes, 1973). The infection threads grow into these meristems and ramify. Subsequently the bacteria are released into the cell cytoplasm (Basset et al., 1977), by a process resembling endocytosis, and become surrounded by a plant derived membrane, the peribacteroid membrane (Robertson et al., 1978). The bacteria continue to divide in the plant cells and finally the infected host cells are fully packed with bacteria that differentiate into nitrogen-fixing bacteroids (Robertson and Lyttleton, 1984). Part of the meristematic cells differentiate into cells that are positioned in between the infected cells in the central tissue of the nodule (Newcomb, 1981). These cells do not become infected and have supporting functions for example in assimilation and transport of fixed nitrogen from the infected cells. For a detailed description of nodule histology see the review by Newcomb et al. (1979).

Molecular studies on plant genes involved in root nodule formation are focussed on nodulin genes. Nodulin genes are genes only expressed in root nodules but not in uninfected roots, nor in any other plant tissue. The proteins encoded by these genes are called nodulins (Van Kammen, 1984). During nodule development nodulin genes are differentially expressed and, based upon the stage of nodule development when expression of nodulin genes starts, they have been divided into early and late nodulin genes (Govers et al., 1985; Gloudemans et al., 1987; Moerman et al., 1987; Dickstein et al., 1988; Norris et al., 1988). The expression of the majority of nodulin genes identified so far starts around the onset of nitrogen fixation. This class of nodulin genes is called late nodulin genes (Nap and Bisseling, 1988). A typical example of a late nodulin gene is leghemoglobin (Verma et al., 1979; Bisseling et al., 1980). Early nodulin genes become expressed during infection and nodule morphogenesis (Nap and Bisseling, 1988). Plant genes 
specifically expressed in the preinfection stage, i.e. the stage before an infection thread is formed (Vincent, 1980), can not be called nodulin genes by the original definition because they are not expressed in a nodule. However, since the specific expression of these genes is linked to root nodule formation, we suggest to name these genes also early nodulin genes.

In nodulin nomenclature a distinction is made based upon the method by which the corresponding nodulin gene has been identified. In general a nodulin is coded by the prefix $\mathrm{N}$ followed by the plant genus and species initials in lower case. If the protein the nodulin gene codes for is known, or the nodulin gene is identified via its polypeptide product, the code is followed by the molecular mass of the nodulin in $\mathrm{kDa}$. If the nodulin gene is only identified via cDNA clones, and the polypeptide product is not known, the nodulin is referred to as ENODx for early nodulins or NODx for late nodulins, where $x$ is an identification number of the cDNA clone.

In this review we will discuss the role of plant genes in the preinfection stage and the infection process, and during nodule morphogenesis. We will especially focus on the early nodulin genes. Furthermore the role of bacterial genes and signals involved in regulating the expression of these plant genes will be discussed.

\subsection{Plant genes involved in the Rhizobium-root hair interaction}

Within a few hours after inoculation with rhizobia more than $50 \%$ of the root hairs in the susceptible zone deform (Bhuvaneswari and Solheim, 1985) and $5-20 \%$ of the hairs form shepherds crooks (Dart, 1977; Nutman, 1959). Subsequently infection threads are formed in only $0.1-1 \%$ of the hairs (Nutman, 1959). The bacteria infect the roots via infection threads which always start in the root hairs and not in the body of the epidermis cells (Callaham and Torrey, 1981; Ridge and Rolfe, 1985). This suggests that the molecular composition of root hairs differs from that of the epidermis cell from which it is a cylindrical outgrowth. On the other hand it might also mean that the pocket formed by curling of the root hair into a shepherds crook is an essential element of the infection process. However, even if bacteria become entrapped in a pocket between a root hair and the body of the epidermis cell, the infection always takes place via the root hair rather than the body of the cell (Callaham and Torrey, 1981; Ridge and Rolfe, 1985) which indicates that the composition of the root hair cell wall is at least equally important for infection as the pocket.

To understand the preference of Rhizobium to start the infection in the hair it will be essential to understand the difference between root hairs and the body of the epidermis cell. So far the differences between root hairs and the body of the epidermis cells have not been studied. Only the composition of root tissue and 
root hairs have been compared at several levels. When the properties of root hairs were compared with those of root cells it was found that there were no qualitative differences in the carbohydrate composition between root hair cell walls and root cell walls, only the total amount of carbohydrate differed (Mort and Grover, 1988; Kape and Werner, 1988). An accumulation of metal ions in whole root hairs has been demonstrated by Werner et al. (1985a), but even when these differences would exist between the root hair and the body of the epidermal root hair cell none of these observations can explain the preference of Rhizobium to infect the hair and not the body of the epidermis cell.

The proteins of root hairs have been compared with total root protein preparations for soybean (Werner and Kuhlman, 1985; Gloudemans et al., 1988a), pea (Werner and Röh 1985; Gloudemans et al., 1988a), and clover (Gerhold et al., 1985) by one dimensional or two dimensional gel electrophoresis. In addition Gloudemans et al. (1988b) have studied the RNA populations of pea root and root hairs. In all these studies some 5 to 10 root hair proteins or RNAs were identified that were not detectable in total root RNA or protein preparations or were only present at much lower amounts. These proteins or RNAs will be named root hair specific (RH) proteins or mRNAs, respectively. The group of Werner (Röh and Werner, 1987) showed the occurrence of some RH-proteins on the outer surface of the plasmamembrane.

Root hairs are only susceptible to infection with Rhizobium during a specific stage of their development (Bhuvaneswari et al., 1981; Calvert et al., 1984). This suggests that during root hair development changes in molecular composition occur in root hairs. The presence of a group of acidic RH-proteins with an apparent molecular mass of $14 \mathrm{kDa}$ appeared to be correlated to the infectibility of root hairs in pea and soybean. If these proteins were present at high levels, the root hairs were infectible by (Brady)Rhizobium (Gloudemans et al., 1988a). In addition Gloudemans et al. (1988b) identified some genes that are expressed at different levels during root hair development. Although the correlation between the presence at high concentration of certain proteins in root hairs and the susceptibility of root hairs towards infection by (Brady)Rhizobium is striking, the function of these proteins remains unclear.

The involvement of plant genes, that are expressed in root hairs, in the Rhizobium-plant interaction has been studied both by classical genetic as well as by molecular approaches. Plant mutants unable to form nodules have been isolated for soybean (Williams and Lynch, 1954; Gresshoff et al., 1988), pea (Degenhardt et al., 1976; Jacobsen, 1984; Kneen and LaRue, 1984; Engvild, 1985; Messager, 1985; Postma et al., 1988), clover (Nutman, 1954 and 1969), and alfalfa (Peterson and Barnes, 1981). In some plant mutants the interaction of Rhizobium 
bacteria with root hairs is normal and the blocking of nodule formation occurs at an other step of the interaction, e.g. the ability to induce cell divisions (Jacobsen, 1984). Other plant mutants have lost the capacity to deform and curl root hairs as well as the ability to form infection threads (Gresshoff et al., 1988), whereas some mutants kept the ability to curl root hairs, but lost the capacity to form infection threads (Nutman, 1954; Postma et al., 1988). In theory these plant mutants are good tools to identify both induced and constitutively expressed genes involved in root hair-Rhizobium interaction. However, none of the genes mutated in plant Nod mutants has yet been isolated and so far studies on plant Nod mutants have not provided much information on the nature of the plant genes involved in the different aspects of Rhizobium-root hair interactions.

Recently it has proven possible to demonstrate changes in gene expression in root hairs as a result of the interaction with Rhizobium bacteria (Gloudemans et al., 1988b). In pea three genes with an altered level of expression in the interaction of Rhizobium with root hairs have been identified. One gene, encoding a root hair specific protein with an apparent molecular mass of $42 \mathrm{kDa}$ which was named $\mathrm{RH}-42$, is specifically expressed in root hairs and the expression of another gene, encoding $\mathrm{RH}-44$, is markedly enhanced in root hairs if pea seedlings are inoculated with Rhizobium (Gloudemans et al., 1988b). Both proteins, RH-42 and $\mathrm{RH}-44$, were detected by in vitro translation of root hair mRNA followed by two-dimensional gel electrophoresis of the translation products. The enhanced expression of the gene encoding RH-44 seemed to be related to deformation of root hairs (see section 6.5) while the expression of the gene encoding RH-42 might be associated with root hair curling. In both cases a causative relationship has, however, not been established. The third gene that is expressed in pea root hairs upon inoculation with Rhizobium is the gene coding for the PSENOD12 nodulin. Using CDNA clone pPsENOD12 as a probe, it was shown on RNA transfer blots of pea root hair RNA that the PsENOD12 gene is expressed in root hairs as a result of interaction with Rhizobium (B. Scheres, in prep). The PsENOD12 gene is expressed both in root hairs of inoculated plants as well as in young nodules of pea, both tissues containing infection threads. Neither in nodules nor in root hairs the PSENOD12 gene was expressed if infection threads are lacking. Therefore, the expression of the PsENOD12 gene seems to be correlated with infection thread formation. The amino acid sequence derived from the cDNA clone shows that the ENOD12 nodulin is a (hydroxy)proline-rich protein built up of two repeating pentapeptides containing two prolines each. The structure of this protein resembles some cell wall proteins like for example extensin (Chen and Varner, 1985a) and 1A10 (Averyhart-Fullard et al., 1988); see also section 6.3.1. Hence it seems plausible that the ENOD12 nodulin also is a cell wall component, that possibly forms part of the infection thread matrix. 
It has not been possible to assign a function to any of the proteins that are either uniquely synthesized or produced at larger amounts in root hairs after inoculation with Rhizobium. Therefore any discussion about their functions is speculative. Nodulin genes that are expressed in root nodules often encode proteins that have counterparts in non-symbiotic tissues; for example glutamine synthetase (Cullimore et al., 1983) and uricase (Legocki and Verma, 1979) are two enzymes involved in nitrogen assimilation which occur in root nodules in the form of nodule specific isozymes. The specific forms of these proteins are most likely adapted to the physiological conditions present in the root nodule and/or the corresponding genes are regulated in a different way. If that also holds for root hairs one might anticipate that the genes induced in root hairs by Rhizobium might encode similar proteins as are found elsewhere in the plant or in the absence of rhizobia. Proteins supposed to function in the infection process are hydrolytic enzymes like cellulase and pectinase (Verma and Long, 1983). These proteins have been shown to be produced by the plant upon inoculation with Rhizobium. Proteins involved in cell wall synthesis might also function in the infection process since infection threads are composed of plant cell wall material (Turgeon and Bauer, 1985). Also lectins, although their function is still unclear, have a role in the Rhizobium-plant interaction since a mutation in the Bradyrhizobium japonicum genome which causes a delayed nodulation on their host plant can be complemented with soybean lectin (Halverson and Stacey, 1986). Along the line that the genes specifically induced by Rhizobium in root hairs might encode proteins for which slightly different non-symbiotic counterparts exist, we speculate that possible functions might be: hydrolytic enzymes, proteins involved in cell wall synthesis or lectins, although the latter can be questioned since recently it has been shown in pea that the lectin gene family contains only one functional gene (Kaminski et al., 1987).

\subsection{Nodulins involved In nodule morphogenesis}

Upon inoculation of roots with Rhizobium, cells in the cortex of the root dedifferentiate independently from the infection process and start dividing, usually anticlinally, to form meristematic centers within the cortex (Libbenga and Harkes, 1973; Newcomb et al., 1979; Finan et al., 1985). What will be the nodule meristem is already formed before the infection thread reaches the cortex (Libbenga and Bogers, 1974; Calvert et al., 1984; Dudley et al., 1987). Bauer et al. (1985) made it clear that, without physical contact between bacteria and plant, anticlinal divisions can be induced in the outer cortex of soybean roots. This was later confirmed by Niehaus et al. (1988) who showed that Rhizobium meliloti separated by a membrane from alfalfa roots was still able to induce the formation of nodule structures. Both observations show that diffusible compounds are involved in the induction of meristems which develop into nodules. 
Based upon morphology, roughly two types of leguminous root nodules can be described: determinate and indeterminate nodules (Corby et al., 1983). In figure 6-1 a schematic drawing of the histology of an indeterminate nodule is presented (Sutton, 1983). From the outside of the nodule to the inside one encounters the cortex, which is divided into an inner and outer cortex separated by an endodermis. The cortex surrounds the nodule and in the inner cortex vascular bundles are located which go from the vascular strand in the root to the meristem. Separating the inner cortex from the central tissue are two cell layers composed of small uninfected cells; this tissue is termed the boundary layer (Gresshoff and Delves, 1986). In mature nodules the central tissue can be divided into distinct zones. At the apex a meristem is located, which is followed by the invasion zone composed of enlarging cells. In this zone the infection threads penetrate cells. Next, in the early symbiotic zone, bacteria are released from the infection thread and proliferate, and the differentiation into infected and uninfected cells becomes apparent. The late symbiotic zone consists of uninfected cells and cells fully packed with bacteria. In this zone nitrogen fixation and ammonia assimilation occurs. Closer to the root, plant cells and bacteroids degenerate; this zone is called senescent zone.

Figure 6-1: Overall organization of an indeterminate root nodule (modified after Sutton (1983).

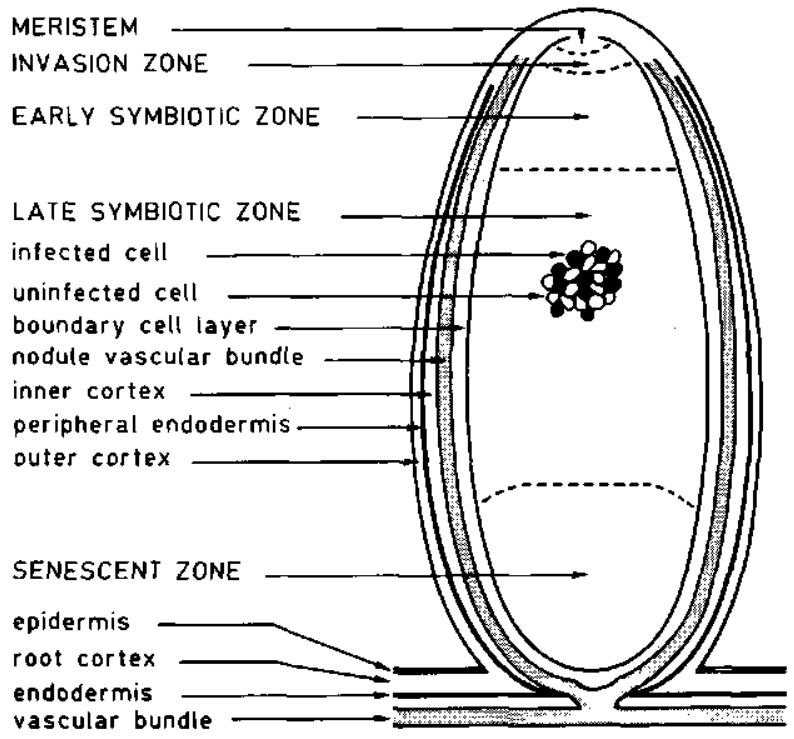


The histology of a determinate nodule is different; in such nodules the duration of meristematic activity is restricted and the meristem is not persistent (Newcomb et al., 1979). When bradyrhizobia are released from the infection thread, the infected cells continue to divide until one week after nitrogen fixation has started (Bieberdorf, 1938; Dart, 1977). As a consequence, not every infected cell in a determinate nodule is actually penetrated by an infection thread. After mitotic activity has ceased, increase in nodule size is achieved by cell enlargements. In the development of a determinate nodule the cells in the central tissue are progressing together through the same developmental stages. As a consequence, in determinate nodules the developmental stages are separated in time, while in indeterminate nodules they are separated in time as well as in space. The vascular bundle system in determinate nodules is closed, while in indeterminate nodules the vascular bundle system is open.

The organization and histology of a root nodule is quite different from a lateral root. A nodule does not form a root cap, the vascular bundles are located peripherically and not centrally, and the meristem originates from the root cortex and not from the pericycle of the root. For these reasons the nodule can be considered to be a unique organ, different from lateral roots (Libbenga and Bogers, 1974).

Nodule morphology is under control of the host plant. For a number of broad host range Rhizobium strains it has been demonstrated that they can induce determinate nodules on one host, indeterminate nodules on another, and can also nodulate the non-legume Parasponia (Dart, 1977; Trinick and Galbraith, 1987).

Classical genetic studies have revealed that plant genes are involved in nodule formation. There are genes involved in the initiation of meristem formation in the cortex. It has been found for a certain pea mutant that root hair reactions as hair curling and infection thread formation are not inhibited, while a meristem is not formed (Jacobsen, 1984). Other genes might be involved in later stages of development, since nodules formed on plants in which these genes are mutated have a characteristically altered structure or morphology. For a review concerning these plant genes see Nutman (1981) and Rolfe and Gresshoff (1988).

The plant genes related to root nodule morphogenesis that have been studied in greatest detail are the nodulin genes. These have been identified by in vitro translation of nodule mRNA followed by two-dimensional gel electrophoresis of the translation products and by CDNA cloning of nodule mRNA. In the next two sections the identification of early nodulins will be discussed and their relation to nodule morphogenesis (6.3.1), and the possible involvement of late nodulin genes in the differentiation into infected and uninfected cells (6.3.2). 


\subsubsection{Early nodulins involved in nodule morphogenesis}

By far the best studied early nodulin gene is the gene encoding the early nodulin Ngm-75 first identified in soybean (Gloudemans et al., 1987). Ngm-75 was identified on two-dimensional gels of the in vitro translation products from soybean nodule mRNA. From a cDNA library, prepared against soybean nodule mRNA, clone pGmENOD2 hybrid selected mRNAs encoding Ngm-75 (Franssen et al., 1987). Using this clone homologous ENOD2 mRNA was demonstrated to occur in pea (Govers et al., 1986), vetch (Moerman et al., 1987), bean (Padilla et al., 1988), alfalfa (Dickstein et al., 1988), sesbania (N. Chua, personal communication), clover and birdsfoot trefoil ( $F$. Govers, personal communication). The amino acid sequence of the ENOD2 protein derived from the nucleotide sequence of the soybean CDNA and genomic GmENOD2 clones revealed that this protein has an $\mathrm{N}$-terminal signal peptide followed by a sequence of two repeating elements: Pro-Pro-Glu-Tyr-Gln and Pro-Pro-His-Glu-Lys (Franssen et al., 1987 and in prep). The amino acid sequence of ENOD2 proteins from pea (C. Van de Wiel, in prep) and alfalfa (Dickstein et al., 1988) were also derived from the corresponding CDNA sequences and appeared to possess the same repeat units as soybean ENOD2. In table 6-1 the organization of the repeat units for the three ENOD2 proteins is summarized.

\begin{tabular}{|l|l|}
\hline soybean ENOD2 & $\begin{array}{l}\text { (-PPEYQ-PPHEK- In } \\
\text { pea ENOD2 }\end{array}$ \\
(-PPEYQ-PPHEK-PPHEK-)n \\
(-PPEYQ-PPHEK-PPXXX-)n
\end{tabular}

Table 6-1: Amino acid sequence of the repeat units from early nodulin ENOD2 from soybean, pea, and alfalfa derived from cDNA clones. The one-letter amino acid code is used; $P=$ Proline, $E=$ Glutamic acid, $Y=$ Tyrosine, $Q=$ Glutamine, $H=$ Histidine, $K=$ Lysine, $x=$ any amino acid. The sequence of the repeat units were determined for soybean by Franssen et al. (1987), for pea by $C$. Van de Wiel (in prep), and for alfalfa by Dickstein et al. (1988).

All three ENOD2 proteins have repeat units composed of Pro-Pro-Glu-Tyr-GIn and Pro-Pro-His-Glu-Lys. In soybean these two repeat units occur alternating, in pea one Pro-Pro-Glu-Tyr-Gln unit alternates with two Pro-Pro-His-Glu-Lys units consecutively. Alfalfa ENOD2 is like pea ENOD2 except that the second of the pair of Pro-Pro-His-Glu-Lys units is replaced by a unit consisting of two prolines followed by three random amino acids. So in the ENOD2 proteins from three different legume species the same repeat units occur which differ in the alternation 
of the units. This suggests that the ENOD2 genes have arisen from a common ancestor gene containing the two repeat units which have differently been duplicated in soybean, and pea and alfalfa.

It has been proposed that the ENOD2 nodulin might be a hydroxyproline-rich glycoprotein (HRGP), because in plants proline-rich proteins which are not hydroxylated and glycosilated have not been found (Franssen et al., 1987). In analogy with other HRGPs nodulin ENOD2 might be a cell wall protein like for example extensin. Strong support for this presumption is that recently a protein was isolated from cell walls of soybean suspension culture which has a repeat structure similar to the ENOD2 nodulin (Averyhart-Fullard et al., 1988); the amino acid sequence of this protein is built up of Pro-Pro-Val-Tyr-Lys repeat units and $50 \%$ of the prolines are modified into hydroxyprolines.

Studies with bacterial strains or mutants which are able to induce the formation of nodule structures but fail to infect the host plant, have revealed a possible function of nodulin ENOD2 in nodule morphogenesis. Rhizobium fredii USDA257 (Franssen et al., 1987) and Rhizobium meliloti exo" mutants (Dickstein et al., 1988) show this behavior in their hosts soybean and alfalfa, respectively. In nodules formed by both these strains on soybean and alfalfa respectively, the gene encoding ENOD2 is expressed. Therefore, it looks more likely that ENOD2 has a role in nodule morphogenesis than a function in the infection process. Such a role for nodulin ENOD2 in the differentiation process leading to a nodule tissue was further proven by in situ hybridization studies (C. Van de Wiel, in prep) in which it was shown that the ENOD2 gene was exclusively expressed in the inner cortex of soybean and pea nodules. Both in pea and soybean nodules ENOD2 mRNA was detectable as soon as meristem cells differentiate into inner cortical cells. Hence nodulin ENOD2 might directly be involved in creating and/or sustaining the specific properties of the inner cortical cell layer. Recently it was shown that the inner cortex of soybean nodules is part of an oxygen barrier which contributes to a low oxygen concentration in the inner nodule tissue (Witty et al., 1986). This oxygen barrier was proposed to be formed by dense packing of the cells. Since it is very likely that the cell wall structure is involved in cell packing, a role for the ENOD2 nodulin in creating or sustaining this oxygen barrier is conceivable.

Recently a second early nodulin, ENOD13, that might be involved in nodule morphogenesis has been described (Franssen et al., 1988 and chapter III). Only a part of the amino acid sequence could be determined from the sequence of the corresponding CDNA and this sequence shows that in principle nodulin ENOD13 has a structure very similar to ENOD2: the available sequence contains a recurring motif of two or three prolines followed by three other amino acids and like the ENOD2 protein nodulin ENOD13 has a high content in glutamine, lysine, and 
tyrosine. In nodule-like structures, devoid of infection threads and infected cells, formed on soybean roots by Rhizobium fredii USDA257 the GmENOD13 gene is expressed as the GmENOD2 gene. It remains to be established where in the nodule tissue the GmENOD13 gene is expressed. Since nodulin ENOD13 has a proline-rich repeat and probably occurs as a HRGP, it seems plausible that also ENOD13 is a cell wall protein.

For some HRGPs it has been proposed that they are involved in the plant defense mechanism (Cassab and Varner, 1988). The expression of the gene encoding the HRGP extensin was shown to be enhanced after attack of plants by several pathogens, however, in soybean nodules extensin genes are expressed at normal levels (T. Bisseling, unpublished data). In addition the production of phytoalexins, found to be enhanced in several plant defense reactions (Darvill and Albersheim, 1984), was not enhanced in soybean nodules (Werner et al., 1985b). This indicates that the soybean nodule might not be regarded as a defense response from the plant, and functions of early nodulins in plant defense are not likely. So probably the (hydroxy)proline-rich early nodulins are related to a group of HRGPs involved in developmental processes (Hong et al., 1987; Averyhart-Fullard et al., 1988). The question remains why the plant needs different cell wall proteins and why several early nodulins are cell wall proteins.

Besides the early nodulins containing similar proline repeats, a third early nodulin, GmENOD55, composed of an amino acid sequence with a different structure was identified (Franssen et al., 1988 and chapter III). The early nodulin ENOD55 contains in the central part of the polypeptide chain a stretch of 32 alternating proline and serine residues and the total amino acid composition does not resemble that of any of the known hydroxyproline-rich proteins. In contrast to the ENOD2 and ENOD13 gene the ENOD55 gene is not expressed in nodules in which bacteria are not released from the infection thread. This indicates that nodulin ENOD55 is not essential for formation of the nodule structure, but rather may be involved in infection processes or, alternatively, the gene is first expressed when the bacteria have been released from the infection thread into the cells.

By the method of in vitro translation of nodule mRNA followed by two-dimensional gel electrophoresis of the translation products for pea (Govers et al., 1985), soybean (Gloudemans et al., 1987), vetch (Moerman et al., 1987) and alfalfa (Dickstein et al., 1988; Norris et al., 1988) in each case $2-5$ early nodulins have been identified. Until now only for one early nodulin identified in this way the corresponding gene/cDNA has been cloned; this is the soybean early nodulin Ngm-75 encoded by the GmENOD2 gene isolated by Franssen et al. (1987 and in prep). The processes in which early nodulins identified via in vitro translation are involved are not yet determined. Based upon developmental timing of expression 
of early nodulin genes a correlation between the differentiation of nodule meristem and the presence of the early soybean nodulins Ngm-38 and Ngm-41 was suggested (Gloudemans et al., 1987). The expression of the gene encoding soybean nodulin Ngm-44 was correlated to the presence of a nodule meristem because this gene was expressed markedly before the GmENOD2 gene which was correlated to the differentiation of a nodule meristem. However, the data of Gloudemans et al. (1987) do not rule out the possibility that Ngm-44 is related to e.g. the infection process.

\subsubsection{Bacterial release and late nodulin gene expression}

Late nodulin gene expression starts after release of bacteria from the infection thread. However, immunocytological experiments showed that the leghemoglobin (Lb) genes are not immediately induced in the invaded cells of the nodule (Van de Wiel et al., 1988). There appears to be a gap in time between the release of the bacteria and the induction of late nodulin gene expression. This poses the question whether bacterial release per se is the sole signal for triggering late nodulin gene expression. Important tools to shed some light on this subject are bacterial mutants that arrest nodule development directly after release from the infection thread.

After release from the infection thread bacteria enter the cytoplasm of nodule cells in a process resembling endocytosis and become surrounded by a host derived membrane structure, called the peribacteroid membrane (PBM). Morrison and Verma (1987) have used Bradyrhizobium japonicum mutant T8-1 which is defective in the endocytosis process. Nodules formed by mutant T8-1 are almost completely devoid of intracellular bacteria, and the PBM is not formed. In these nodules late nodulin genes typically expressed in infected cells, e.g. leghemoglobin genes, and in uninfected cells, e.g. the n-uricase gene, are normally expressed. The genes encoding PBM nodulins were expressed at a very low level, except for the gene encoding PBM nodulin Ngm-26b, which was expressed at wildtype level. This distinction into two sets of PBM nodulin genes which are differentially regulated was also found by Werner et al. (1988) who used Bradyrhizobium japonicum mutant 2960 which induces nodules on soybean with abundant proliferation of PBM structures in the infected cells but only few bacteroids. In these nodules only half of the PBM nodulins found in wildtype nodules could be identified. Ramseier et al. (1988, and chapter IV) found with the same mutant that PBM nodulin transcripts of members of the small gene family encoding Ngm-23 and Ngm-42 (Nerma et al., 1986; Sengupta-Gopalan et al., 1986) were detectable. These data are not conflicting since the method Werner et al. (1988) used might not be sensitive enough to detect low amounts of PBM nodulins, while Ramseier et al. (1988) only tested a few PBM nodulins. 
In nodules induced by Bradyrhizobium japonicum mutant 3160 bacteria are occasionally released from the infection thread (Franssen et al., 1988). The uninfected cells appear to be normally developed, since n-uricase could be detected, while the infected cells appear to be affected since only a very low amount of Lb mRNA was found. Sengupta-Gopalan et al. (1986) and Gloudemans et al. (1987) used Bradyrhizobium japonicum mutant HS124 (Noel et al., 1982) that induces nodules on soybean in which bacteria are rarely released from the infection thread and in the few cells that become infected the bacteria and the PBM are in various stages of disintegration. Nodulins specific for infected cells were detected at very low levels; Lb gene expression, for example, was just above detection level, and the nodulins encoded by the small gene family of PBM nodulins (Verma et al., 1986) were also barely detectable. The nodulin n-uricase was detectable at low levels in these nodules.

In nodules induced by a Bradyrhizobium japonicum nifA mutant (Fischer et al., 1986) the bacteria are released from the infection thread, but proliferation of the bacteria does not occur. In these nodules the Lb genes were expressed at markedly lower levels while all other nodulin gene transcripts tested, including n-uricase and PBM nodulins, were found at nearly normal levels (Studer et al., 1987; chapter IV).

Nap et al. (1988) used Agrobacterium transconjugants which induced nodules on vetch in which some bacteria are released and become surrounded by a PBM. In that case only the early nodulin genes were expressed. Cytologically the uninfected cells appeared normal, but since no marker late nodulins have been identified yet for uninfected cells, it could not be concluded that the uninfected cells are really formed.

In alfalfa nodules induced by Rhizobium meliloti mutant Fix21 (Kieber et al., 1987) most infection threads are aborted (Norris et al., 1988). In some nodules infection does occur and the bacteria become surrounded by a PBM which degenerates rapidly. The early nodulins are present and also late nodulins are detectable in such nodules, albeit at a very low level. The expression of late nodulins is consistent with cytological observations which showed that the infected cells are formed in these nodules.

With few exceptions, it seems that if bacteria are released from the infection thread all nodulin genes become eventually expressed. Only in nodules induced by the Agrobacterium transconjugants Nap et al. (1988) used, the late nodulin genes are not expressed, although bacteria are released from the infection thread. However, this does not necessarily mean that the Agrobacterium transconjugant does not give the signal for induction of the late nodulin genes, but since the bacterium is 
rapidly degrading it might be the subject of a plant defense reaction (Van de Wiel et al., 1988; see also 6.4.2) and therefore nodule development might be arrested. The experiments with bacterial mutants that arrest nodule formation directly after release suggest that bacterial release is the step needed for induction of late nodulin gene expression in infected cells.

\subsection{Rhizobium genes involved in nodulin gene expression}

Rhizobium is essential for the induction of legume root nodules and certain mutated rhizobia are able to form nodules in which only part of the nodulin genes are expressed. This strongly points to factors encoded by the bacterial genome involved in the induction of expression of nodulin genes in the plant. In the following three sections the bacterial genes involved will be discussed.

\subsubsection{Nitrogen fixation genes}

A feasible mechanism for regulating late nodulin gene expression would be by the ammonia produced in the nitrogen fixation process. However, in nodules which do not fix nitrogen, formed by bacterial nif or fix mutants all nodulin genes appear to be expressed (Govers et al., 1985; Gloudemans et al., 1987). The level of expression of the late nodulin genes is influenced in nodules formed by bacterial nif and fix mutants. In soybean nodules formed by Bradyrhizobium japonicum mutant SM5 the concentration of late nodulin mRNAs is approximately $50 \%$ of the level found in wildtype nodules (Fuller and Verma, 1984). Quantifications of Studer et al. (1987) also showed that the level of several late nodulins in soybean nodules induced by Bradyrhizobium japonicum mutant $\mathrm{F} 4-6$, in which the nifDKEN genes were deleted, was slightly reduced.

In agreement with the practically normal expression of nodulin genes is the histology of these nodules. Most nodules induced by bacterial nif and fix mutants only show very small differences on a cytological level as compared to nodules induced by wildtype rhizobia (Hirsch et al., 1983; Hahn et al., 1984; Hirsch et al., 1987). The only exception is the nifA gene of Bradyrhizobium japonicum (Fischer et al., 1986). NifA has a role in regulation of expression of the other nif and fix genes, but in the Bradyrhizobium japonicum-soybean interaction also nodule development is influenced by the nifA gene. The Bradyrhizobium japonicum nifA mutant $A 9$ induces nodules on soybean in which release of the bacteria from the infection thread is normal, but proliferation of the bacteria thereafter does not occur (Studer et al., 1987). In these nodules all nodulin genes appear to be expressed and most of the late nodulin genes appear to be expressed at similar levels as in other Fix nodules. The amount of Lb protein, however, is less than $3 \%$ of that in the wildtype nodules. This drastic decrease is partly due to an effect on 
the transcriptional level, since the Lb mRNA level in these nodules is $10 \%$ of that in the wildtype nodule. On the other hand, the expression of the early nodulin gene GmENOD2 is not decreased at all. The dramatic effect of the Bradyrhizobium japonicum nifA mutation on accumulation of $L b$ suggests that the nifA gene product might be involved in the regulation of the level of expression of some late nodulin genes.

The conclusion can be drawn that nif and fix genes have only a "regulatory" role in late nodulin gene expression, rather than a role in induction of nodulin genes.

\subsubsection{Nodulation genes}

The nod genes are the genes in Rhizobium required for, or involved in nodulation of legume hosts (Long, 1984). In the genus Rhizobium these genes are located on a large plasmid, the Sym plasmid, while in the genus Bradyrhizobium the nod genes are located on the chromosome. Several nod genes have been identified in different Bradyrhizobium and Rhizobium species (Downie and Johnston, 1986). In all species there are nodDABC genes and these genes are interchangeable among the species (Kondorosi et al., 1984; Djordjevic et al., 1985). The nodDABC genes appear to be absolutely necessary for nodulation; mutations in each of these genes result in a Nod phenotype on the host. Mutations in the nod genes $E-J$ result in most cases only in delay of nodulation and/or reduced nodulation. Exception e.g. is a gene determining host-specificity in Rhizobium meliloti, nodH (Debellé et al., 1986) and $h s n D$ (Horvath et al., 1986). In the case of delayed and reduced nodulation still $\mathrm{Fix}^{+}$nodules are formed and presumably all nodulin genes are expressed in these nodules.

The nodDABC genes are thus the most likely candidates to be responsible for induction of the processes leading to nodulin gene expression. The nodDABC genes are organized in one operon and the nodD gene is transcribed separately in the opposite direction. The nodD gene is constitutively expressed and, in combination with flavonoids excreted by the roots of leguminous plants, the nod $D$ gene product is required for the induction of expression of all other nod genes (Rossen et al., 1985; Firmin et al., 1986; Peters et al., 1986; Redmond et al., 1986; Zaat et al., 1987). The nodD gene products of different rhizobia differ in responsiveness to flavonoids in a host specific manner (Horvath et al., 1987; Spaink et al., 1987). The flavone excreted by for example pea is better able to induce nod gene expression in Rhizobium leguminosarum than in Rhizobium meliloti.

The nodDABC genes are essential for the earliest steps in the developmental program leading to the formation of a nodule: root hair curling (Downie and 
Johnston, 1986; Jacobs et al., 1985), formation of an infection thread (Djordjevic et al., 1985; Debellé et al., 1986), and the induction of cortical cell divisions (Dudley et al., 1987). Recently Gloudemans et al. (1988b) showed that mutation of the nodD or nodC gene in Rhizobium leguminosarum abolished the ability of this Rhizobium to regulate the expression of root hair genes encoding $\mathrm{RH}-42$ and $\mathrm{RH}-44$ (see section 6.2). It has not yet been studied whether other nod genes are also involved in regulation of these plant genes.

Even the nod genes in an Agrobacterium chromosomal background are sufficient to induce nodule development on vetch and alfalfa (Nap et al., 1988). Both in alfalfa and vetch nodules formed by Agrobacterium carrying the nod genes, the early nodulins Nms-30 and MsENOD2, and Nvs-40 and VsENOD2 were present, respectively, but not the late nodulins. These observations strongly suggest that the nod genes are involved in the induction of early nodulin gene expression. If the nod genes were introduced into a cured Rhizobium leguminosarum strain nodule structures were formed on pea and vetch, in which all nodulin genes are expressed. This suggests that chromosomal, or non-Sym plasmid genes of Rhizobium are essential for the induction of expression of late nodulin genes. However, cytological observations suggest that nodule development arrests due to a plant defense response against Agrobacterium (Van de Wiel et al., 1988). If that is true, the expression of late nodulin genes need not be induced although genetic information present in the Agrobacterium transconjugant may be involved in late nodulin gene expression.

There is some indirect evidence that somehow the nod genes are involved in induction of late nodulin gene expression. Two Sym plasmid cured Rhizobium strains in which nod genes of different sources were introduced, induced nodules on vetch in which with one strain late nodulin genes were expressed, whereas with the other strain only the early nodulin genes were expressed. The exact nature of the difference in the introduced nod genes is not known, but since the chromosomal background is identical such observations imply that the nod genes can be involved in induction of late nodulin genes (Nap et al., 1988). Also complementation studies of Reddy et al. (1988) suggest a role for the nod genes in late nodulin gene expression. They showed that a Rhizobium meliloti nodA mutant which gives a Nod phenotype on alfalfa could be complemented by Frankia genes to elicit empty nodules on alfalfa. The histology of these nodules closely resembled that of empty nodules formed by the exo mutants of Rhizobium meliloti (see section 6.4.3 and Finan et al., 1985) and it can be expected that only early nodulin genes are expressed. This suggests a role for the nodA gene in late nodulin gene expression. Support for a role of nod genes in late stages of nodule development can further be found in the observations of Schmidt et al. (1986), who have shown that in Rhizobium meliloti bacteroids the nodA and nodC genes 
are transcribed. Moreover, it was shown by these authors that the nodC gene product is processed in bacteroids in a different way than in bacteria.

In summary, there is good evidence that the nodDABC genes are involved in the induction of the expression of early nodulin genes in the preinfection processes, i.e. before the formation of an infection thread, and in nodule organogenesis. Besides, a role of the nod genes in inducing the expression of late nodulin genes cannot be excluded. It remains unclear whether the bacterial chromosome has a role in late nodulin gene expression. In section 6.5 the possible signals from the rhizobia and the mechanism through which nodulin gene expression may be induced will be discussed.

\subsubsection{Surface determining genes}

Several compounds on the surface of Rhizobium bacteria appear essential for the interaction between bacteria and roots resulting in root nodule development. Rhizobia with mutations in the genes for the synthesis of exopolysaccharides (EPS) and lipopolysaccharides (LPS) form nodules that are arrested at certain stages of root nodule development.

In Rhizobium meliloti eight genes involved in EPS synthesis have been identified (Hynes et al., 1986; Djordjevic et al., 1987). These are the so called exo genes. Mutations in any of these genes resulted in nodules on alfalfa which were either completely devoid of infection threads and intracellular bacteria, or infection threads were formed but bacterial release was seldom observed (Leigh et al., 1987). in both kinds of exo- nodules two early nodulins, Nms-30 and MsENOD2, were found, but late nodulin gene products could not be detected (Dickstein et al., 1988). Rhizobium meliloti mutants deficient in EPS and mutants deficient in extracellular cyclic glucan production both formed empty nodule structures cytologically similar to the nodules induced by Agrobacterium supplied with cloned nod genes. In all such nodules only early nodulins Nms-30 and MsENOD2 were detectable, but no late nodulins (Dickstein et al., 1988). In our opinion the mutations do not affect the production of signals for late nodulin gene expression but it seems more plausible that nodule development is arrested in these cases due to a plant defense reaction induced by a different bacterial surface and not because of the lacking of a signal from the bacteria.

Genes involved in EPS synthesis seem not to be involved in inducing root hair specific genes (Gloudemans et al., 1988b). A Rhizobium leguminosarum exomutant in the gene pss1 (Borthakur et al., 1986) still induces curling of root hairs but an infection thread is not made. In root hairs from pea plants inoculated with this mutant the gene encoding $\mathrm{RH}-42$ was still expressed. 
Surface components like LPS and capsular EPS have been shown to affect nodule development of several legume species on a morphological level (Noel et al., 1986; Gardiol et al., 1987; Puvanesarajah et al., 1987), but in all these studies the effect on nodulin gene expression has not been examined.

\subsection{Bacterial signals involved in plant gene expression}

The experiments reviewed in the previous sections prove that the nod genes are involved in interactions at several levels of the legume-Rhizobium symbiosis. Certain mutations in the nod genes abolish the ability of Rhizobium to deform and curl root hairs, and to induce the expression of certain plant genes in root hairs (see section 6.4.2). Such nod mutants have also lost the ability to induce cortical cell divisions as well as infection thread formation. Besides, Agrobacterium transconjugants provided with Rhizobium nod genes gain the ability to form nodules on leguminous plants in which early nodulin genes are expressed. These different observations point to a role of the nod genes in the production of signals to induce the developmental program leading to nodule formation. In contrast, evidence for the involvement of other bacterial genes in eliciting a certain step of the developmental program of nodule formation is not strong. It may be more difficult to obtain such indications because mutations in these genes seem to lead to defense responses in the plant (Rolfe and Gresshoff, 1988; Nap and Bisseling, 1988) by which the developmental program is arrested. Only for the exopolysaccharides it has been shown in one experiment that they might have a role in inducing plant genes at a defined stage of nodule development. Djordjevic et al. (1987) showed that Rhizobium EPS mutants, which form small Fix nodules on Leucaena, siratro or clover can be complemented at the time of inoculation by addition of an oligosaccharide repeat unit isolated from EPS of the parent Rhizobium strain. After complementation they produce large pigmented Fix ${ }^{+}$ nodules resembling wildtype nodules. This suggests that an oligosaccharide is involved in eliciting a step in nodule development although it is unclear in which stage exactly EPS is involved.

As to the mechanism by which the nod genes induce the different aspects of plant-Rhizobium interactions we are still in the dark. The nodD gene product, in cooperation with a flavone excreted by the plant root, stimulates the synthesis of the products of the other nod genes in Rhizobium (Downie and Johnston, 1986). Rhizobium cultures in which the nod genes are expressed, either by addition of an artificial flavone or by addition of root exudate, excrete in the medium a factor that is able to induce deformations and branching of root hairs and/or the formation of thick short roots on vetch. The factor(s) produced by the rhizobia are named deformation factor (DF) or branching factor (BF) (Bhuvaneswari and Solheim, 1985), and thick short root (TSR) factor (Van Brussel et al., 1986). DF might be 
different from the TSR factor, since the TSR phenomenon is only observed if Rhizobium nod genes are induced with high concentrations of flavones, whereas deformation and branching are also observed if low doses of inducer are added to the Rhizobium culture (Zaat et al., 1987a).

In Rhizobium leguminosarum the nodD and nodABC genes are required for production of (a) factor(s) able to deform root hairs and induce the TSR phenomenon (Van Brussel et al., 1986). In Rhizobium meliloti, however, in addition to the nodDABC genes, also the nodH gene is necessary (Faucher et al., 1988). If nodH is present the factor that is produced can deform only alfalfa root hairs but if the nodH gene in Rhizobium meliloti is mutated the factor that is then produced deforms no longer root hairs of its original host alfalfa, but it deforms root hairs on vetch. This suggests that the nodABC genes are involved in producing a factor, which is then modified by other nod genes. So far attempts to purify the factor have been unsuccessful; the only thing known is that the factor must be of low molecular weight and is diffusible (Bhuvaneswari and Solheim, 1985). Studies of John et al. (1988) show that the nodA and nodB genes of Rhizobium meliloti are indeed involved in the synthesis of low molecular weight factors that induce cell divisions of soybean protoplasts.

Since macroscopic reactions of deformation factor on root hairs occur, one might wonder if there is an effect as well on gene expression in root hairs by DF. Gloudemans et al. (1988b) have shown that the nod genes which are thought to be responsible for the production of DF are essential for the induction and enhancement of expression of the $\mathrm{RH}-42$ and $\mathrm{RH}-44$ genes in root hairs. They also studied whether DF is able to induce expression of these plant genes. They showed that the expression of the RH-44 gene was markedly enhanced when a culture medium with DF activity, free of bacteria, was added to pea plants. The RH-42 gene was not induced when DF was applied to pea seedlings. This suggests that for induction of RH-42 gene expression other factors made by Rhizobium are necessary, or that as for root hair curling (Bhuvaneswari, 1984) the physical presence of Rhizobium is essential.

Effects of deformation factor on cortical cell divisions have not been studied yet, but when factors produced by Rhizobium meliloti nod genes are added to soybean protoplasts, they divide (John et al., 1988), which suggests that the bacteria produce diffusible factors that can induce cell divisions. Experiments of Bauer et al. (1985) with Bradyrhizobium japonicum and Niehaus et al. (1988) with Rhizobium meliloti showed that if the bacteria were separated from the root by a membrane, cortical cell divisions were induced in soybean and even nodule structures were formed in alfalfa, respectively. These observations show clearly that Rhizobium produces diffusible factors that elicit nodule formation; the factor 
might be DF, as it is also diffusible, but conclusive evidence is lacking and therefore there might be still other factors required for eliciting nodule formation.

Another source for factors eliciting nodule development are phytohormones since cell divisions could be initiated in the cortex of pea root explants by exogenously applied auxin and cytokinin (Libbenga and Bogers, 1974). The involvement of phytohormones in nodule formation is further suggested by the fact that Rhizobium bacteria are able to produce auxins, cytokinins, and gibberellins (for review see Verma and Nadler, 1984). Allen et al. (1953) observed on the roots of leguminous plants the formation of nodule-like structures, or pseudonodules, in response to treatment with inhibitors of auxin transport. These pseudonodules resemble closely nodules induced by Rhizobium meliloti exo' mutants (Finan et al., 1985) except for vascular differentiation which does not proceed into the distal part of the structure. A. Hirsch (in prep) used the early nodulins ENOD2 and Nms-30 as molecular probes to determine whether the nodule like structures induced by auxin transport inhibitors resemble root nodules induced by Rhizobium also on a molecular level. She used the auxin transport inhibitors 2,3,5-triiodobenzoic acid (TIBA) and N-1-naphthylphthalamic acid (NPA) to induce nodule-like structures on roots of alfalfa and found that in such structures the genes encoding the early nodulins ENOD2 and Nms-30 were expressed, but not the late nodulin genes. Therefore, the pseudonodules induced by auxin transport inhibitors do not only resemble the Rhizobium meliloti exo- induced nodules in a histological way, but also on the molecular level with respect to genes expressed in the nodule structure.

For the first time it has thus been shown that a compound with a known structure and activity is able to elicit nodule-like structures in which nodulin genes become expressed. This system can become an important tool to shed light on the mechanism of the induction of nodule formation. It certainly can not be concluded that the bacterial factor eliciting nodule formation is an auxin transport inhibitor, but it is feasible that factors produced by Rhizobium, dependent on expression of Rhizobium nod genes are in one way or another able to bring about a local disturbance of the phytohormone balance in the root. Some support for involvement of the phytohormone balance in nodule formation comes from experiments of $\mathrm{J}$. Cooper (in prep), who showed that a Rhizobium meliloti nodA mutant which lost the ability to form nodules on alfalfa regains this upon introduction of a cytokinin gene from Agrobacterium tumefaciens in the Rhizobium mutant. Isolation and characterization of the factor(s) made by Rhizobium eliciting nodule formation must now be the next step in clarifying the mechanism of the eliciting of nodule formation. 
From the data available now it can be concluded that upon reception of a plant signal, a flavonoid-like molecule, Rhizobium nod genes become expressed. These nod genes are involved in the production and modification of diffusible factor(s), which, on the one hand are able to induce processes taking place in the root hair (deformation and enhancement of RH-44 gene expression), and on the other hand disturb the root phytohormone balance resulting in the formation of a nodule structure. These factor(s) might not be the same and it can not be excluded that Rhizobium excretes a scala of related molecules having distinct effects on root hairs and roots. The diffusible factor(s) produced by the bacteria are by themselves not sufficient to induce all processes, since the RH-42 gene is not expressed in root hairs treated with these factor(s). As for curling of root hairs, the physical presence of bacteria seems to be required, and it may therefore be suggested that diffusible factor(s) from Rhizobium prepare the formation of a nodule structure and the root hair for infection while the physical presence or attachment of Rhizobium is essential for the chain of events leading to infection. 
References 


\section{References}

Allen, A.K., Desai, N.N., Neuberger, A., and Creeth, J.M. (1978). Properties of potato lectin and the nature of its glycoprotein linkages. Biochem. J. 171, 665-674.

Allen, E.K., Allen, O.N., and Newman, A.S. (1953). Pseudonodulation of leguminous plants induced by 2-bromo-3,5-dichlorobenzoic acid. Am. J. Bot. 40, 429-435.

Appleby, C.A. (1984). Leghemoglobin and Rhizobium respiration. Annu. Rev. Plant Physiol. 35, 443-478.

Appleby, C.A., and Bergersen, F.J. (1980). Preparation and experimental use of leghemoglobin. In: Bergersen, F.J. (ed.) Methods for evaluating biological nitrogen fixation. Wiley, Chichester, pp 315-335.

Auger, S., Baulcombe, D., and Verma, D.P.S. (1979). Sequence complexities of the poly(A)-containing mRNA in uninfected soybean root and the nodule tissue developed due to the infection by Rhizobium. Biochem. Biophys. Acta 563, 496-507.

Averyhart-Fullard, V., Datta, K., and Marcus, A. (1988). A hydroxyproline-rich protein in the soybean cell wall. Proc. Natt. Acad. Sci. USA 85, 1083-1085.

Avissar, Y.J., and Nadler, K.D. (1978). Stimulation of tetrapyrrole formation in Rhizobium japonicum by restricted aeration. J. Bacteriol. 135, 782-789.

Basset, B., Goodman, R.N., and Novacky, A. (1977). Ultrastructure of soybean nodules. Release of rhizobla from the infection thread. Can. J. Microbiol. 23, 573-582.

Bauer, W.D. (1981). Infection of legumes by rhizobia. Ann. Rev. Plant Physiol. 32, 407-449.

Bauer, W.D., Bhuvaneswari, T.V., Calvert, H.E., Law, I.J., Malik, N.S.A., and Vesper, S.J. (1985). Recognition and infection by slow-growing rhizobia. In: Evans, H.J., Bottomley, P.J., and Newton, W.E. (Eds.) Nitrogen fixation research progress. Martinus Nijhoff publishers, Dordrecht pp. 247-253.

Berg, D.E., Schmandt, M.A., and Lowe, J.B. (1983). Specificity of transpason Tn5 insertion. Genetics 105, 813-828.

Beringer, J.E. (1974). R factor transfer in Rhizobium leguminosarum. J. Gen. Microbiol. 84, 188-198.

Beyerinck, M.W. (1888). Die Bacterien der Papilionaceae-Knöllchen. Bot. Zeitung 46-50, 725-804. 
Bhuvaneswari, T.V., Turgeon, B.G., and Bauer, W.D. (1980). Early events in the infection of soybean (Glycine max L. Merr) by Rhizobium japonicum. I. Localization of infectible root cells. Plant Physiol. 66, 1027-1031.

Bhuvaneswari, T.V., Bhagwat, A.A., and Bauer, W.D. (1981). Transient susceptibility of root cells in four common legumes to nodulation by rhizobia. Plant Physiol. 68, 1144-1149.

Bhuvaneswari, T.V. (1984). Preinvasion events in legume/Rhizobium symblosis. In: Veeger, C., and Newton, W.E. (Eds.) Advances in nitrogen fixation research. Nijhoff/Junk publishers, The Hague pp. 389-396.

Bhuvaneswari, T.V., and Solheim, B. (1985). Root hair deformation in the white clover/Rhizobium trifolii symbiosis. Physiol. Plant. 63, 25-34.

Bieberdort, F.W. (1938). The cytology and histology of the root nodules of some leguminosae. J. Am. Soc. Agron. 30, 375-389.

Biggin, M.D., Gibson, T.J., and Hong, G.F. (1983). Buffer gradient gels and [ ${ }^{35}$ S] label as an aid to rapid DNA sequence determination. Proc. Natl. Acad. Sci. USA 80, 3963-3965.

Bimboim, H.C. (1983). A rapid alkaline extraction method for the isolation of plasmid DNA. Methods Enzymol. 100, 243-255.

Bisseling, T., van den Bos, R.C., and van Kammen, A. (1978). The effect of ammonium nitrate on the synthesis of nitrogenase and the concentration of leghaemoglobin in pea root nodules induced by Rhizobium leguminosarum. Biochem. Biophys. Acta 539, 1-11.

Bisseling, T., Moen, L.L., Van den Bos, R.C., and Van Kammen, A. (1980). The sequence of appearance of leghaemoglobin and nitrogenase components I and II in root nodules of Pisum satwum. J. Gen. Microblol. 118, 377-381.

Borthakur, D., Barber, C.E., Lamb, J.W., Daniels, M.J., Downie, J., and Johnston, A.W.B. (1986). A mutation that blocks exopolysaccharide synthesis prevents nodulation of peas by Rhizobium leguminosarum but not of beans by $R$. phaseoli and is corrected by cloned genes from Rhizobium or the phytopathogen Xanthomonas. Mol. Gen. Genet. 203, 320-323.

Bradford, M.M. (1976). A rapid and sensitive method for the quantitation of microgram quantities of protein using the principle of protein-dye binding. Anal. Biochem. 72, 248-254.

Callaham, D.A., and Torrey, J.G. (1981). The structural basis for infection of root hairs of Trifolium repens by Rhizobium. Can. J. Bot. 59, 1647-1664.

Calvert, H.E., Pence, M.K., Pierce, M., Malik, N.S.A., and Bauer, W.D. (1984). Anatomical analysis of the development and distribution of Rhizobium infections in soybean roots. Can. J. Bot. 62, 2375-2384. 
Cantrell, M.A., Haugland, R.A., and Evans, H.J. (1983). Construction of a Rhizobium japonicum gene bank and use in isolation of a hydrogen uptake gene. Proc. Natl. Acad. Sci. USA 80, 181-185.

Cassab, G.I. (1986). Arabinogalactan proteins during the development of soybean root nodules. Planta 168, 441-446.

Cassab, G.I., and Varner, J.E. (1988). Cell wall proteins. Ann. Rev. Plant Physiol. Plant Mol. Biol. $39,321-353$.

Chen, J., and Varner, J.E. (1985a). An extracellular matrix protein in plants: characterization of a genomic clone for carrot extensin. EMBO J. 4, 2145-2151.

Chen, J., and Varner, J.E. (1985b). Isolation and characterization of cDNA clones for carrot extensin and a proline-rich 33 kDa protein. Proc. Natl. Acad. Sci. USA 82, 4399-4403.

Chriapeels, M.J., Sadava, D., and Cho, Y.P. (1974). Enhancement of extensin biosynthesis in ageing disks of carrot storage tissue. J. Exp. Bot. 25, 1157-1166.

Church, G.M., and Gilbert, W. (1984). Genomic sequencing. Proc. Natl. Acad. Sci. USA 81, 1991-1995.

Cole, M.A., and Elkan, G.H. (1973). Transmissible resistance to penicillin G, neomycin and chloramphenicol in Rhizobium japonicum. Antimicrob. Agents \& Chemother. 4, 248-253.

Cooper, J.B., and Varner, J.E. (1983). Insolubilization of hydroxyproline-rich cell wall glycoprotein in aerated carrot root slices. Blochem. Biophys. Res. Commun. 112, 161-167.

Cooper, J.B. (1984). Hydroxyproline synthesis is required for cell wall regeneration. In: Dugger, W.M., and Bartnicki-Garcia, S. (Eds.) Structure and biosynthesis of plant cell walls. Am. Soc. Plant Physiol., Waverly Press, Baltimore, pp. 397-399.

Corby, H.D.L., Polhill, R.M., and Sprent, J.I. (1983). Taxonomy. In: Nitrogen Fixation, vol 3: Legumes. Broughton, W.J. (Ed.) Clarendon Press, Oxford pp. 1-35.

Cullimore, J.V., Lara, M., Lea, P.J., and Miflin, B.J. (1983) Purification and properties of two forms of glutamine synthetase from the plant fraction of Phaseolus root nodules. Planta 157, 245-253.

Cullimore, J.V., and Miflin, B.J. (1984). Immunological studies on glutamine synthetase using antiserum raised against the two plant forms of the enzyme from Phaseolus root nodules. J. Exp. Bot. 35, 581-587.

Daniel, R.M., and Appleby, C.A. (1972). Anaerobic nitrate, symbiotic and aerobic growth of Ahizobium japonicum: effects on cytochrome $\mathrm{P}_{450}$, other haemoproteins, nitrate and nitrite reductase. Biochim. Biophys. Acta 275, 347-354. 
Dart P.J. (1977). Infection and development of leguminous root nodules. In: Hardy, R.N.F., and Silver, W.S. (Eds.) A treatise on Dinitrogen Fixation, Sect. III, Biology. John Wiley and Sons, New York pp. 367-472.

Darvill, A.G., and Albersheim, P. (1984). Phytoalexins and their elicitors - a defense against microbial infection in plants. Ann. Rev. Plant Physiol. 35, 243-275.

Dazzo, F.B., Hollingsworth, R.I., Philip, S., Smith, K.B., Welsch, M.A., Salzwedel, J., Morris, P., and McLaughlin, L. (1987). Involvement of pSym nodulation genes in production of surface and extracellular components of Rhizobium trifolii which interact with white clover root hairs. In: Verma, D.P.S., and Brisson, N. (Eds.) Molecular Genetics of Plant-Microbe Interactions. Martinus Nijhoff publishers, Dordrecht, pp. 171-172.

Debelle, F., Rosenberg, C., Vasse, J., Maillet, F., Martin6́z, E., Dénarí,, J., and Truchet, G. (1986). Assignment of symbiotic developmental phenotypes to common and specific nodulation (nod) genetic loci of Rhizobium meliloti. J. Bacteriol. 168, 1075-1086.

Degenhardt, T.L., LaRue, T.A., and Paul, E.A. (1976). Investigation of a non-nodulating cultivar of Pisum sativum. Can. J. Bot. 54, 1633-1636.

De Vries, S.C., Springer, J., and Wessels, J.G.H. (1982). Diversity of abundant mANA sequences and patterns of protein synthesis in etiolated and greened pea seedlings. Planta 156, 129-135.

Dickstein, R., Bisseling, T., Reinhold, V.N., and Ausubel, F.M. (1988). Expression of nodule-specific genes in alfalfa root nodules blocked at an earty stage of nodule development. Genes and Development 2, 677-687.

Djondjevic, M.A., Schofield, P.R., Ridge, R.W., Morrison, N.A., Bassam, B.J., Plazinski, J., Watson, J.M., and Rolfe, B.G. (1985). Rhizobium nodulation genes involved in root hair curling (Hac) are functionally conserved. Plant Mol. Biol. 4, 147-160.

Djordjevic, S.P., Chen, H., Batley, M., Redmond, J.W., and Rolfe, B.G. (1987). Nitrogen fixation ability of exopolysaccharide synthesis mutants of Rhizobium sp. strain NGR234 and Rhizobium trifolii is restored by the addition of homologous exopolysaccharides. J. Bacteriol. 169, 53-60.

Downie, J.A., Hombrecher, G., Ma, Q.-S., Knight, C.D., Wells, B., and Johnston, A.W.B. (1983). Cloned nodulation genes of Rhizobium leguminosarum determine host-range specificity. Md. Gen. Genet. 180, 359-365.

Downie, J.A., and Johnaton, A.W.B. (1986). Nodulation of legumes by Rhizobium: The recognized root? Cell 47, 153-154.

Dudley, M.E., Jacobs, T.W., and Long, S.R. (1987). Microscopic studies of cell divisions induced in alfalfa roots by Rhizobium meliloti. Planta 171, 289-301. 
Ebeling, S., Hahn, M., Fischer, H.-M., and Hennecke, H. (1987). Identification of nifE-, nifN-, and nifS-like genes in Bradyrhizobium japonicum. Mol. Gen. Genet. 207, 503-508.

El Mokadem, M.T., and Keister, D.L. (1982). Electron transport in Rhizoblum japonicum: isolation of cytochrome c deficient mutants. Isr. J. Botany 31, 102-111.

Engvild, K.C. (1985). Nitrogen fixation mutants of pea. In: Marcellin, R. (Ed.) Analysis of the plant gene involved in the legume-Rhizobium symbiosis. OECD, Paris p. 49.

Faucher, C., Maillet, F., Vasse, J., Rosenberg, C., Camut, S., Van Brussel, A.A.N., Dénarie, J., and Truchet, G. (1988). Evilence that the Rhizobium meliloti nodH gene determines host specificity via an extracelludar symbiotic signal. In: Palacios, R. (Ed.) Proceedings of the $4^{\text {th }}$ international symposium on molecular genetics of plant microbe interactions, Acapulco, Mexico. In press.

Finan, T.M., Hirsch, A.M., Leigh, J.A., Johansen, E., Kuldau, G.A., Deegan, S., Walker, G.C., and Signer, E.R. (1985). Symbiotic mutants of Rhizobium meliloti that uncouple plant from bacterial differentiation Cell 40, 869-877.

Firmin, J.L., Wilson, K.E., Rossen, L. and Johnston, A.W.B. (1986). Flavonoid activation of nodulation genes in Rhizobium reversed by other compounds present in plants. Nature 324, 90-92.

Fischer, H.-M., Alvarez-Morales, A., and Hennecke, H. (1986). The pleiotropic nature of symbiotic regulatory mutants: Bradyrhizobium japonicum nitA gene is involved in control of nif gene expression and formation of determinate symbiosis. EMBO J. 5, 1165-1173.

Fischer, H.-M., and Hennecke, H. (1987). Direct response of Bradyrhizobium japonicum nifA-mediated nif gene regulation to cellular oxygen status. Mol. Gen. Genet. 209, 621-626.

Fortin, M.G., Morrison, N.A., and Verma, D.P.S. (1987). Nodulin-26, a peribacteroid membrane nodulin is expressed independently of the development of the peribacteroid compartment. Nucl. Acids Res. 15, 813-824.

Franssen, H.J., Nap, J.P., Gloudemans, T., Stiekema, W., Van Dam, H., Govers, F., Louwerse, J., Van Kammen, A., and Bisseling, T. (1987). Characterization of cDNA for nodulin-75 of soybean: a gene product involved in early stages of root nodule development. Proc. Natl. Acad. Sci. USA 84, 4495-4499.

Franssen, H.J., Scheres, B., Van de Wiel, C., and Bisseling, T. (1988). Characterization of soybean (hydroxy)proline-rich proteins. In: Palacios, R. (Ed.) Proceedings of the $4^{\text {th }}$ international symposium on molecular genetics of plant microbe interactions, Acapulco, Mexico. In press.

Freytag, J.W., Noelken, M.E., and Hudson, B.G. (1979). Physical properties of collagen-sodiumdodecyl sulphate complexes. Biochemistry 18, 4761-4768. 
Friedman, A.M., Long, S.R., Brown, S.E., Buikema, W.J., and Ausubel, F.M. (1982). Construction of a broad host-range cosmid cloning vector and its use in the genetic analysis of Rhizobium mutants. Gene 18, 289-296.

Fuhrmann, M., and Hennecke, H. (1982). Coding properties of cloned nitrogenase structural genes. Mol. Gen. Genet. 187, 419-425.

Fuller, F., Künstner, P.W., Nguyen, T., and Verma, D.P.S. (1983). Soybean nodulin genes: analysis of cDNA clones reveals several major tissue-specific sequences in nitrogen-fixing root nodules. Proc. Natt. Acad. Sci. USA 80, 2594-2598.

Fuller, F., and Verma, D.P.S. (1984). Appearance and accumulation of nodulin mPNAs and their relationship to the effectiveness of root nodules. Plant Mol. Biol. 3, 21-28.

Gardiol, A.E., Hollingsworth, R.P., and Dazzo, F.B. (1987). Alteration of surface properties in a Tn5 mutant strain of Rhizobium trifolii. J. Bacteriol. 169, 1161-1167.

Gerhold, D.L., Dazzo, F.B., and Gresshoff, P.M. (1985). Selective removal of seedling root hairs for studies of the Rhizobium-legume symbiosis. J. Microbiol. Meth. 4, 95-102.

Gloudemans, T., De Vries, S.C., Bussink, H.J., Malik, N.S.A., Franssen, H.J., Louwerse, J., and Bisseling, T. (1987). Nodulin gene expression during soybean (Glycine max) nodule development. Plant Mol. Biol. 8, 395-403.

Gloudemans, T., Moerman, M., Van Beckum, J., Gundersen, J., Van Kammen, A., and Bisseling, T. (1988a). Identification of plant genes involved in the Rhizobium leguminosarum-pea root hair interaction. In: Bothe, H., de Bruyn, F.J., and Newton, W.E. (Eds.) Nitrogen flxation: Hundred years after. Gustav Fischer Verlag, Stuttgart pp. 611-616.

Gloudemans, T., Bhuvaneswari, T.V., Moerman, M., Van Brussel, A.A.N., Van Kammen, A., and Bisseling, T. (1988b). Involvement of Rhizobium leguminosarum nodulation genes on gene expression in pea root hairs. Plant Mol. Biod., in press.

Govers, F., Gloudemans, T., Moerman, M., Van Kammen, A., and Bisseling, T. (1985). Expression of plant genes during the development of pea root nodules. EMBO J. 4, 861-867.

Govers, F., Moerman, M., Downie, J.A., Hooykass, P., Franssen, H.J., Louwerse, J., Van Kammen, A., and Bisseling, T. (1986). Rhizobium nod genes are involved in inducing an early nodulin gene. Nature $323,564-566$.

Gresshoff, P.M., and Delves, A.C. (1986). Plant genetic approaches to symbiotic nodulation and nitrogen flxation in legumes. In: Blonstein, A.D., and King, P.J. (Eds.) A Genetic Approach to Plant Biochemistry. Springer-Verlag pp. 159-206. 
Gresshoff, P.M., Mathews, A., Krotzky, A., Olsson, J.E., Carrol, B.J., Delves, A.C., Kosslak, R., Appelbaum, E.R., and Day, D.A. (1988). Supernodulation and non-nodulating mutants of soybean. In: Palacios, R. (Ed.) Proceedings of the $4^{\text {th }}$ international symposium on molecular genetics of plant microbe interactions, Acapulco, Mexico. In press.

Gubler, M., and Hennecke, H. (1986). FixA, B, and C genes are essential for symbiotic and free-living, microaerobic nitrogen fixation. FEBS. Lett. 200, 186-192.

Hahn, M., and Hennecke, H. (1984). Localized mutagenesis in Rhizobium japonicum. Mol. Gen. Genet. 193, 46-52.

Hahn, M., Meyer, L., Studer, D., Regensburger, B., and Hennecke, H. (1984). Insertion and deletion mutants within the nif-region of Rhizobium japonicum. Plant Molec. Biol. 3, 159-168.

Hahn, M., and Hennecke, H. (1988). Cloning and mapping of a novel nodulation region from Bradyrhizobium japonicum by genetic complementation of a deletion mutant. Appl. Environ. Microbiol. 54, 55-61.

Halverson, LJ., and Stacey, G. (1986). Signal exchange in plant-microbe interactions. Microbiol. Rev. 50, 193-225.

Hammerschmidt, R., Lamport, D.T.A., and Muldoon, E.P. (1984). Cell wall hydroxyproline enhancement and lignin deposition as an early event in the resistance of cucumber to Cladosporium cucumerinum. Physid. Plant Pathol. 24, 43-47.

Hanus, F.J., Carter, K.R., and Evans, H.J. (1978). Techniques for measurement of hydrogen evolution by nodules. Methods Enzymol. 69, 731-739.

Haugland, R.A., Hanus, F.J., Cantrell, M.A., and Evans, H.J. (1983). A rapld colony screening method for identifying hydrogenase activity in Rhizobium japonicum. Appl. Environ. Microbiol. 45, 892-897.

Hellriegel, H. (1886). Welche Stickstoffquellen stehen der Pflanze zu Gebote? Z. Ver. Rübenzucker-Industrie Deutschen Reichs 36, 863-877.

Hennecke, H., Gunther, I., and Binder, F. (1982). A novel cloning vector for the direct selection of recombinant DNA in E. coli. Gene 19, 231-234.

Hennecke, H., Fischer, H.-M., Ebeling, S., Gubler, M., Thöni, B., Göttert, M., Lamb, J., Hahn, M., Ramseler, T., Regensburger, B., Alvarez-Morales, A., and Studer, D. (1987). Nif, ftx, and nod gene clusters in Bradyrhizobium japonicum, and nifA-mediated control of symbiotic nitrogen fixation. In: Verma, D.P.S., and Brisson, N. (Eds.) Molecular genetics of plant-microbe interactions. Martinus Nijhoff Publishers, Dordrecht, The Netherlands, pp 191-196. 
Hirel, B., Bonet, C., King, B., Layzell, D., Jacobs, F.A., and Verma, D.P.S. (1987). Glutamine synthetase genes are regulated by ammonia provided externally or by symbiotic nitrogen fixation. EMBO J. 6, 1167-1172.

Hirsch, A.M., Bang, M., and Ausubel, F.M. (1983). Ultrastructural analysis of ineffective alfalfa nodules formed by nif::Tn5 mutants of Rhizobium meliloti. J. Bacteriol. 155, 367-380.

Hirsch, A.M., and Smith, C.A. (1987). Effects of Rhizobium meliloti nif and fix mutants on alfalfa root nodule development. J. Bacteriol. 169, 1137-1146.

Hong, J.C., Nagao, R.T., and Key, J.L. (1987). Characterization and sequence analysis of a developmentally regulated putative cell wall protein gene isolated from soybean. J. Biol. Chem. 262, 8367-8376.

Horvath, B., Bachem, C.W.B., Schell, J., and Kondorosi, A. (1985). Host-specific regulation of nodulation genes in Rhizobium is mediated by a plant signal, interacting with the nod $D$ gene products. EMBO J. 6, 841-848.

Horvath, B., Kondorosi, E., John, M., Schmidt, J., Török, L., Györgypal, Z, Barabas, I., Wieneke, U., Schell, J., and Kondorosi, A. (1986). Organization, structure and symbiotic function of Rhizobium meliloti nodulation genes determining host specificity for alfalfa. Cell 46, 335-343.

Humbeck, C., and Werner, D. (1987). Two succinate uptake systems in Bradyrhizobium japonicum. Curr. Microbiol. 14, 259-262.

Hynes, M.F., Simon, R., Muller, P., Niehaus, K., Labes, M., and Pühler, A. (1986). The two megaplasmids of Rhizobium meliloti are involved in the effective nodulation of alfalfa. Mol. Gen. Genet. 202, 356-362.

Jacobs, T.W., Egelhoff, T.T., and Long, S.R. (1985). Physical and genetic map of a Rhizobium meliloti nodulation gene region and nucleotide sequence of nodC. J. Bacteriol. 162, 469-476.

Jacobs, F.A., Zhang, M., Fortin, M.G., and Verma, D.P.S. (1987). Several nodulins of soybean share structural domains but differ in their subcellular locations. Nucl. Acids Pes. 15, 1271-1280.

Jacobsen, E. (1984). Modification of symbiotic interaction of pea (Pisum sativum L.) and Rhizobium leguminosarum by induced mutations. Plant and Soil 82, 427-438.

Jensen, E.O/., Paludan, K., Hyldig-Nielsen, J.J., Jo/rgensen, P., and Marcker, K.A. (1981). The structure of a chromosomal leghaemoglobin gene from soybean. Nature 281, 677-679.

Josey, D.P., Beynon, J.L., Johneton, A.W.B., and Beringer, J.B. (1979). Strain identification of Rhizobium using intrinsic antibiotic resistance. J. Appl. Microbiol. 46, 343-350. 
Kaminski, P.A., Buffard, D., and Strosberg, A.D. (1987). The pea lectin gene family contains only one functional gene. Plant Molec. Blol. 9, 497-507.

Kape, R., and Werner, D. (1988). The cell wall composition of the root hairs of Pisum sativum L. Cv. Kleine Rheinlānderin. In: Bothe, H., de Bruyn, F.J., and Newton, W.E. (Eds.) Nitrogen fixation: Hundred years after. Gustav Fischer Verlag, Stuttgart p. 655.

Kieber, J., Clover, R., Finan, T.M., and Signer, E.R. (1987). Surface properties of Rhizobium meliloti associated with symbiosis. In: Verma, D.P.S., and Brisson, N. (Eds.) Molecular genetics of plant microbe interactions. Martinus Nijhoff publishers, Dordrecht pp. 182-184.

Kneen, B.E., and LaRue, T.A. (1984). Nodulation resistant mutant of Pisum sativum L. J. Heredity 75, 238-240.

Kondorosi, E., Banfalvi, Z, and Kondorosi, A. (1984). Physical and genetic analysis of a symbiotic region of Rhizobium meliloti: identffication of nodulation genes. Mol. Gen. Genet. 193, 445-452.

Kondorosi, E., and Kondorosi, A. (1986). Nodule induction on plant roots by Rhizobium. Trends Biochem. Sci. 11, 296-299.

Kuhn, L.A., and Leigh, J.S. (1985). Blochim. Biophys. Acta 828, 351-361.

Kyte, J., and Doolittle, R.F. (1982). A simple method for displaying the hydropathic character of a protein. J. Mol. Biol. 157, 105-132.

Laemmli, U.K. (1970). Cleavage of structural proteins during the assembly of the head of bacteriophage T4. Nature 227, 680-685.

Lamb, J.W., and Hennecke, H. (1986). In Bradyrhizobium japonicum the common nodulation genes, nodABC, are linked to nifA and fixA. Mol. Gen. Genet. 202, 512-517.

Lamb, J.W., Regensburger, B., Fischer, H.-M., Göttert, M., Meyer, L., Ebeling, S., Studer, D., Hahn, M., and Hennecke, H. (1986). Bradyrhizobium japonicum genes involved in soybean root-nodule development. In: Lugtenberg, B.J.J. (Ed.) Recognition in Microbe-Plant Symbiotic and Pathogenic Interactions. Springer Verlag, Berlin, Heidelberg, New York, pp. 79-86.

Lambert, G.R., Cantrell, M.A., Hanus, F.J., Russell, S.A., Haddad, K.R., and Evans, H.J. (1985). Intra- and interspecies transfer and expression of Rhizobium japonicum hydrogen uptake genes and autotrophic growth capacity. Proc. Natl. Acad. Sci. USA 82, 3232-3236.

Lamport, D.T.A., and Catt, J.W. (1981). Glycoproteins and enzymes of the cell wall. In: Tanner, W.A., and Loewus, F.A. (Eds.) Plant carbohydrates II. Extracellular carbohydrates. Encyclopedia of Plant Physiology, vol 13b, Springer Verlag, Berlin, pp. 133-165. 
Lang-Unnasch, N., and Ausubel, F.M. (1985). Nodule-specific polypeptides from effective alfalfa root nodules and from ineffective nodules lacking nitrogenase. Plant Physiol. 77, 833-839.

Lara, M., Cullimore, J.V., Lea, P.J., Mifilin, B.J., Johnston, A.W.B., and Lamb, J.W. (1983). Appearance of a novel form of plant glutamine synthetase during nodule development in Phaseolus vulgaris L. Planta 157, 254-258.

Larsen, K., and Jochimsen, B.U. (1986). Expression of nodule-specific uricase in soybean callus tissue is regulated by oxygen. EMBO J. 5, 15-19.

Leach, J.E., Cantrell, M.A., and Sequeira L. (1983). Hydroxyproline-rich bacterial agglutinin from potato: extraction, purfication, and characterization. Plant Physiol. 70, 1353-1358.

Legocki, R.P., and Verma, D.P.S. (1979). A nodule-specific plant protein (Nodulin-35) from soybean. Cell 205, 190-193.

Legocki, R.P., and Verma, D.P.S. (1980). Identification of 'nodule-specific' host proteins (nodulins) involved in the developement of Rhizobium-legume symbiosis. Cell 20, 153-163.

Leigh, J.A., Reed, J.W., Hanks, J.F., Hirsch, A.M., and Walker, G.C. (1987). Rhizobium melilot/ mutants that fail to succinylate their Calcofluor-binding exopolysaccharide are defective in nodule invasion. Cell 51, 579-587.

Libbenga, K.R., and Harkes, P.A.A. (1973). Initial proliferation of cortlcal cells in the formation of root nodules in Pisum sativum L. Planta 114, 17-28.

Libbenga, K.R., and Bogers, R.J. (1974). Root nodule morphogenesis. In: Quispel, A. (Ed.) The Biology of Nitrogen Fixation. North-Holland Publishing Company, Amsterdam. pp. 430-472.

Lim, V.l. (1974). Algorithms for prediction of alpha-helical and bèta-structural regions in globular proteins. J. Mol. Biol. 88, 873-894.

Lipman, D.J., and Pearson, W.R. (1985). Rapid and sensitive protein similarity searches. Science 227, 1435-1441.

Long, S.R. (1984). Genetics of Rhizobium nodulation. In: Kosuge, T., and Nester, E. (Eds.) Plant-Microbe Interactions. MacMillan Publishing Co. Inc. New York. pp 265-306.

Luft, J.H. (1961). Improvements in epoxy resin embedding methods. J. Biophys. Biochem. Cytol. 8 , 409-414.

Maier, R.J., Campbell, N.E.R., Hanus, F.J., Simpson, F.B., Russell, S.A., and Evans, H.J. (1978). Expression of hydrogenase activity in free-living Rhizobium japonicum. Proc. Natl. Acad. Sci. USA 75, 3258-3262. 
Maier, R.J., Graham, L., Keele, R.G., Plhl, T., and Smith, E. (1987). Bradyrhizobium japonicum mutants defective in nitrogen fixation and molybdenum metabolism. J. Bacteriol. 169, 2548-2554.

Maniatis, T., Fritsch, E.F., and Sambrook, J. (1982). Molecular cloning. A laboratory manual. Cold Spring Harbor Laboratory Press, Cold Spring Harbor, NY.

Marcker, A., Land, M., Jensen, E.O/., Marcker, K.A. (1984a). Transcription of the soybean leghaemoglobin genes during nodule development. EMBO J. 3, 1691-1695.

Marcker, K.A., Bojsen, K., Jensen, E.O/., and Paludon, K. (1984b). The soybean leghemoglobin genes. In: Veeger, C., and Newton, W.E. (Eds.) Advances in Nitrogen Fixation Research. Martinus Nijhoff, The Hague, pp. 573-578.

Mauro, V.P., Nguyen, T., Katinakis, P., and Verma, D.P.S. (1985). Primary structure of the soybean nodulin-23 gene and potential regulatory elements in the 5 '-flanking region of nodulin and leghemoglobin genes. Nucl. Acids Res. 13, 239-248.

Maxam, A.M., and Gilbert, W. (1980). Sequencing end-labeled DNA with base-specfic chemical cleavages. Methods Ezymol. 65, 499-560.

McNell, M., Darvill, A.G., Fry, S.C., and Albersheim, P. (1984). Structure and function of the primary cell walls of plants. Ann. Rev. Biochem. 53, 625-663.

Messager, A. (1985). Selection of pea mutants for nodulation and nitrogen flxation. In: Marcellin, R. (Ed.) Analysis of the plant genes involved in the legume-Rhizobium symbiosis. OECD, Paris pp. $52-60$.

Messing, J. (1983). New M13 vectors for cloning. Methods Enzymol. 101, 20-78.

Meyer, L. (1988). Entdeckung einer neuen Bradyrhizobium japonicum DNA Region fur dle symbiontische Stickstoff-Fixienung: ungewöhnliche Gene für die respiratorische Ubichinol-Cytochrom c Oxidoreduktase. Ph. D. Thesis, ETH, Zürich.

Miller, J.H. (1982). Experiments in molecular genetics. Cold Spring Harbour Laboratory. Cold Spring Harbour, New York.

Moerman, M., Nap, J.P., Govers, F., Schilperoort, R., Van Kammen, A., and Bisseling, T. (1987). Rhizobium nod genes are involved in the induction of two early nodulin genes in Vicia sativa root nodules. Plant Mol. Biol. 9, 171-179.

Morrissey, J.H. (1981). Silver staln for proteins in polyacrylamide gels: A modified procedure with enhanced uniform sensitivity. Anal. Biochem. 117, 307-310.

Morrison, N., and Verma, D.P.S. (1987). A block in the endocytosis of Rhizobium allows cellular differentiation in nodules but affects the expression of some peribacteroid membrane nodulins. Plant Mol. Biol. 9, 185-196. 
Mort, A.J., and Grover, P.B. Jr. (1988). Characterization of root hair cell walls as potential barriers to the infection of plants by rhizobia. Plant Physiol. 86, 638-641.

Muller, L.L., and Jack, T.J. (1975). Rapid chemical dehydration of samples for electron microscopic examinations. J. Histochem. Cytochem. 23, 107-110.

Nap, J.P., and Bisseling, T. (1988). Nodulin function and nodulin gene regulation in root nodule development. In: Gresshoff, P.M. (Ed.) The molecular biology of symbiotic nitrogen fixation. CRC press, Florida. In press.

Nap, J.P., Van de Wiel, C., Spaink, H.P., Moerman, M., Van den Heuvel, M., Djordjevic, M.A., Van Lammeren, A.A.M., Van Kammen, A., and Bisseling, T. (1988). The relationship between nodulin gene expression and the Rhizobium nod genes in Vicia sativa root nodules. In prep.

Newcomb, W., Sippel, D., and Peterson, R.L. (1979). The early morphogenesis of Glycine max and Pisum sativum root nodules. Can. J. Bot. 57, 2603-2616.

Newcomb, W. (1981). Nodule morphogenesis and differentiation. In: Giles, K.L., and Atherley, A.G. (Eds.) Biology of the Rhizobiaceae. Int. Rev. Cytol. Suppl. 13 Academic Press, New York. pp. 247-297.

Newcomb, W., and Mclntyre, L (1981). Development of root nodules in mung bean (Vigna radiata): a reinvestigation of endocytosis. Can. J. Bot. 58, 2478-2499.

Nguyen, T., Zelechowrka, M., Foster, V., Bergmann, H., and Verma, D.P.S. (1985). Primary structure of the soybean nodulin-35 gene encoding uricase II localized in the peroxisomes of uninfected cells of nodules. Proc. Natl. Acad. Sci. USA 82, 5040-5044.

Nlehaus, K., Kapp, D., Quandit, J., Müller, P., and Pühler, A. (1988). Meristem induction and Infection thread formation of alfalfa root nodules are stimulated independently by two different factors of Rhizobium meliloti. In: Palacios, R. (Ed.) Proceedings of the $4^{\text {th }}$ international symposium on molecular genetics of plant microbe interactions, Acapulco, Mexico. In press.

Nieuwkoop, A.J., Banfalvi, Z., Deshmane, N., Gerhold, D., Schell, M.G., Sirotkin, K.M., and Stacey, G. (1987). A locus encoding host range is linked to the common nodulation genes of Bradyrhizobium japonicum. J. Bacteriol. 169, 2631-2638.

Nikolnikov, S., Postai, G., and Sain, B. (1984). The construction of a versatlle plasmid vector that allows direct selection of fragments cloned into six unique sites of the cl gene of coliphage 434. Gene 30, 261-265.

Noel, K.D., Stacey, G., Tandon, S.R., Silver, L.E., and Brill, W.J. (1982). Rhizobium japonicum mutants defective in symbiotic nitrogen fixation. J. Bacteriol. 152, 485-494.

Noel, K.D., Van den Bosch, K.A., and Kulpaca, B. (1986). Mutations in Rhizobium phaseoli that lead to arrested development of infection threads. J. Bacteriol. 168, 1392-1401. 
Norris, J.H., Macol, L.A., and Hirsch, A.M. (1988). Nodulin gene expression in effective alfalfa nodules and in nodules arrested at three different stages of development. Plant Physiol. In press.

Nutman, P.S. (1954). Symbiotic effectiveness in nodulated red clover II: A major gene for ineffectiveness in the host. Heredity 8, 47-60.

Nutman, P.S. (1959). Some observations on root hair infection by nodule bacteria. J. Exp. Bot. 10, 250-263.

Nutman, P.S. (1969). Genetics of symbiosis and nitrogen fixation in legumes. Proc. Roy. Soc. B. 172, 417-437.

Nutman, P.S. (1981). Hereditary host factors affecting nodulation and nitrogen fixation. In: Gibson, A.H., and Newton, W.E. (Eds.) Current Perspectives in Nitrogen Fixation. Elsevier, Amsterdam. pp. 194-204.

O'Brian, M.R., Kirshbom, P.M., and Maier, R.J. (1987a). Tn5-induced cytochrome mutants of Bracyrhizobium japonicum: Effects of the mutations on cells grown symbiotically and in culture. $\mathrm{J}$. Bacteriol. 169, 1089-1094.

O'Brian, M.R., Kirshbom, P.M., and Maier, R.J. (1987b). Bacterial heme synthesis is required for expression of the leghemoglobin holoprotein but not the apoprotein in soybean root nodules. Proc. Natl. Acad. Sci. USA 84, 8390-8393.

O/stergaard-Jensen, E., Marcker, K.A., and Villadsen, I.S. (1986). Heme regulates the expression in Saccharomyces cerevisiae of chimeric genes containing 5 '-flanking soybean leghemoglobin sequences. EMBO J. 5, 843-847.

Padilla, J.E., Campos, F., Lara, M., and Sanchez, F. (1988). Expression of major nodulins from bacterial-conditioned symbiosis in Phaseolus vulgaris: an approach to developmental plant responses during nodule ontogeny. In: Palacios, R. (Ed.) Proceedings of the $4^{\text {th }}$ international symposium on molecular genetics of plant microbe interactions, Acapulco, Mexico. In press.

Pelham, H.R.B., and Jackson, R.J. (1976). An efficient mRNA-dependent translation system from reticulocyte lysate. Eur. J. Biochem. 67, 247-256.

Peters, N.K., Frost, J.W., and Long, S.R. (1986). A plant flavone, luteolin, induces expression of Rhizobium mellloti nodulation genes. Science 233, 977-980.

Peters, A.C., Wimpenny, J.W.T., and Coombs, J.P. (1987). Oxygen profiles in, and in the agar beneath, colonies of Bacillus cereus, Staphylococcus albus and Escherichia coll. J. Gen. Microbiol. 133, 1257-1263. 
Peterson, M.A., and Barnes, D.K. (1981). Inheritance of ineffective nodulation and non-nodulation traits in alfalfa. Crop Science 21, $611-616$.

Postma, J.G., Jacobsen, E., and Feenstra, W.J. (1988). Three pea mutants with an altered nodulation studied by genetic analysis and grafting. J. Plant Physiol. 132, in press.

Poulson, R., and Polglase, W.J. (1975). The enzymic conversion of protoporphyrinogen IX to protoporphyrin IX. J. Biol. Chem. 250, 1269-1274.

Puvanesarajah, V., Schell, F.M., Gerhold, D., and Stacey, G. (1987). Cell surface polysaccharides from Bradyrhizobium japonicum and a non-nodulating mutant. J. Bacteriol. 169, 137-141.

Ramseier, T.M., Kaluza, B., Studer, D., Gloudemans, T., Bisseling, T., Jordan , P.M., Zuber, M., and Hennecke H. (1988). Cloning of a Bradyrhizobium japonicum DNA region encoding pleiotropic functions in heme metabolism and respiration. Submitted

Reddy, A., Torrey, J.G., and Hirsch, A.M. (1988). Isolation of Frankia strain HFPCcl3 nodulation genes by cross-species complementation of Rhizobium meliloti. In: Palacios, R. (Ed.) Proceedings of the $4^{\text {th }}$ international symposium on molecular genetics of plant microbe interactions, Acapulco, Mexico. In press.

Redmond, J.W., Batley, M., Djordjevic, M.A., Innes, R.W., Kuempel, P.L., and Rolfe, B.G. (1986). Flavones induce expression of nodulation genes in Rhizobium. Nature 323, 632-633.

Regensburger, B., and Hennecke, H. (1983). RNA polymerase from Rhizobium japonicum. Arch. Microbiol. 135, 103-109.

Regensburger, B., and Hennecke, H. (1984). Free-living and symbiotic nitrogen fixing ability of Rhizobium japonicum is unaffected by rifampicin resistance mutations. FEMS Microbiol. Lett. 21, 77-81.

Regensburger, B., Meyer, L, Filser, M., Weber, J., Studer, D., Lamb, J.W., Fischer, H.-M., Hahn, M., and Hennecke, H. (1986). Bradyrhizobium japonicum mutants defective in root-nodule bacteroid development and nitrogen fixation. Arch. Microbiol. 144, 355-366.

Reynolds, E.S. (1963). The use of lead citrate at high pH as an electron-opaque stain in electron microscopy. J. Cell Biol. 17, 208-212.

Ridge, R.W., and Rolle, B.G. (1985). Rhizobium sp. degradation of legume root hair cell wall at the site of infection thread origin. J. Plant Physiol. 122, 121-137.

Robertson, J.G., Lyttleton, P., Bullivant, S., and Grayston, G.F. (1978). Membranes in lupin root nodules. I. The role of Golgi bodies in the biogenesis of infection threads and peribacteroid membranes. J. Cell Sci. 30, 129-149. 
Robertson, J.G., and Lyttleton, P. (1984). Division of peribacteroid membranes in root nodules of white clover. J. Cell Sci. 68, 147-157.

Robertson, J.G., Wells, B., Bisseling, T., Farnden, K.J.F., and Johnston, A.W.B. (1984). Immuno-gold localization of leghemoglobin in cytoplasm in nitrogen-fixing root nodules of pea. Nature 311, 254-256.

Röhm, M., and Werner, D. (1987). Isolation of root hairs from seedlings of Pisum sativum. Identification of root hair specific proteins by in situ labeling. Physiol. Plantarum 69, 129-136.

Rolie, B.G., and Gresshoff, P.M. (1988). Genetic analysis of legume nodule initiation. Ann. Rev. Plant Physiol. Plant Mol. Biol. 39, 297-319.

Ronson, C.W., and Astwood, P.M. (1985). Genes involved in the carbon metabolism of bacteroids. In: Evans, H.J., Bottomley, P.J., and Newton, W.E. (Eds.) Nitrogen Fixation Plesearch Progress. Martinus Nijhoff Publishers, Dordrecht, The Netherlands, pp. 201-207.

Rossen, K., Shearman, C.A., Johnston, A.W.B., and Downie, J.A. (1985). The nodD gene of Rhizobium leguminosarum is autoregulatory and in the presence of plant exudate induces the nodA,B,C genes. EMBO J. 4, 3369-3373.

Sandal, N.N., Bojsen, K., and Marcker, K.A. (1987). A small family of nodule-specific genes from soybean. Nucl. Acids Res. 4, 1507-1519.

Sanger, F., Nicklen, S., and Coulson, A.R. (1977). DNA sequencing with chain-terminating Inhibltors. Proc. Natt. Acad. Sci. USA 74, 5463-5467.

Schmidt, J., John, M., Wieneke, U., Krussmann, H-D., and Schell, J. (1986). Expression of the nodulation gene nodA in Rhizobium meliloti and localization of the gene product in the cytosol. Proc. Natl. Acad. Sci. USA 83, 9581-9585.

Scott, D.B., Hennecke, H., and Lim, S.T. (1980). The biosynthesis of nitrogenase MoFe protein polypeptides in free-living cultures of Rhizobium japonicum. Biochim. Biophys. Acta 565, 365-378.

Sengupta-Gopalen, C., Thomas, D., Pitas, J.W., and Hoffman, L.M. (1985). Nucleotide sequence analysis of two soybean nodulin cDNA clones. In: Evans, H.J., Bottomley, R.J., and Newton, W.E. (Eds.) Nitrogen Flxation Research Progress. Martinus Nijhoff, Dordrecht, pp. 67.

Sengupta-Gopalan, C., and Pitas, J.W. (1986). Expression of nodule-specific glutamine synthetase genes during nodule development. Plant Molec. Biol. 7, 189-199.

Sengupta-Gopalan, C., Pitas, J.W., Thompson, D.V., and Hoffman, L.M. (1986). Expression of host genes during nodule development in soybean. Mol. Gen. Genet. 203, 410-420. 
Showalter, A.M., Bell, J.N., Cramer, C.L., Bailey, J.A., Varner, J.E., and Lamb, C.J. (1985). Accumulation of hydroxyproline-rich glycoprotein mRNAs in response to fungal elicitor and infection. Proc. Natt. Acad. Sci. USA 82, 6551-6555.

Simon, R., Priefer, U., and Pühler, A. (1983). Vector plasmids for in vivo and in vitro manipulations of Gram-nogatlve bacteria. In: Pühler, A. (Ed.) Molecular genetics of the bacteria-plant interaction. Springer Verlag, Heidelberg, pp. 98-106.

Smibert, R.M., and Krieg, N.R. (1981). General characterization. In: Gerhardt, P., Murray, R.G.E., Costilow, R.N., Nester, E.W., Wood, W.A., Krieg, N.R., and Briggs-Phillips, G. (Eds.) Manual of methods for general bacteriology. American Society for Microbiology, Washington DC, pp. 409-444.

So, J.-S., Hodgson, A.L.M., Haugland, R., Leavitt, M., Banfalvi, Z., Nieuwkoop, A.J., and Stacey, G. (1987). Transposon induced symbiotic mutants of Bradyrhizobium japonicum: Isolation of two gene regions essential for nodulation. Mol. Gen. Genet. 207, 15-23.

Southern, E.M. (1975). Detection of specific sequences among DNA fragments separated by gel electrophoresis. J. Mol. Biol. 98, 503-517.

Spaink, H.P., Wiffelman, C.A., Pees, E., Okker, R.J.H., and Lugtenberg, B.J.J. (1987). Rhizobium nodulation gene nodD as a determinant of host specificity. Nature $328,337-340$.

Staden, R. (1984). Graphic methods to determine the function of nucleic acid sequences. Nucl. Acids Res. 12, 521-538.

Strozyckj, P., Konieczny, A., and Legocki, A.B. (1985). Identification and synthesis in vitro of plant-specific proteins in yellow lupin root nodules. Acta Biochim. Polon. 32, $27-34$.

Studer, D., Gloudemans, T., Franssen, H.J., Fischer, H.-M., Bisseling, T., and Hennecke, H. (1987). Involvement of the bacterial nitrogen fixation regulatory gene (nifA) in control of nodule-specific host-plant gene expression. Eur. J. Cell. Biol. 45, 177-184.

Sutton, W.D. (1983). Nodule development and senescence. In: Broughton, W.J. (Ed.) Nitrogen fixation vol. 3: Legumes. Clarendon press, Oxford pp. 144-212.

Thommler, F., and Verma, D.P.S. (1986). Nodulin-100 gene of soybean codes for nodule-specfic sucrose synthetase. In: Verma, D.P.S. (Ed.) Third Int. Symp. on the Molecular Genetics of Plant-Microbe Interactions (Book of Abstracts). McGill University, Montreal, pp. 182.

Trinick, M.J., and Galbraith, J. (1980). The Rhizobium requirements of the nontegume Parasponia in relation to the cross-inoculation concept of legumes. New Phytol. 86, 17-26.

Turgeon, B.G., and Bauer, W.D. (1982). Early events in the infection of soybean by Rhizobium japonicum. Time course and cytology of the initial infection process. Can. J. Bot. 60, 152-161. 
Turgeon, B.G., and Bauer, W.D. (1985). Ultrastructure of infection-thread development during the infection of soybean by Rhizobium japonicum. Planta 163, 328-349.

Turner, G.L., and Gibson, A.H. (1980). Measurement of nitrogen fbxation by indirect means. In: Bergersen, F.J. (Ed.) Methods for evaluating biological nitrogen fixation. John Wiley, Chichester, pp. 111-138.

Van Brussel, A.A.N., Zaat, S.A.J., Canter Cremers, H.C.J., Wuffelman, C.A., Pees, E., Tak, T., and Lugtenberg, B.J.J. (1986). Role of plant root exudate and Sym plasmid-localized nodulation genes in the synthesis by Rhizobium leguminosarum of Tsr factor, which causes thick and short roots on common vetch. J. Bacteriol. 165, 517-522.

Van Brussel, A.A.N., Pees, E., Spaink, H.P., Tak, T., Wijffelman, C.A., Okker, R.J.H., Truchet, G., and Lugtenberg, B.J.J. (1988). Correlation between Rhizobium leguminosarum nod genes and nodulation phenotypes on Vicia. In: Bothe, H., de Bruyn, F.J., and Newton, W.E. (Eds.) Nitrogen Fixation, Hundred years after. Gustav Fischer Verlag, Stuttgart, pp. 483.

Vance, C.P., Boylan, K.L.M., Stade, S., and Somers, D.A. (1985). nodule specific proteins in alfalfa (Medicago sativa L.). Symbiosis 1, 69-84.

Van den Bosch, K.A., and Newcomb, E.H. (1986). Immunogold localization of nodule-specific uricase in developing soybean root nodules. Planta 167, 425-436.

Van de Wiel, C., Nap, J.P., Van Lammeren, A., and Bisseling, T. (1988). Histological evidence that a defence response of the host plant interferes with nodulin gene expression in Vicia sativa root nodules induced by an Agrobacterium transconjugant. J. Plant. Physiol. 132, 446-452.

Van Holst, G.J., Klis, F.M., De Whdt, P.J.M., Hazenberg, C.A.M., Buij3, J., and Stegwee, D. (1981). Arabinogalactan protein from a crude cell organelle fraction of Phaseolus vulgaris L. Plant Physiol. 68, 910-913.

Van Holat, G.J., and Varner, J.E. (1984). Reinforced polyproline II conformation in a hydroxyproline-rich cell wall protein from carrot root. Plant Physiol. 74, 247-251.

Van Loon, LC. (1981). In: Wood, F.K.S. (Ed.) Active defense mechanisms in plants. plenum Publishing Corporation, New York, pp. 247-274.

Van Kammen, A. (1984). Suggested nomenclature for plant genes involved in nodulation and symbiosis. Plant Mol. Biol. Rep. 2, 43-45.

Verma, D.P.S., Ball, S., Guerin, C., and Wanamaker, L. (1979). Leghemoglobin biosynthesis in soybean root nodules. Characterization of the nascent and released peptides and the relative rate of synthesis of the major leghemoglobins. Biochemistry 18, 476-483.

Verms, D.P.S., and Long, S.R. (1983). The molecular biology of the Rhizobium-legume symbiosis. Int. Rev. Cyt. Suppl. 14, 211-245. 
Verma, D.P.S., and Nadier, K. (1984). Legume-Rhizobium symbiosis: Host's point of view. In: Verma, D.P.S., and Hohn, T. (Eds.) Genes involved in microbe-plant interactions. Springer-Verlag. Vienna pp. 57-93.

Verma, D.P.S., Fortin, M.G., Stanley, J., Mauro, V.P., Purohit, S., and Morrison, N. (1986). Nodulins and nodulin genes of Glycine max, a perspective. Plant Mol. Biol. 7, 51-61.

Vincent, J.M. (1970). A manual for the practical study of root nodule bacteria. IBP handbook No. 15, Blackwell Scientific Publication, Oxford, pp. 1-164.

Vincent, J.M. (1980). Factors controlling the legume-Rhizobium symbiosis. In: Newton, W.E., and Orme-Johnson, W.H. (Eds.) Nitrogen Fixation II. University Park Press, Baltimore pp. 103-129.

Werner, D., and Kuhlmann, K.-P. (1985). In: De Neftancourt, N., and Magnien, E. (Eds.) Genetic engineering of plants and microorganisms important for agriculture. Nijhoff/Junk publishers, The Hague. ISBN 90-247-3131-3.

Werner, D., Kuhlmann, K.-P., Gloystein, F., and Richter, F.-W. (1985a). Calcium, iron and cobalt accumulation in root hairs of soybean (Glycine max). Z. Naturforsch. 40C, 912-913.

Werner, D., Mellor, R.B., Hahn, M.G., and Grisebach, H. (1985b). Soybean root response to symbiotic infection. Glyceollin I accumulation in an ineffective type of soybean nodules with an early loss of the peribacteroid membrane. Z. Naturforsch. 40c, 179-181.

Werner, D., and Röhm, M. (1985). In: De Nettancourt, N., and Magnien, E. (Eds.) Genetic engineering of plants and microorganisms important for agriculture. Nijhoff/Junk publishers, The Hague. ISBN 90-247-3131-3.

Werner, D., Mellor, R.B., Mörschel, E., Kinnback, A., Bassarab, S., Mumbeck, C., and Parniske, M. (1988). Peribacteroid membrane nodulin and particle frequency induction by Bradymizobium japonicum mutants. In: Palacios, R. (Ed.) Proceedings of the $4^{\text {th }}$ international symposium on molecular genetics of plant microbe interactions, Acapulco, Mexico. In press.

Wijffelman, C.A., Pees, E., Van Brussel, A.A.N., Okker, R.H.J., and Lugtenberg, B.J.J. (1985). Genetic and functional analysis of the Rhizobium leguminosarum Sym plasmid pRL1JI. Arch. Microbiol. 143, 225-232.

Williams, L.F., and Lynch, D.L. (1954). Inheritance of a non-nodulating character in soybean. Agron. J. 46, 28-29.

Whtty, J.F., Minchin, F.R., Sko/t, L, and Sheehy, J.E. (1986). Nitrogen fixation and oxygen in legume root nodules. Oxford surveys of plant and cellular biology 3, 275-315. 
Zaat, S.A.J., Van Brussel, A.A.N., Tak, T., Pees, E., and Lugtenberg, B.J.J. (1987a). Flavonoids induce Rhizobium leguminosarum to produce nodDABC gene-related factors that cause thick, short roots and root hair responses on common vetch. J. Bacteriol. 169, 3388-3391.

Zaat, S.A.J., Wjiffelman, C.A., Spaink, H.P., Van Brussel, A.A.N., Okker, R.J.H., and Lugtenberg, B.J.J. (1987b). Induction of the nodA promoter of Rhizobium leguminosarum Sym plasmid pRLIJl by plant flavanones and flavones. J. Bacteriol. 169, 198-204.

Zabel, P., Moerman, M., Van Straaten, F., Goldbach, R., Van Kammen, A. (1982). Antibodies against the genome-linked protein VPg of cowpea mosaic virus recognize a 60,000 dalton precursor polypeptide. J. Virol. 41, 1083-1088. 


\section{Samenvatting}




\section{Samenvatting}

Sinds een eeuw geleden ontdekt is dat wortelknollen van vlinderbloemige planten stikstofbindende organen zijn (Hellriegel, 1886) en vervolgens bacteriën geïsoleerd werden die verantwoordelijk zijn voor stikstofbinding in de wortelknollen (Beyerinck, 1888) is er veel onderzoek gedaan om dit systeem en het tot stand komen ervan te begrijpen. Het is bekend dat bacteriën van de geslachten Rhizobium en Bradyrhizobium in symbiose kunnen leven met specifieke vlinderbloemige planten waarbij de bacterie de wortel van de gastheer binnendringt en de wortelknol gevormd wordt, waarin de bacterie dan in staat is om stikstof uit de lucht om te zetten in ammonia.

In het algemeen worden in de wortelknolontwikkeling vier stadia onderkend Nincent, 1980): (i) preïnfectie, (ii) infectie en knolformatie, (iii) knolfunctie en instandhouding en (iv) knolveroudering. In het preïnfectie stadium hechten Rhizobium of Bradyrhizobium bacteriën zich aan de oppervlakte van de wortelharen van hun gastheer en induceren daar krulling van de wortelharen in een korte karakteristieke krul, die een 'shepherd's crook' (herdersstaf) genoemd wordt. Daarna, in het stadium van infectie en knolformatie, dringen de bacteriën de wortelhaar binnen via een door de plant nieuw gevormde buisstructuur, de infectiedraad. Tegelijkertijd, onafhankelijk van het infectieproces, dedifferentiëren plaatselijk cellen in de cortex van de wortel, gaan delen en vormen meristemen. De infectiedraad, waarin de bacteriën zich blijven vermeerderen, groeit naar de nieuw gevormde meristematische centra en vertakt zich daar (Bauer, 1981). Infectiedraden dringen binnen in ongeveer de helft van de plantecellen in deze centra en de bacteriën komen vrij uit de infectiedraad door middel van een proces dat lijkt op endocytose (Basset et al., 1977). Na het vrijkomen differentiëren de bacteriën tot hun endosymbiontische vorm, de bacteroïd, die veel groter is dan een vrijlevende bacterie en een karakteristieke vorm heeft (Robertson en Lyttleton, 1984). Tijdens de endocytose, worden de bacteriën omgeven door een van de plant afkomstige membraan, de peribacteroïd membraan (Robertson en Lyttleton, 1984). De cellen van de plant die bacteriën bevatten differentiëren en worden geinfecteerde cellen genoemd, terwijl de andere meristematische cellen tot niet-geïnfecteerde cellen differentiëren, beide met verschillende eigenschappen (Newcomb, 1981). Deze twee cel-types vormen het centrale weefsel van de knol. Op dat moment is het orgaan voor stikstofbinding gereed en kunnen de bacteriën beginnen met het stikstofbindings-proces. Later, in het stadium van 
knolveroudering, stopt de symbiontische stikstofbinding en begint de wortelknol te degenereren, gekenmerkt door het uiteenvallen van cellen en membranen.

De genomen van bacterie en plant werken samen in alle stadia van de knolvorming: van preiinfectie (i) tot knolfunctie en instandhouding (iii) (Nap en Bisseling, 1988). Aangezien het bacteriële genoom beter toegankelijk is voor onderzoek dan het genoom van de plant is de rol van de bacteriën in de symbiose het best onderzocht. Verscheidene bacterie genen die betrokken zijn bij het tot stand komen van een effectieve symbiose zijn geïdentificeerd (Downie en Johnston, 1986); dit zijn bijvoorbeeld de nodulatie (nod) genen en de genen betrokken bij de stikstofbinding (nif en fix). In Rhizobium bacteriën liggen deze genen op een groot endogeen plasmide, het Sym plasmide, terwil in Bradyrhizobium de nod, fix en nif genen geïntegreerd zijn in het chromosoom van de bacteriën.

De plantegenen die specifiek tot expressie komen gedurende de knolontwikkeling worden noduline genen genoemd (Van Kammen, 1984). Zij komen differentieel tot expressie vanaf het preinfectie stadium tot en met het ontstaan van een stikstofbindende wortelknol. Dit heeft geleid tot een onderscheid tussen late en vroege nodulines (Nap en Bisseling, 1988). De genen die coderen voor vroege nodulines komen tot expressie tijdens de preinfectie, de infectie en de vorming van de wortelknol (stadia (i) en (ii)) terwijl late noduline genen pas tot expressie komen tijdens de stadia (iii) en (iv), vanaf het begin van de stikstofbinding, als de knolstructuur al gevormd is. Omdat in de symbiose de genomen van bacterie en plant samenwerken bij de vorming van een stikstofbindende knol, is het mogelijk gebleken om de knolontwikkeling te beïnvloeden door middel van bacteriemutanten. Dit leidt in het algemeen tot knollen waarvan op een bepaald stadium de ontwikkeling stopt (Nap en Bisseling, 1988). Daarmee is de ontwikkeling van een stikstofbindende wortelknol een aantrekkelijk systeem voor ontwikkelings-biologisch onderzoek dat makkelijk toegankelijk is voor manipulatie en kan onderzoek op dit gebied leiden tot een beter begrip van het verloop van differentiatie processen en regulatie van de genen die erbij betrokken zijn.

In dit proefschrift wordt de identificatie en karakterisering van een aantal noduline genen die betrokken zijn bij de preïnfectie, stadium (i) en bij infectie en wortelknolvorming, stadium (ii), van de Rhizobium-leguminose symbiose beschreven. In hoofdstuk II is het onderzoek beschreven naar de expressie van plantegenen tijdens de soya knolontwikkeling. Door middel van in vitro vertaling van boodschapper RNA (mRNA) geïsoleerd uit wortelknollen van verschillende ontwikkelingsstadia, gevolgd door twee-dimensionale gel electroforese van deze translatieproducten, is de expressie van vroege en late noduline genen in soya onderzocht. Door de anatomie van wortelknollen te vergelijken met het 
expressiepatroon van nodulinegenen, kan er een correlatie gemaakt worden tussen een stap in de knolontwikkeling en de aanwezigheid van een noduline. De meeste vroege nodulines zijn gecorreleerd aan de differentiatie van meristeem cellen in de knol, alleen de aanwezigheid van één vroeg noduline, Ngm-44, treedt samen op met meristematische activiteit in de knol. Bovendien is er in knollen waarin bacteriën zelden vrij komen uit de infectiedraad waargenomen dat een gedeelte van de late noduline mRNAs onder de detectiegrens blijt, suggererend dat deze noduline genen op een andere manier worden gereguleerd dan de andere late noduline genen.

In hoofdstuk III worden drie vroege noduline genen gekarakteriseerd. Uit een CDNA bank gemaakt van mRNA uit wortelknollen zijn drie kloons geissoleerd die allen blijken te coderen voor proline-rijke eiwitten. Het GmENOD2 CDNA (hoofdstuk III, sectie 3.1), dat codeert voor noduline Ngm-75 al geïdentificeerd in hoofdstuk II als een vroeg noduline, en GmENOD13 cDNA (hoofdstuk III, sectie 3.2) zijn waarschijnlijk betrokken bij de knolmorfogenese omdat in knol-achtige structuren waarin zich geen infectiedraden bevinden en waarin geen intracellulaire bacteriën voorkomen, deze genen wel tot expressie komen. Omdat de structuur van ENOD2 en ENOD13 polypeptide lijkt op die van plante-hydroxyproline-rijke structurele celwand eiwitten zoals extensine, is het aannemelijk dat deze vroege nodulines waarschijnlijk (hydroxy)proline-rijke eiwitten zijn die een bestanddeel vormen van de celwand. Het ENOD55 polypeptide, hoewel ook proline-rijk, heeft een andere structuur en de expressie van het gen dat codeert voor dit noduline is niet wezenlijk voor de vorming van een wortelknol, maar is afhankelijk van het vrijkomen van de bacterie uit de infectiedraad (hoofdstuk III, sectie 3.2).

In hoofdstuk IV is de expressie van late noduline genen onderzocht in wortelknollen die stoppen in hun ontwikkeling na het vrijkomen van de bacterie uit de infectiedraad. In sectie 4.1 worden knollen beschreven geïnduceerd door Bradyrhizobium japonicum gemuteerd in het nifA gen, dat de expressie van andere nif en fix genen reguleert. Het nifA gen product bijkt ook betrokken te zijn bij de regulatie van de leghemoglobine genen op transcriptie niveau, maar niet bij regulatie van vroege noduline genen. Sectie 4.2 handelt over Bradyrhizobium japonicum gemuteerd in een gen dat waarschijnlijk betrokken is bij heem biosynthese. In wortelknollen geïnduceerd door deze mutant komen vroege noduline genen op het zelfde niveau tot expressie als in wortelknollen geïnduceerd door wild-type bradyrhizobia. Ook de expressie van late noduline genen is vrijwel normaal. Maar de synthese van leghemoglobine eiwit is wel beinvloed of, alternatief, het gevormde leghemoglobine apo-proteine is extreem instabiel. In dit hoofdstuk is de betrokkenheid van bacteriën bij de regulatie van een aantal late noduline genen op transcriptie (4.1) dan wel translatie (4.2) niveau vastgesteld. 
Studie van expressie van vroege noduline genen was tot voor kort beperkt tot die stadia van de knolontwikkeling waar de knollen zichtbaar zijn en expressie van vroege noduline genen in processen gedurende de preïnfectie kon niet worden vastgesteld. Met een recent ontwikkelde techniek voor het isoleren van grote hoeveelheden wortelharen (Röhm en Werner, 1987) werd het mogelijk om eiwitten en RNA te extraheren uit deze wortelharen. Hiermee is het mogelijk geworden om de rol van plantegenen in preinfectie processen zoals wortelhaar deformatie en krulling op te helderen. In hoofdstuk $V$ wordt een eerste aanzet gegeven tot de identificatie van plantegenen die betrokken zijn bij deze processen. In sectie 5.1 wordt met behulp van twee-dimensionale gel electroforese van in vivo eiwitten geïsoleerd uit wortelharen van erwt en soya een groep van eiwitten aangetoond die in hoge concentratie aanwezig zijn in de wortelhaar als deze niet meer geïnfecteerd kan worden door Rhizobium of Bradyrhizobium, respectievelijk. In sectie 5.2 wordt twee-dimensionale gel electroforese van in vitro getransleerd wortelhaar mRNA gebruikt om plante-genen te identificeren die specifiek betrokken zijn bij preiinfectie processen. De expressie van twee plante-genen blijkt afhankelijk te zijn van de expressie van de nod genen van Rhizobium. De expressie van een van deze plante-genen, coderend voor $\mathrm{RH}-42$, lijkt geassociēerd te zijn met wortelhaar krulling. De expressie van het andere gen, coderend voor $\mathrm{RH}-44$, is gerelateerd aan wortelhaar deformatie omdat een factor, geproduceerd door Rhizobium nod genen, die wortelharen deformeert, ook de expressie van dit gen blijkt te beinvloeden. Dit zou de basis kunnen zijn voor een test voor bacteriële signalen in de preinfectie en dit opent de weg naar identificatie en zuivering van deze bacteriële signalen.

In hoofdstuk 6 wordt de huidige kennis over plantegenen, betrokken bij preinfectie (stadium (i)), en infectie en knolvorming (stadium (ii)), en de betrokkenheid van bacterie genen en signalen die verantwoordelijk zijn voor gastheer reacties bediscussiëerd. De resultaten in de voorgaande hoofdstukken zijn hierin geîntegreerd en er wordt gespeculeerd over de aard van het mechanisme van de initiatie van knolvorming door bacteriële signalen. 
Nawoord 


\section{Nawoord}

Het boekje is af. Ik heb dat niet alleen gedaan: het schrijven van een proefschrift is een proces waarbij veel mensen betrokken zijn, zeker als je in plaats van artikelen te schrijven liever achter de labtafel staat. Het is onmogelijk om iedereen die betrokken is geweest bij de totstandkoming van mijn proefschrift bij naam te noemen, de drukkosten zouden gierend uit de hand lopen. Vergeef het mij dat ik een aantal mensen als groep bedank.

$A b$ van Kammen, promotor, bedankt voor je altijd aanwezige belangstelling, je kritische kanttekeningen bij de teksten die ik op papier zette, je vermogen om uit een concept verhaal een leesbaar artikel te maken, je stimulerende enthousiasme en de heerlijke gembergebakjes op je verjaardag. Ton Bisseling, bedankt voor de gelegenheid die je mij geboden hebt om een radertje in het geheel van jouw groep te zijn. Ik heb heel veel van je geleerd en ook steeds met bewondering gekeken hoe jij steeds weer de, naar achteraf bleek, juiste conclusies wist te trekken. Je hebt een sterke drang tot onthullen, hetgeen zich, naar mijn mening als leek, ook uit in de beeldjes die jij maakt. Om de bekende Ton B vingerafdrukken op natte autoradiogrammen te vermijden moest ik vaak sluipwegen bewandelen van de doka naar het rec lab. Sacco (C.) de Vries, van jou heb ik het twee deeën geleerd; ik ben geworden tot Twee Dee Ton Gee. Je hebt me ook geleerd hoe 2-D gels geinterpreteerd moesten worden: met een zwarte, rode en groene stift. Ook bedankt voor de gastvrijheid die wij in jouw kleine labje boven genoten als we weer eens verdreven werden van het rec lab door het practicum. Henk (J.) Franssen, het is een voorrecht geweest om met jou te mogen werken in het Agrigenetics project. Als ik iets wilde weten, of weer eens iets vergeten was, kon ik altijd bij je aankloppen. Het DNA werk was bij jou goed uitbesteed. Je kunt wel stellen dat ik een post-doc voor mij had werken. Willem Stiekema, evenals de voorgaande twee een lid van het A-team, ik heb je maar een paar maanden meegemaakt, toch heb ik veel van je geleerd. Jan-Peter Nap, rookloze kamergenoot, over jou zal ik geen grapjes maken want die typische Gloudemans-grapjes zul je nooit begrijpen. Ik zal nooit vergeten hoe je mij de kamer opgelokt hebt. We hebben samen van kamer 029 een leefbaar hok gemaakt. Alle andere mensen van lab 1, Francine Govers, Ben Scheres, Clemens van der Wiel en Jeanine Louwerse, bedankt voor al jullie hulp en gezelligheid. De laatste plaats in de rij namen van de noduline groep, maar voor mij eigenlijk de eerste plaats, is voor Marja Moerman. Marja, jij bent op het lab (het reklap) mijn ondersteuning geweest, en niet alleen analytisch. Ik wil jou heel speciaal bedanken voor alles wat je voor mij gedaan hebt. Ik vond bij jou altijd een gewillig oor voor alles wat ik kwijt moest. Samen hebben we het reklap onveilig gemaakt tijdens het schrapen van wortelharen; de erwten en de olifanten met witte sokjes waren niet van de lucht. Marja....bedankt. 
De rest van de vakgroep Moleculaire Biologie, de mensen op lab 0 , pardon paviljoen A, lab 2, lab 3 en de penengroep, het was gezellig in jullie midden. Ik zal jullie missen en niet alleen omdat je bij jullie altijd de mooiste spullen kon lenen. Peter Roelvink wil ik apart nog even noemen want wij reden iedere dag samen op en neer van Utrecht (m'n stadsie wor) naar Wageningen. Als ik nu door Utrecht loop en het carillon van de Dom hoor spelen, dan moet ik altijd aan je denken. De studenten die een vak bij mij gedaan hebben bedank ik ook. Zonder hen zou het proefschrift aanmerkelijk minder zijn geworden. Henk-Jan Bussink, bedankt voor je 2-D gels, hoewel je liever kloneerde. Jens Gundersen, your root hair 2-D work did at last lead to something; fortunately you never reached 100. You were the one who introduced the name Real Ton for Ton B, and Little Ton for me. You also let me enjoy the taste of the danish nouvelle cuisine, scrambled pancakes. Dirk Martens, ik moest jou leren Northern blotten, terwijl ik dat zelf nog nauwelijks gedaan had. Je hebt uitstekend werk verricht. Jeanne Jacobs, jij was altijd luid en duidelijk aanwezig. De geduldige oren zijn alweer wat opgeknapt. Marcel Thalen, met jou heb ik me weer op de immunologie kunnen storten als 'monocionale wortelschrapper'. Frans Mulckhuyse, bedankt voor je bijdrage aan het onderzoek. Je wist altijd een goede bestemming te vinden voor overblijvende vloeibare stikstof. Joke van Beckum en Irma Vijn, jullie zijn geen studenten bij mij geweest maar bij Marja. Toch bedank ik jullie voor jullie gezelligheid op het reklap.

De vrouwen op het secretariaat, Marie-José van Neerven, Gré Heitkönig, Hedy Adriaansz en Angélique (Bunny) Jonkers, bedankt voor jullie goede zorgen. Piet Madern, Reindert de Fluiter, Job Tielens en Peter van Druten, bedankt voor het snelle en goede teken- en fotowerk en de hulp bij alle technische problemen die een promovendus met zijn apparaten kan hebben. Piet de Kam, bedankt voor het inoculeren en verzorgen van mijn plantjes. Je was altijd bereid om iets extra's te doen. Leen Peterse, bedankt voor de gastvrijheid in het phytotron van PFO.

Nasir Malik, thank you for your help. When we started scraping root hairs everyone in the lab stopped by to have a look (but nobody helped). Ann (Annie) Hirsch, the time you spent in the rec lab was a great time for all of us. I even know my name in spanish now: Tonito. Bhuvaneswari, thank you for teaching me the secrets of DF. It was nice working with you.

Ten slotte bedank ik mijn ouders die mij in de gelegenheid hebben gesteld om te studeren en altijd belangstellend zijn naar mijn resultaten. Als laatste bedank ik Adrie, mijn vrouw en vriendin, zonder jou had ik dit noolt bereikt.

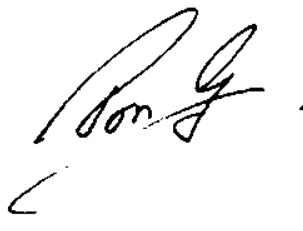




\section{Curriculum vitae}




\section{Curriculum vitae}

Ton Gloudemans werd op 22 juli 1956 geboren te Heer (L). Hij bezocht in Tilburg het Sint Odulphus lyceum en aansluitend in Baarn het Baarnsch lyceum, alwaar hij in 1975 slaagde voor het eindexamen gymnasium B. In het zelfde jaar begon hil de studie celbiologie aan de toenmalige Landbouwhogeschool te Wageningen. De ingenieursstudie werd in 1984 afgesloten met als hoofdvakken Fysiologie der planten (Prof. Dr. W.J. Vredenberg) en Immunologie (Prof. Dr. W.B. van Muiswinkel), en als bijvak Moleculaire Biologie (Prof. Dr. A. van Kammen). Van mei 1984 tot augustus 1984 was hij in dienst van de Landbouwhogeschool bij de vakgroep Moleculaire Biologie. Vanaf augustus 1984 was hij in het kader van een onderzoeksproject gefinancierd door Agrigenetics (ARA Ltd) werkzaam bij de vakgroep Moleculaire Biologie van de Landbouwhogeschool als wetenschappelijk projectmedewerker, alwaar het in dit proefschrift beschreven onderzoek is uitgevoerd. Vanaf augustus 1988 is hij werkzaam als toegevoegd onderzoeker bij het laboratorium voor Fysiologische Chemie van de Geneeskundige faculteit van de Rijksuniversiteit te Utrecht in het kader van een project gefinancierd door het Koningin Wilhelmina Fonds (KWF). 